\title{
EFFECTS OF HIGH TEMPERATURE ON THE PERFORMANCE OF ALNICO V AND ALNICO VI PERMANENT MAGNETS
}

\author{
Submitted to Aircraft Nuclear Propulsion Department by \\ W. H. Roberts \\ D. L. MitchelI \\ Instrumentation Department \\ Measurements and Industrial Products Division
}

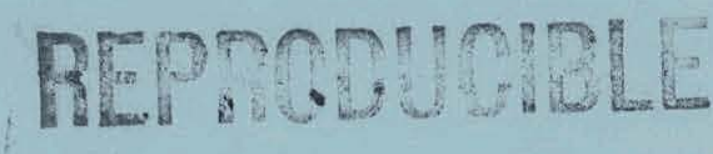

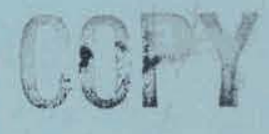

\author{
GENERAL ELECTRIC \\ AIRCRAFT NUCLEAR PROPULSION DEPARTMENT \\ ATOMIC PRODUCTS DIVISION
}




\section{DISCLAIMER}

This report was prepared as an account of work sponsored by an agency of the United States Government. Neither the United States Government nor any agency Thereof, nor any of their employees, makes any warranty, express or implied, or assumes any legal liability or responsibility for the accuracy, completeness, or usefulness of any information, apparatus, product, or process disclosed, or represents that its use would not infringe privately owned rights. Reference herein to any specific commercial product, process, or service by trade name, trademark, manufacturer, or otherwise does not necessarily constitute or imply its endorsement, recommendation, or favoring by the United States Government or any agency thereof. The views and opinions of authors expressed herein do not necessarily state or reflect those of the United States Government or any agency thereof. 


\section{DISCLAIMER}

Portions of this document may be illegible in electronic image products. Images are produced from the best available original document. 


\section{LEGAL NOTICE}

This report was prepared as an account of Government sponsored work. Neither the United States, nor the Commissinn, nnr the A ir Force, nor any person acting on behalf of the Commission or the Air Force:

A. Makes any warranty or representation, express or implied, with respect to the accuracy, completeness, or usefulness of the information contained in this report, or that the use of any information, apparatus, method, or process disclosed in this report may not infringe privately owned rights; or

B. Assumes any liabilities with respect to the use of, or for damages resulting from the use of any information, apparatus, method, or process disclosed in this report.

As used in the above "person acting on behalf of the Commission or Air Force" includes any employee or contractor of the Commission or Air Force to the extent that such employee or contractor prepares, handles, or distributes, or provides access to, any information pursuant to his employment or contract with the Commission or Air Force.

Printed in USA. Price $\$ 2.25$. Available from the

Office of Technical Services

U.S. Department of Commerce

Washington 25 , D.C. 


\title{
APEX-384 \\ UC-25 Metallurgy \\ and Ceramics \\ TID-4500 (13th Ed,, Rev.)
}

\section{EFFECTS OF HIGH TEMPERATURE ON THE PERFORMANCE OF ALNICO V AND ALNICO VI PERMANENT MAGNETS}

\author{
Submitted to Aircraft Nuclear Propulsion Department by \\ W. H. Roberts \\ D. L. Mitchell \\ Instrumentation Department \\ Measurements and Industrial Products Division
}

February, 1957

United States Air Force

United States Atomic Energy Commission
Contract No. AF 33(038)-21102

Contract No. AT $(11-1)-171$

\section{GENERAL ELECTRIC}

AIRCRAFT NUCLEAR PROPULSION DEPARTMENT ATOMIC PRODUCIS DIVISION

Cincinnati 15, Ohio

Pullislied July, lybs 


\begin{abstract}
The effect of temperatures up to $600^{\circ} \mathrm{C}$ and the combined effect of temperature and vibration on the magnetic performance of Alnico V and Alnico VI magnet was investigated.
\end{abstract}




\section{TABLE OF CONTENTS}

\section{Page}

1. Introduction

2. Temperature Cycling 11

3. Temperature Coefficient 19

4. Heat: Aging $: 500^{\circ} \mathrm{C}$

5. Heat Aging $600^{\circ} \mathrm{C}$

6. Heat Exposure 55

7. Combined Heat and Vibration 67

8. General Conclusions 71

9. Experimental Procedure and Test
Erquipment 


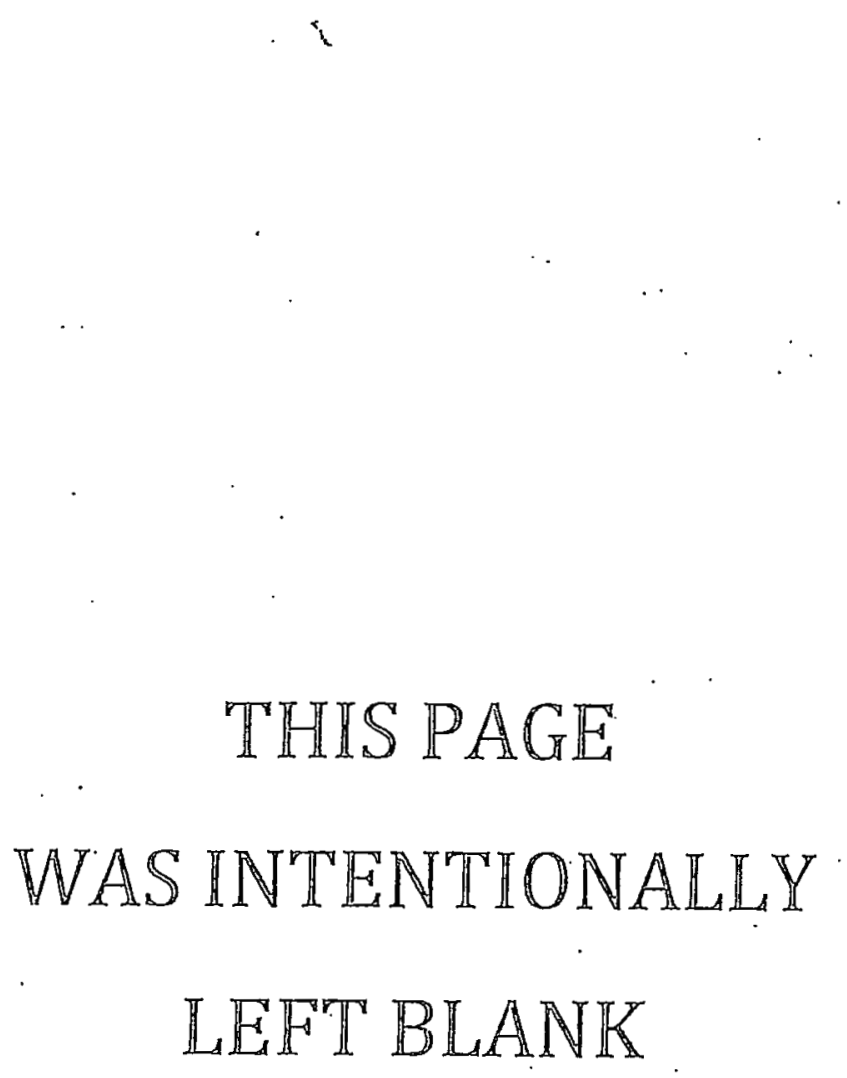




\section{IATRODUCTION}

The objective of this inveatigation was to dotermine the design

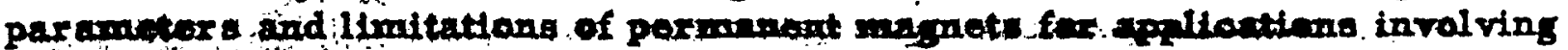

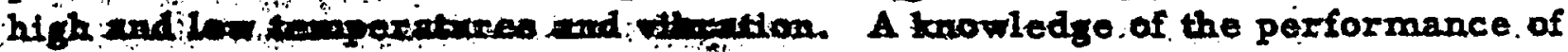

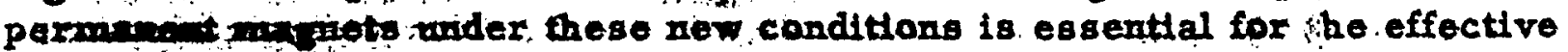
deatren of futwe alferaft instruments: This, is nocessitated by the high aldn

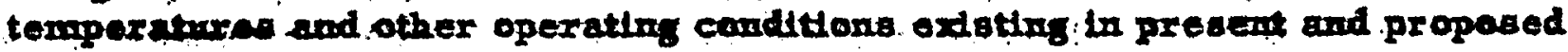
millitary. alreraft.

The tomperature range atudied in the investigation tncluded $-70^{\circ} \mathrm{C}$.to

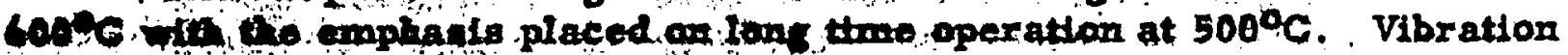

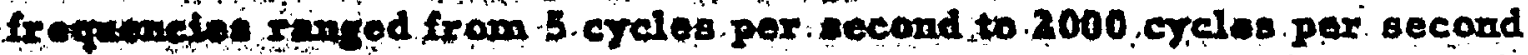

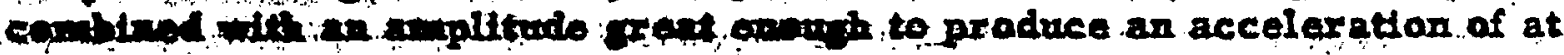
Leare 200 .

Before any exportwontal work was done, a search of the llteraturo,

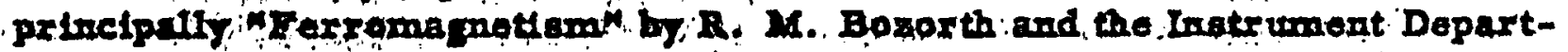

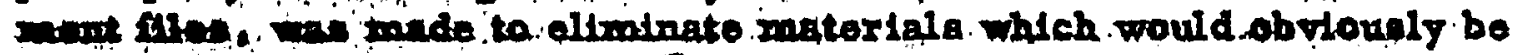

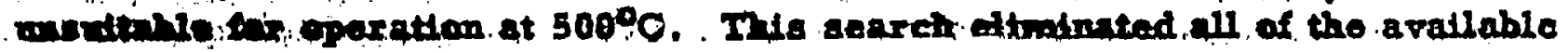

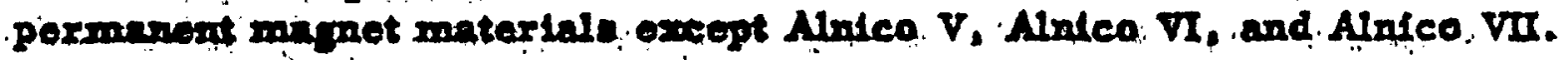

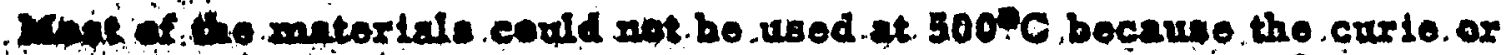

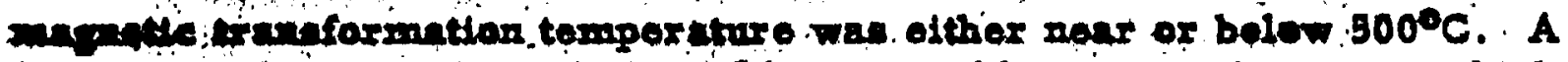
for matertale wore aleo ellmimited becawe of low magnotle oner or which

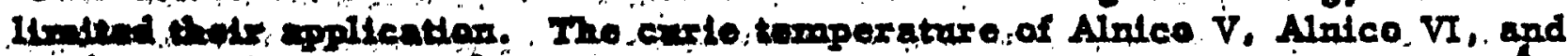

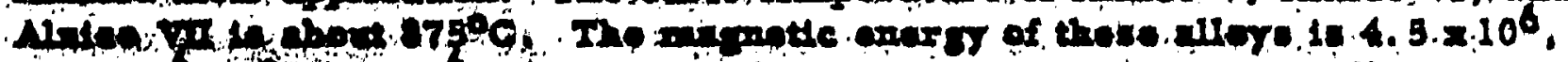

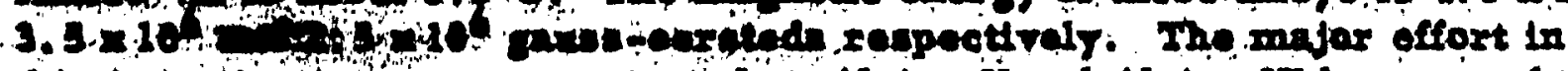

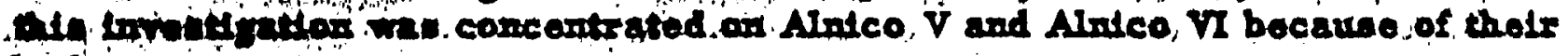
inger motie oniros.

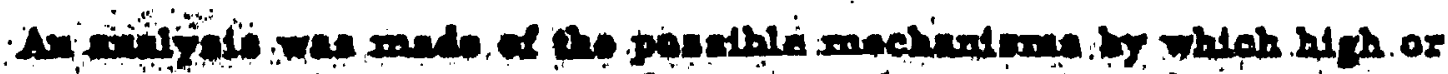

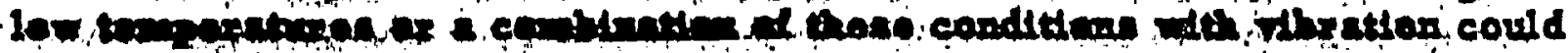

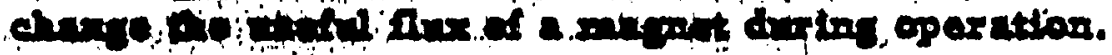

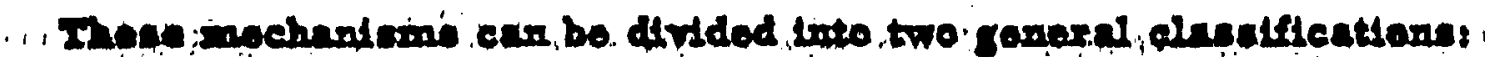

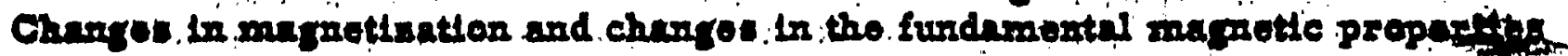

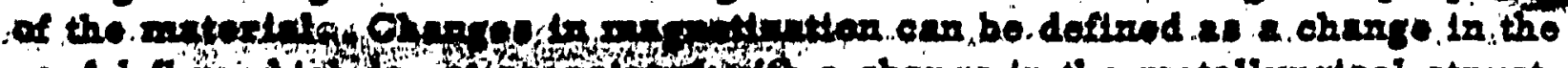

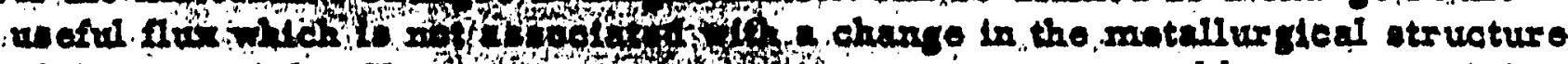

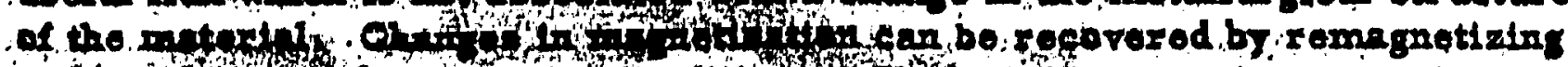

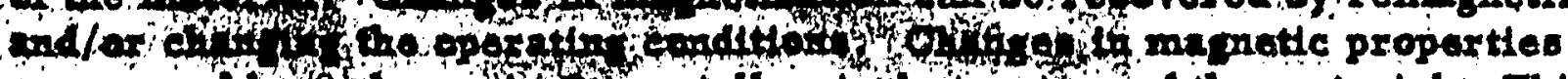

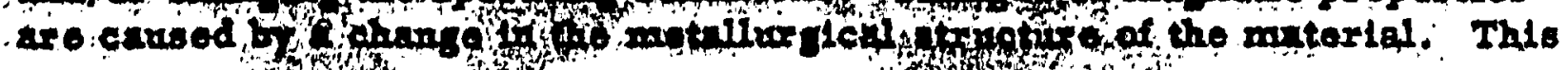

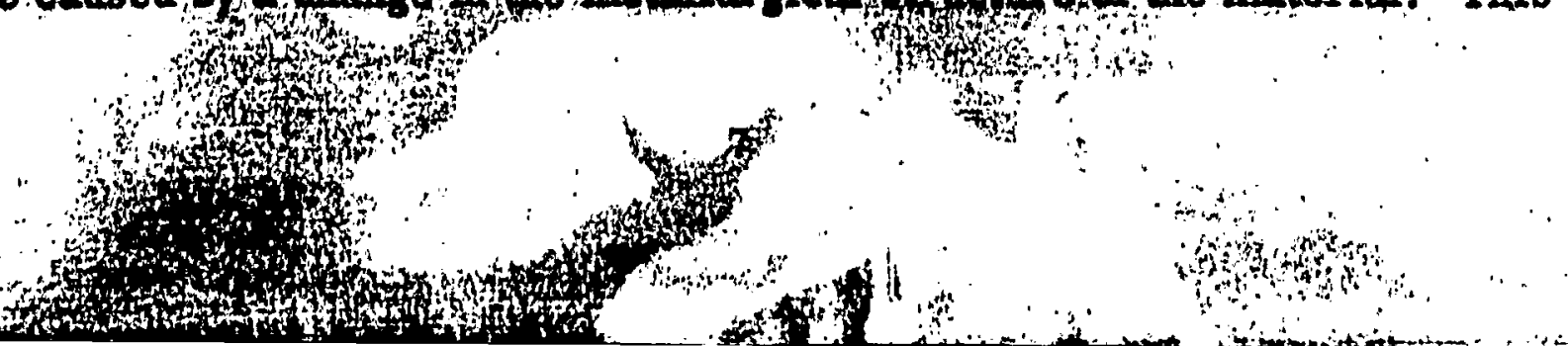


results in a permanen change in the hysteresis loop of the material. It is necessary to reheat-treat the material to restore the original magnetic properties after a change of chis rature.

As a result of this analysis, it was decided that the following mechaniams would be the most probable causes of any change in useful flux:

1) a permanent change in the magnetization of the magnet due to cycling through two extremes of temperature. (Temperature cycling experiment)

2) a temporary change in the magretization of the magret due to changes in temperature. (Temperature coefficient experiment)

3). a permanent change in the magnetic properties of the material due to changes in the structure of the material caused.by holding at high temperature for a long period of time. (Heas aging experiment)

4) a combination of changes in magnetization and magnetic propertiea due to continuous exposure to high temperature. (Heat exposure experimeric)

5) changes in magnetization caused by exposure to a combination of either high or low temperature and vibratertor. (Combined hea and vibracion experiment)

Based on the mechanisms listed above, a series of five experiments was designed to determine the effect of each on the useful flux of Alnico $V$ and Alnico. VI magnets. Because magnet design was known to have a pronounced effect on the magnetization of a masnet, three designs of each material were tested. One design. was the equivalext of a very long magnet $(0,100 \mathrm{in}$. gap), the second was the malent of a medium length magnet (0.300 in. gap), and the third was a very short magnet (cylindrical). These magnets and their operating lines are shown in Figure 1 and Figure 2 . Where possible, the effect of varying heat treatment and practical demagnetization by exposure to an a-c fleld were also.sêdied.

The following section of this repors is a discussion of the results of each experiment along with the specific conclusions which can be drawn from the resulta of that experiment. This is followed by general conclusions and recommendations for the preparation of magnets for operation up to $500^{\circ} \mathrm{C}$. The last section of the repor is a detailed degcription of the preparation of the samples, design and construction nf the toat cquipment and test procedures. 


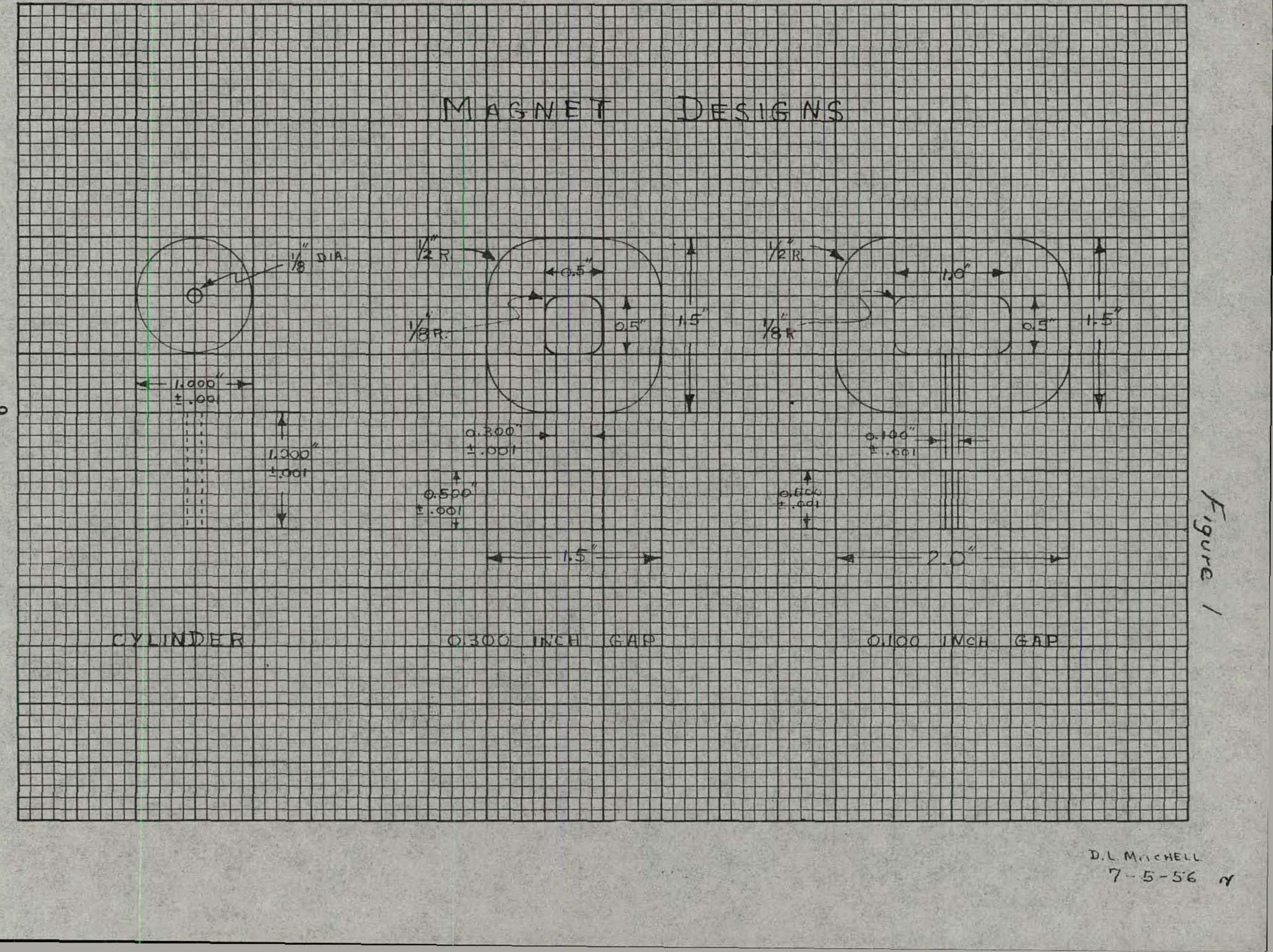


SECOND QUALKANT

DEMAGNETIZATION

CUKVE

ใै

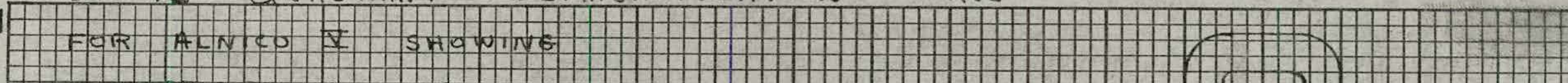

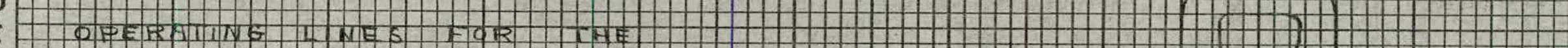

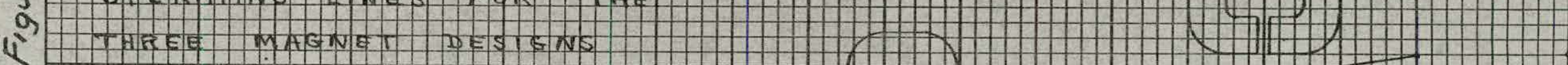

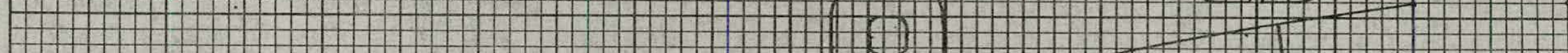

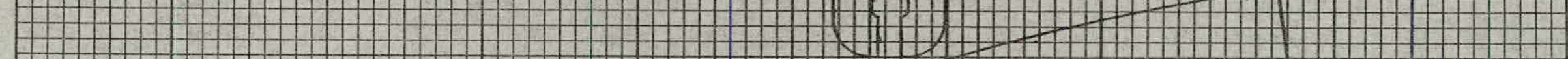

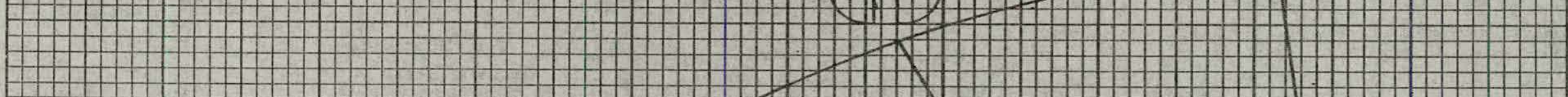

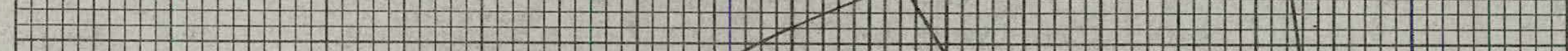

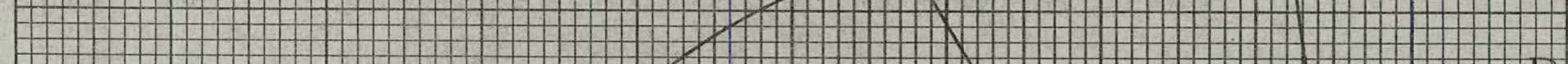

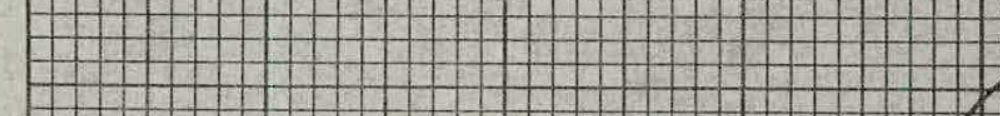

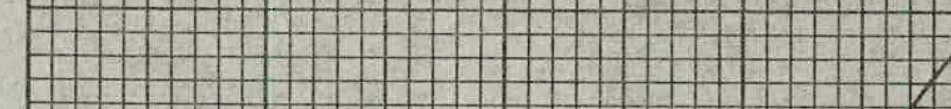

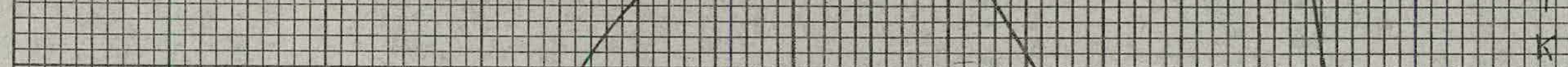

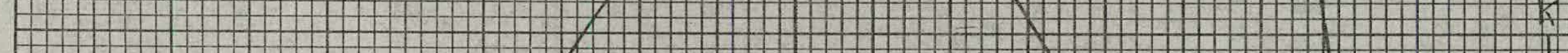

它

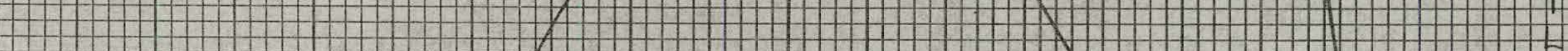

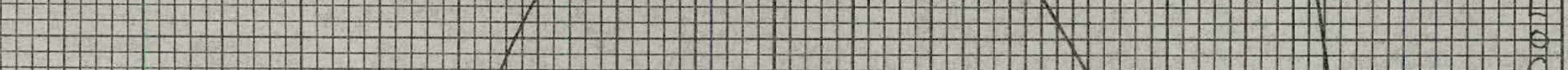

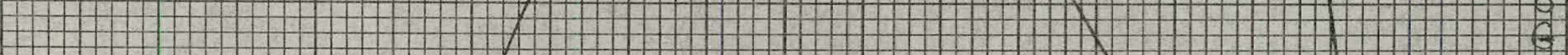

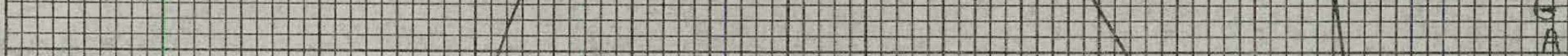

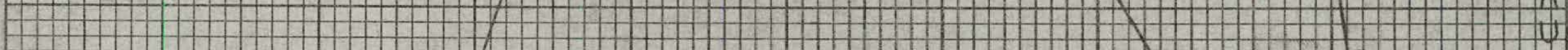

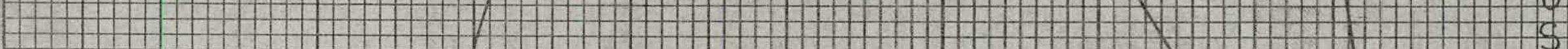

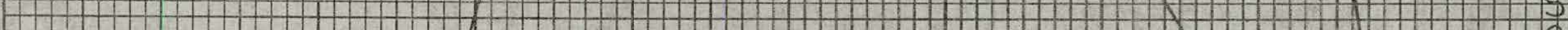

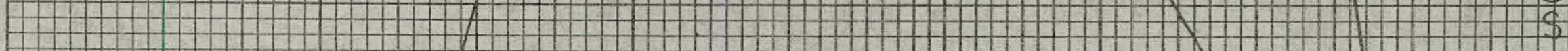

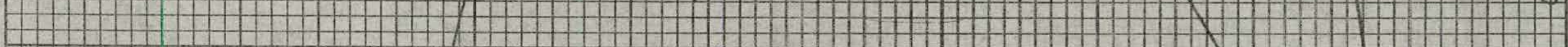

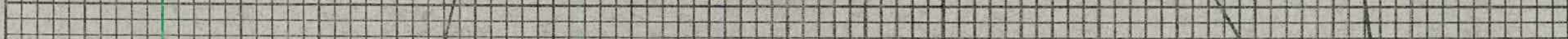

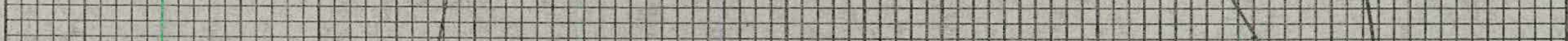

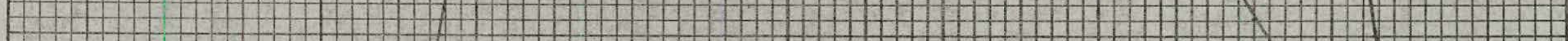

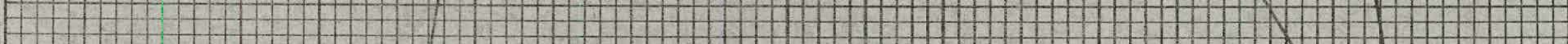

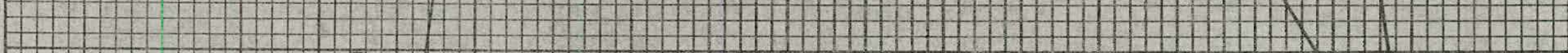

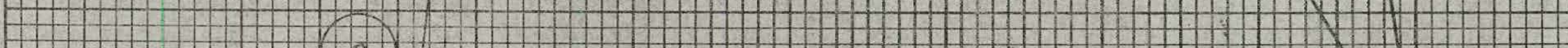

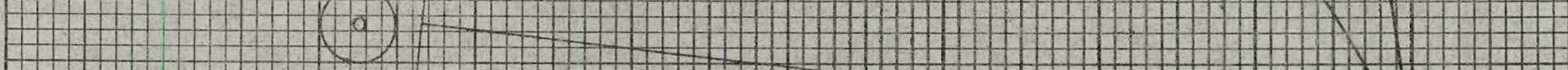

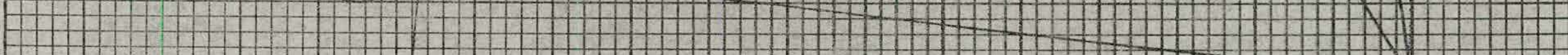

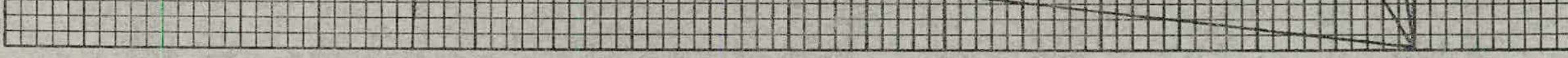

$$
\begin{aligned}
& -800 \\
& -7 c 0 \\
& -60 c \\
& -500 \quad-400 \\
& -200 \\
& -200 \\
& -100 \\
& -0
\end{aligned}
$$

$$
\text { H - OERSTEDS }
$$




\section{TIMOERATUR CXCLING}

If a magnet.is caturated at room temperature and the temperature is either raised or lowered whon the rraghet is brourht brck to room temperature, it will have lest part of its useful flux. This" change in useful flux is caused by a permanent change in the magnetization of the magnet and cannet bectrered without remngetizing.

The magnitude of this lose is determined by the chunge in temperature and the number of such temperature cycles the magnet has experienced after saturation. If the highest temperature does not exceed a critical limit, the magnet will hecome stabllized after a number of cycles between two temperature extremes. When a magnet has been atabilized in this manner, there will be II further change in weful flux due to cycling in that temperature range. For this puxpose of this experiment, stability is defined as a change in us ful flwx of lesp than $1 \%$ between two successive temperatwe cycles.

The purpose of this serten of tests was to establiah the mumber of creles required to etrbilize the raxiew test magnets. The percent loss in uneful flux dwe to stabilization was also determined. The temperature extroms invertigated included she fellowing: $-70^{\circ} \mathrm{C}$ to $200^{\circ} \mathrm{C},-70^{\circ} \mathrm{C}$ to $100^{\circ} \mathrm{C}$, $-70^{\circ} \mathrm{C}$, to $200^{\circ} \mathrm{C},-70^{\circ} \mathrm{O}$ to $300^{\circ} \mathrm{C},-70^{\circ} \mathrm{C}$ to $400^{\circ} \mathrm{C},-70^{\circ} \mathrm{C}$ to $500^{\circ} \mathrm{C}$ and $25^{\circ} \mathrm{C}$ to $600^{\circ} \mathrm{C}$.

Three magnets of each dealgn of Alnico $V$ and Alnico VI were tested. One magnet was saturated, one magnet was partially demacnetized by exposing it to an acefleld of 100 cersteds (KD-100F) and one maget was partially demacnetixed by exposing if to an ac field of 250 oerated. (KD-250H).

The resulta of the temperature cycling test are given in Figures $3-7$, Figures 3 and 4 show the nimber of cycles required to achieve stability, and Ficures 5 and 6 show the percent of useful flux loat due to stabilization. Figure 7 whows the effect of iemperature cycling in the rango $25^{\circ} \mathrm{C}$ to $600^{\circ} \mathrm{C}$.

\section{CONCLUSIONS}

Both the number of cycles to stabilize and the loss of useful flux due to stabilization can be minimized by the following:

1) Uatog long magnets with short air saps.

2) Increacing the prior ac demagnetixation.

3) Reductnd the maxdmum temperature.

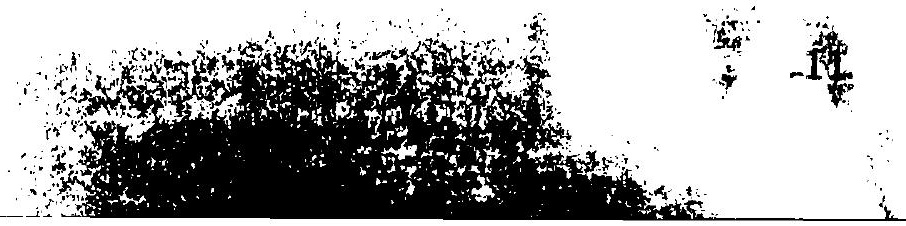


The effect of temperature cycling was slightly less on Alnico VI magnets than on Alnico, V magxets. However, the differ ence is 80 small that it would probably not be elgofficant in design.

Stxbllity was achieved in all cases by five cycles or les up to a termper ature range of $-70^{\circ} \mathrm{C}$.to $500^{\circ} \mathrm{C}$.

Cycling stability. was not achieved after eight cycles in the range $25^{\circ} \mathrm{C}$ to $600^{\circ} \mathrm{C}$. In fact, these tests showed a definite departure from the pattern eatabliahed up to $500^{\circ} \mathrm{C}$. This is to be expected gince metallux gical changes in the structure of the alloy are known to take place quise rapidly at $600^{\circ} \mathrm{C}$. The effects of cycling from $500^{\circ} \mathrm{C}$ down are principally charges in the magnetiration of the magnet. 


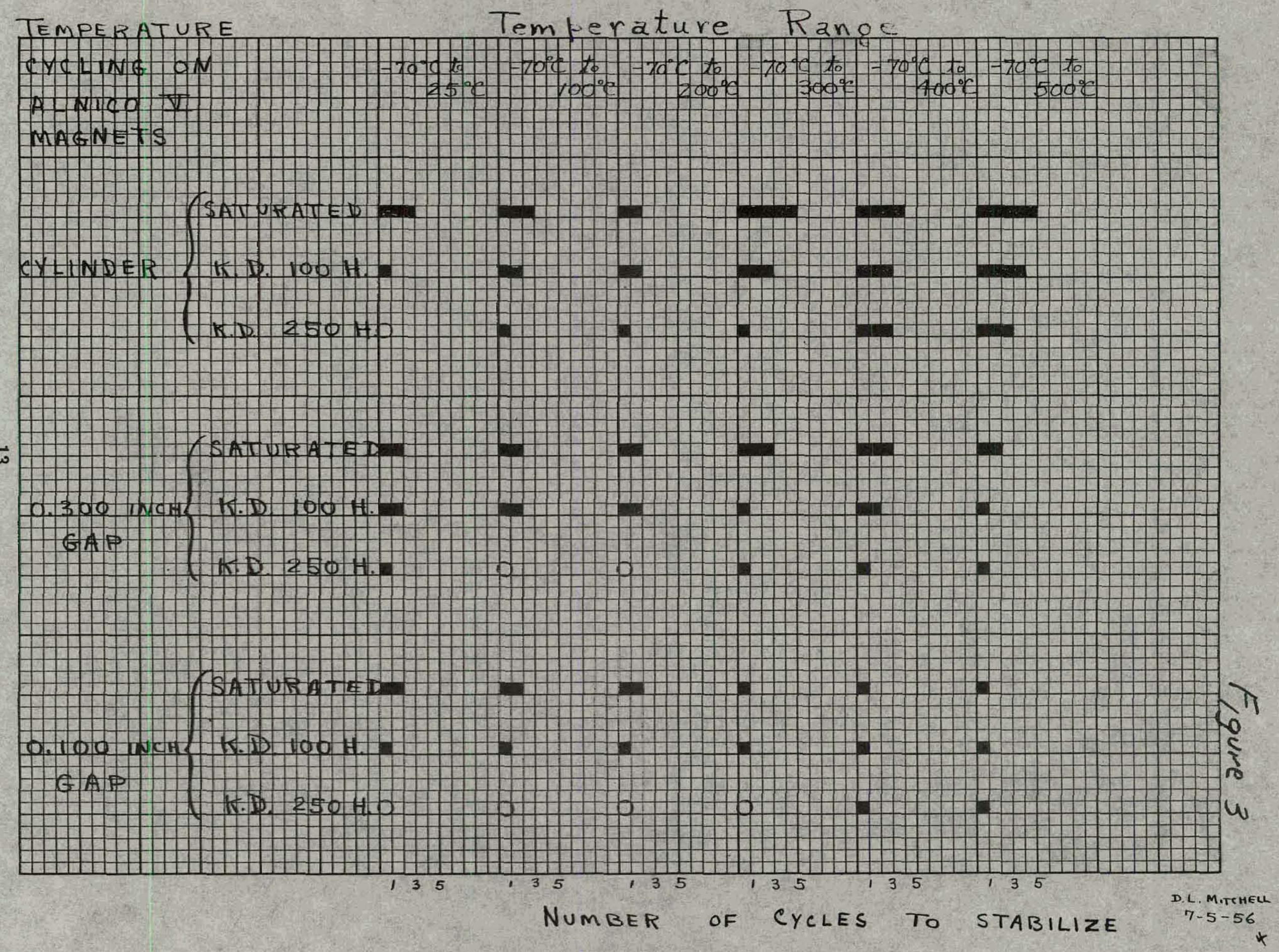




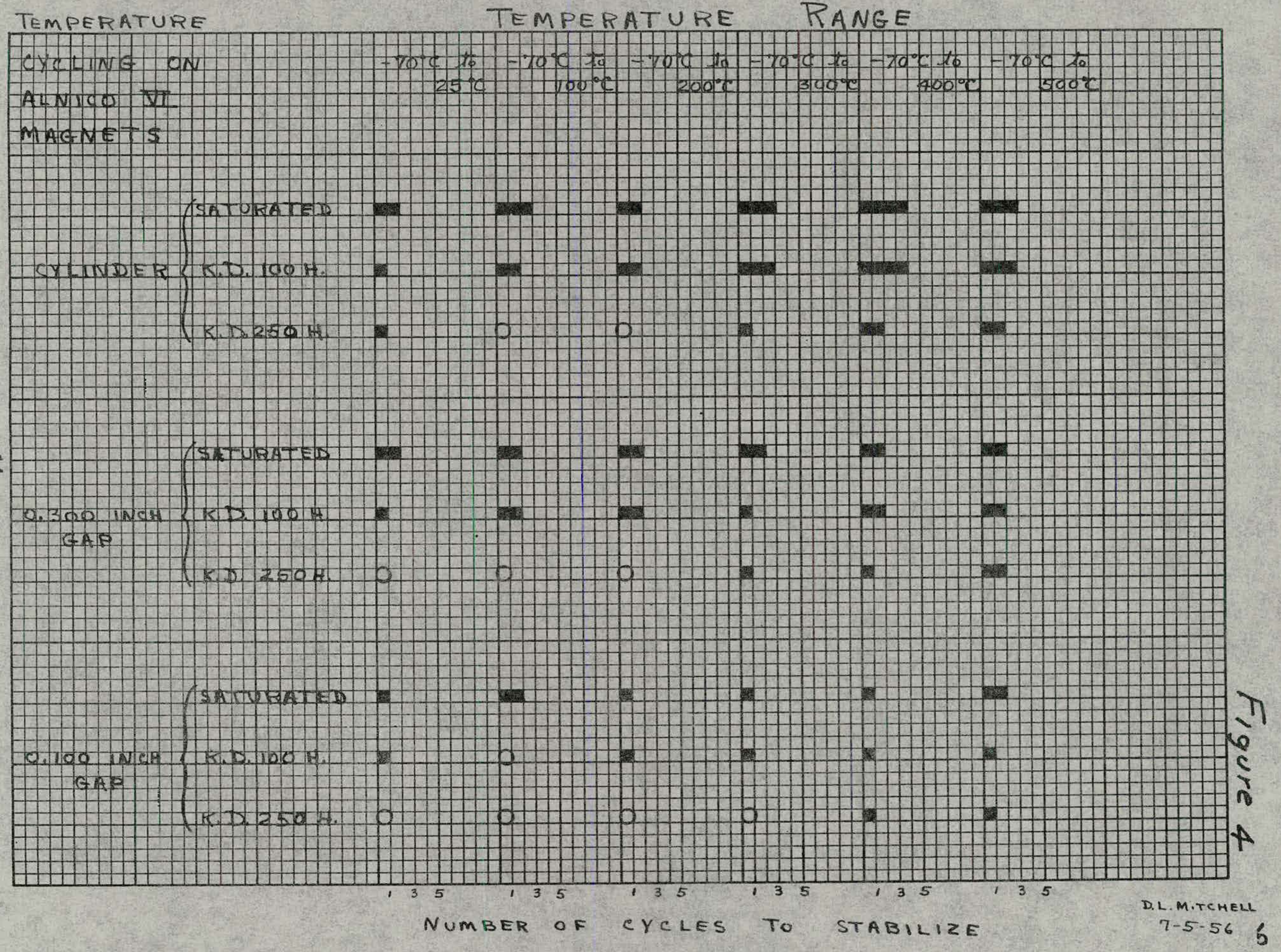




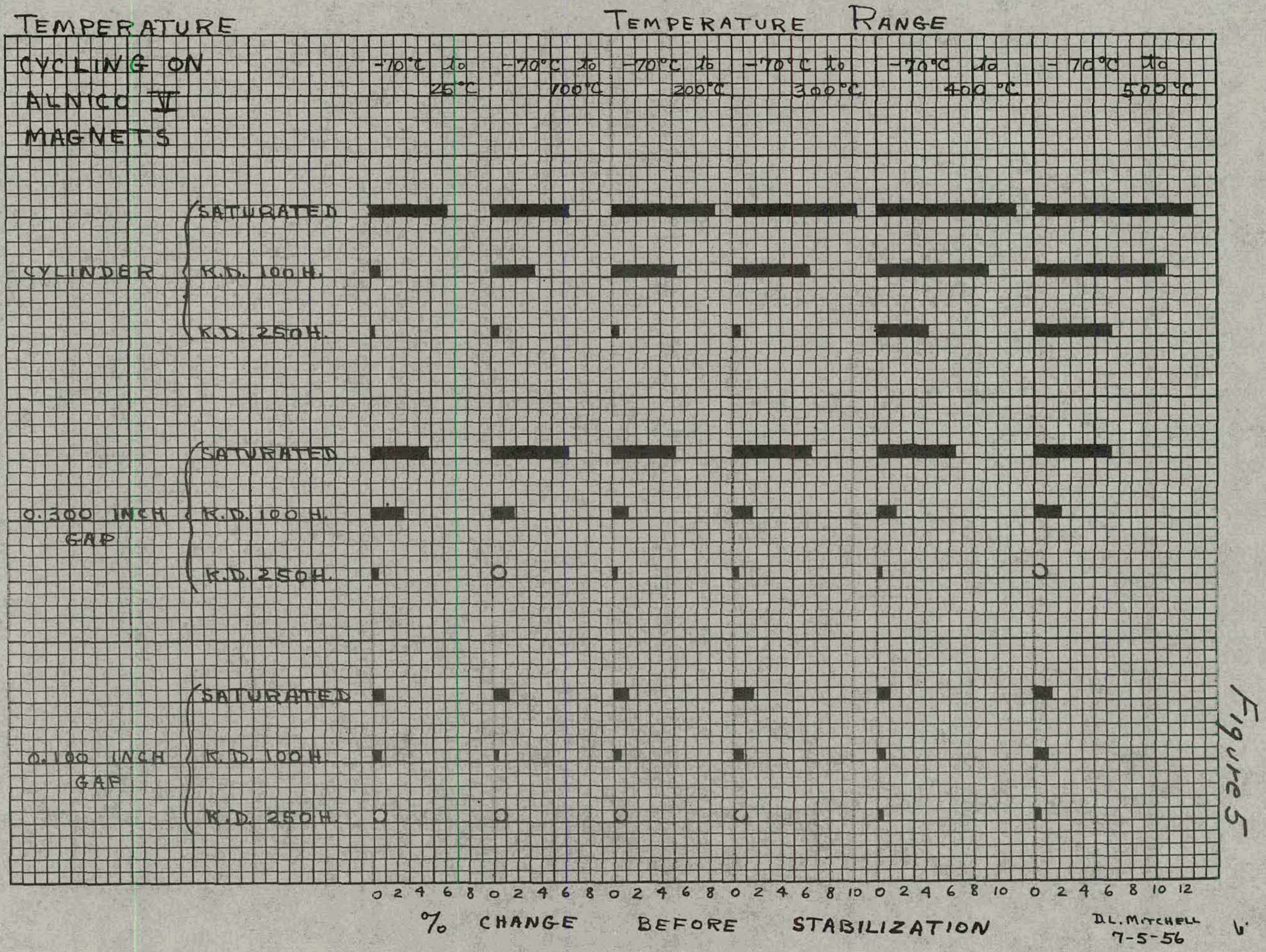




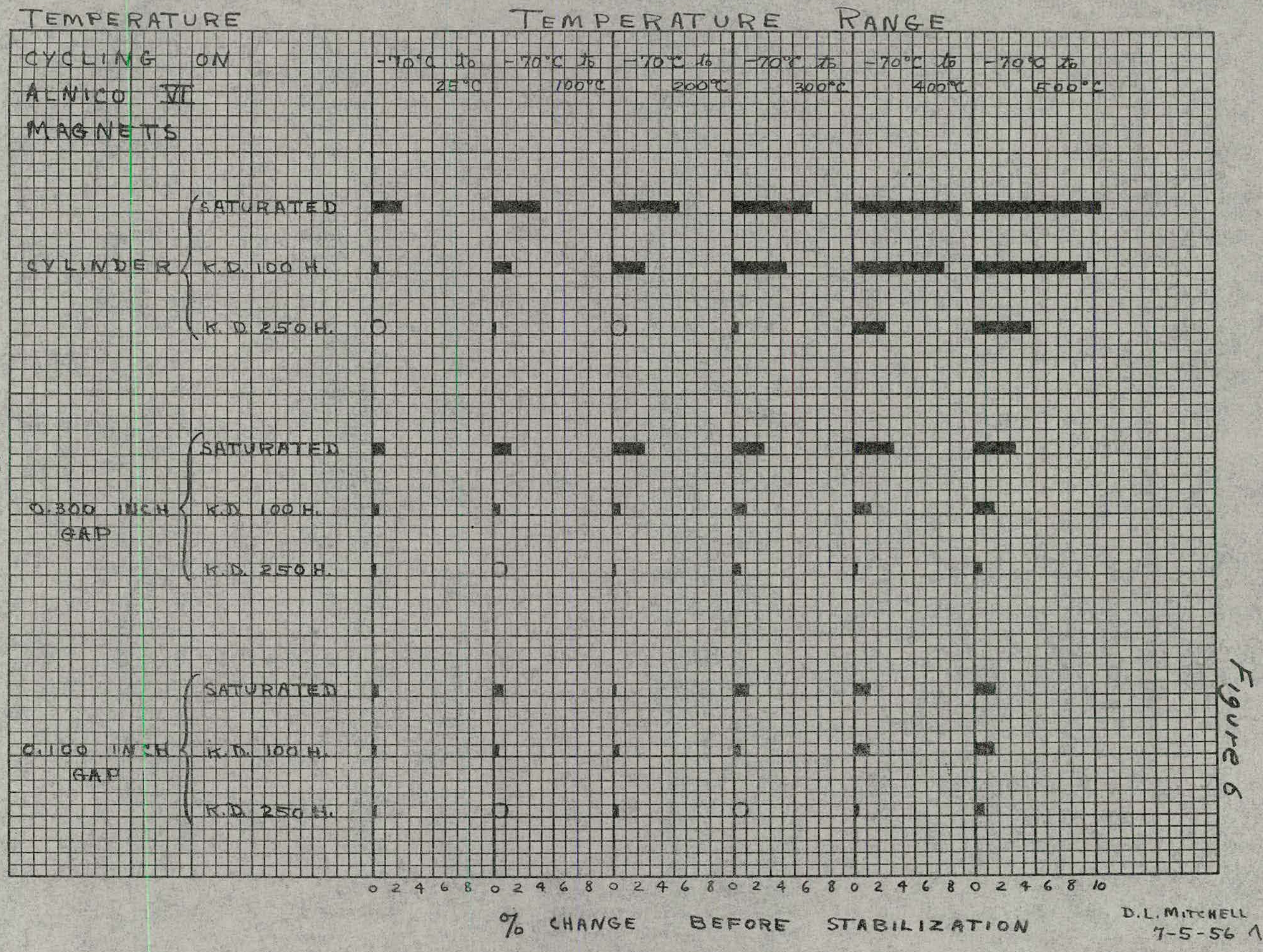




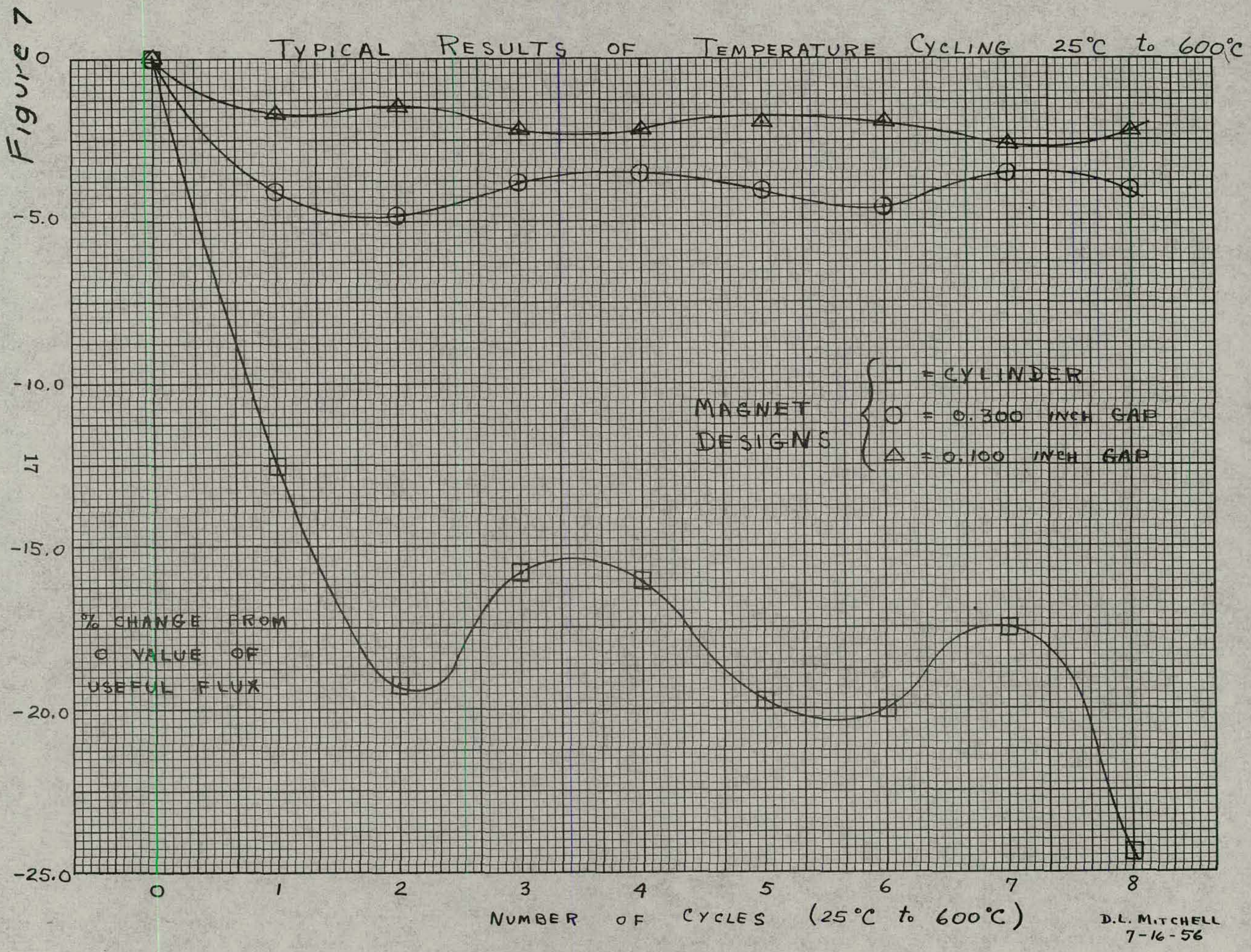




\section{THIS PAGE}

WAS INTENTIONALLY

LEFT BLANK 


\section{TEMPERATURE COEFFICIENT}

When the temperature of a magnet is changed, the amount of useful flux in the gap or surrounding the magnet is changed. In general, low temperatures result in increased flux and high temperatures $x$ esult in decreased flux. If the magnet has been stabilized by femperatuxe cycling through the temperature range involved, the change in useful flux caused by a given change in temperature is quite repearable.

The change in useful flux of stabilized magnets due to changes in temperature is a temporary change in magnetization. This is a distinctly different phenomena than the permanent change in magmetization due to temperature cycling or stabilizing. In order to recover the flux lost due to temperature stabilization, it is necessary to remagnetize the magnet, whereas the flux lost by a stable magnet due to changes in temperature can be recovered by simply bringing the magnet back to room temperature.

Since the change in useful flux per unit change in temperature is not Iinear for a wide range of temperature, it can be expreased most clearly as a flux-temperature curve. The purpose of this series of test was to determine the flux temperature curves for Alnico V and Alnico VI magnets over the temperature range $-70^{\circ} \mathrm{C}$ in $500^{\circ} \mathrm{C}$.

In order to minimize the effect of any metallurgical aging which might take place during the temperature coefficient test, all of the magnets used for this series of test were preaged 100 hours at $500^{\circ} \mathrm{C}$. The magnets were also given five temperature cycles from $-70^{\circ} \mathrm{C}$, to $500^{\circ} \mathrm{C}$ before the temperature coefficient tests were made.

The temperature coefficient curves for Alnico. V and Alnico VI test magnets are given in Figures 8 - 13. The numerical values for the temperature coefficients in $\%$ per ${ }^{\circ} \mathrm{C}$ are given in the following table.

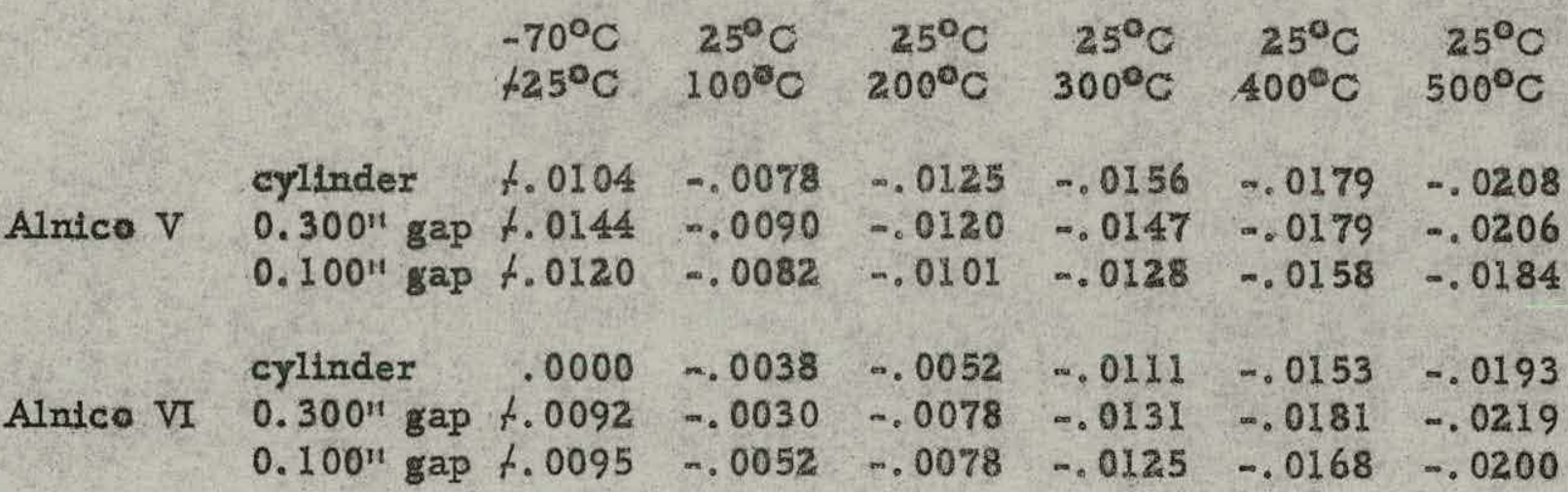


THIS PAGE

\section{WAS INTENTIONALLY \\ LEFT BLANK}




\section{CONCLUSIONS}

In addition to the results indicated above, the following conclusions can be drawn from this data:

1) The temperature coefficient of these magnets is less than half the value established for Alnico $V$ and Alnico VI magnets heat treated in the normal manner and tested near room temperature.

2) The reasor for the unusually low temperature coefficient of these magnets is probably the preaging treatment of 100 hours at $500^{\circ} \mathrm{C}$ whick was given the magnets prior to testing.

3) From $25^{\circ} \mathrm{C}$ to $500^{\circ} \mathrm{C}$ the temperature coefficient increased as the temperature increased.

4) Magnet design had very little effect on the temperature coefficient.

5) The temperature coefficient of the Alnico VI magnets was lower than that of the Alnico $V$ magnets.

6) The temperature coefficient curves for Alnico $V$ are more nearly linear than the curves for Alnico VI.

Although it was not included as a part of this investigation, previous investigations and experience by Instrument Departanent pex sonnel indicate that it would not be practical to magnetically compensate magnets over such a large range as $-70^{\circ} \mathrm{C}$ to $500^{\circ} \mathrm{C}$ for two important $r$ easons. The curie temperatures of the nickle-ixon alloyø generally used as thermo-magnetic shunts are well below $200^{\circ} \mathrm{C}$. Even if the curie temperature were higher, these alloys are metallurgically wrstable and their propertles are affected drastically by the rate of coeling from about $600^{\circ} \mathrm{C}$ to $100^{\circ} \mathrm{C}$.

If it is necessary to compensate for the changes in useful flux of a magnet over a temperature range as great as $-70^{\circ} \mathrm{C}$ to $500^{\circ} \mathrm{O}$ some method other than magnetic shunting maxt be devised. One method which seems feasible is to overcompensate the electrical circuit by means of temperature sensitive shunts or resistors. Another method which might work in certain applications is the selection of a spring material with a matching temperature coefficient to work in conjunction with the magret. 


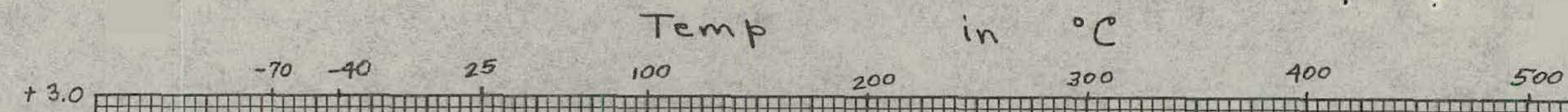

$\infty \mathrm{l}$

¿

$i^{2}$ \#

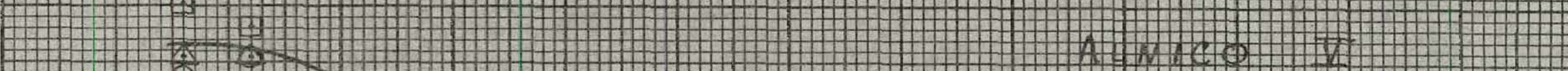

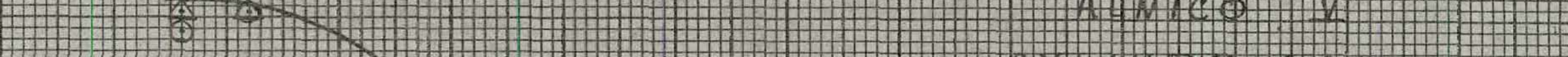

0,0

+ ( ( \#

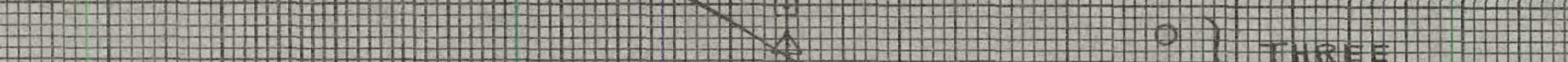
|

$-3,0$

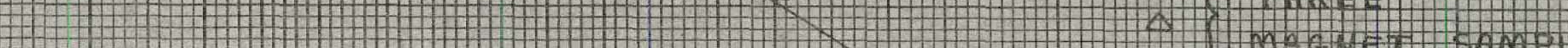
\# H I

กำ

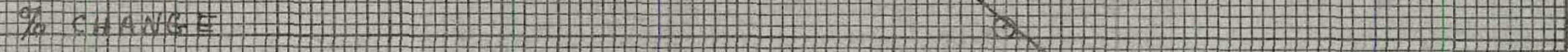

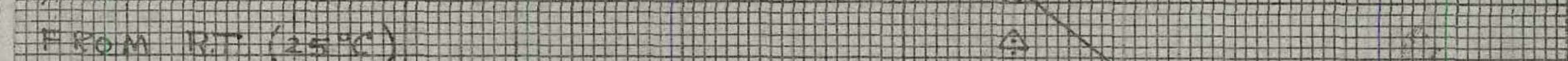
I +

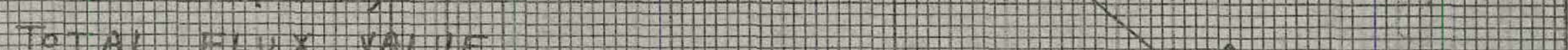

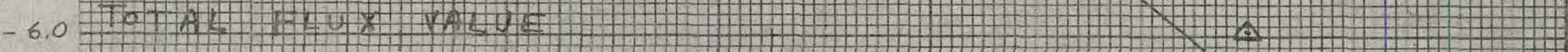
Ka

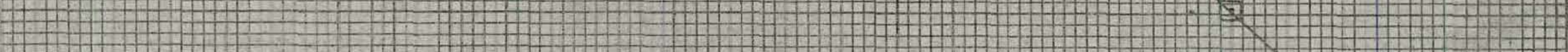
2.

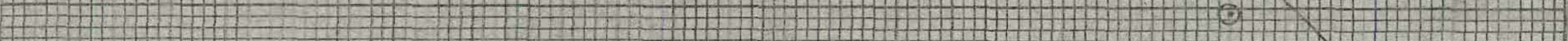
C.

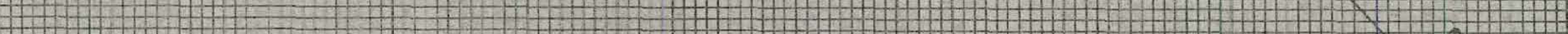
$-9.0 \%$ 2. +

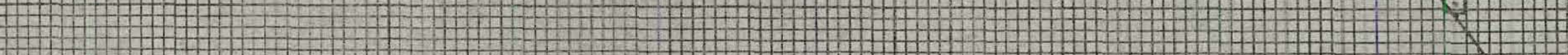

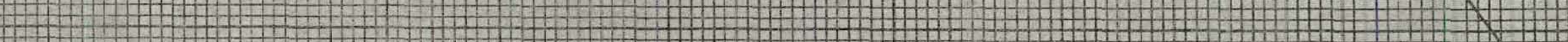
2 (2 $-12,0$ H. \# $-100$

100

200

300

400

500

Temp

in

${ }^{\circ} \mathrm{C}$

D. L. M.TEHELL 
$\begin{array}{llllllll}-70 & -40 & 25 & 100 & \text { Temp. } & & & \\ & & & & & \\ & & 200 & 300 & 400 & 500\end{array}$

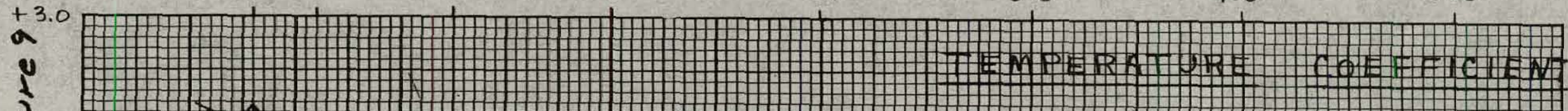

j

4

\

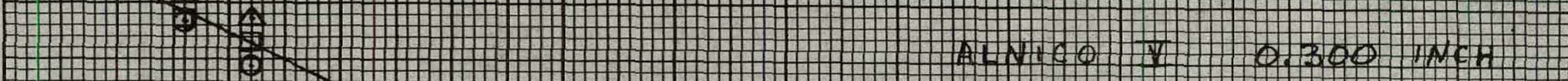

(

0.0

( (

$\because+\frac{1}{1}$

† 그

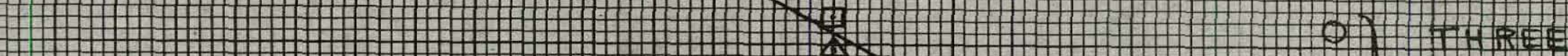

$-3.0$

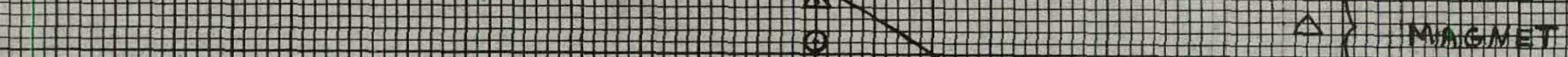
( ) (

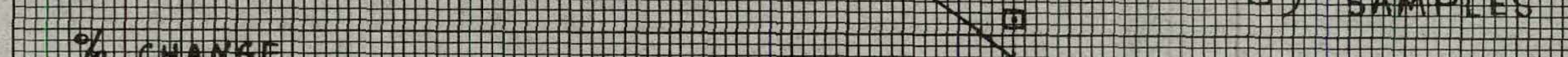

w 狠 (1) (1)

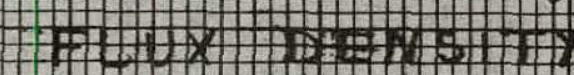

$-6.0$

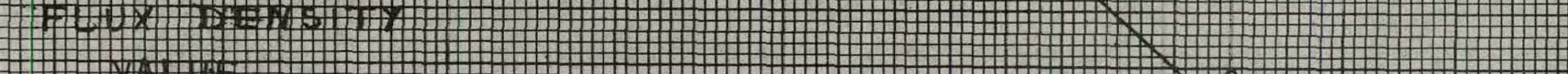
گ §

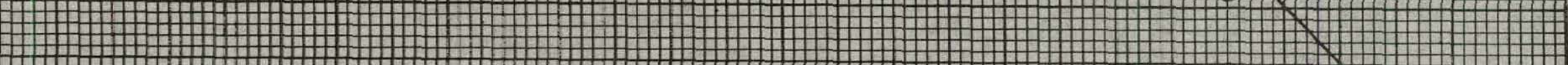

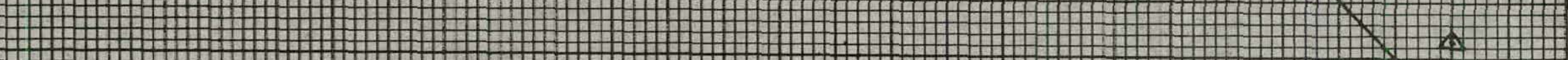

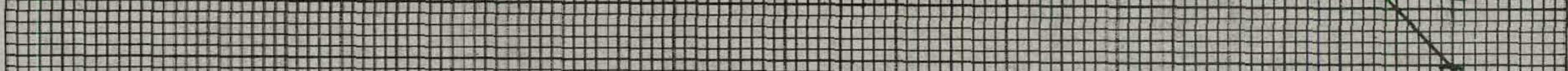
\) ํㅠ

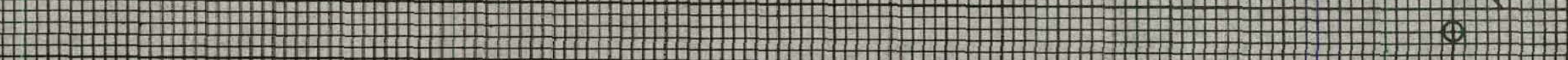

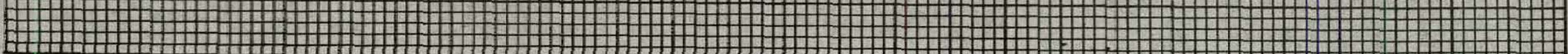

$-12.0$

$-100$

o

100

200

300

Temp.

${ }^{\circ} \mathrm{C}$

400

500

D. L. MITCHELL 


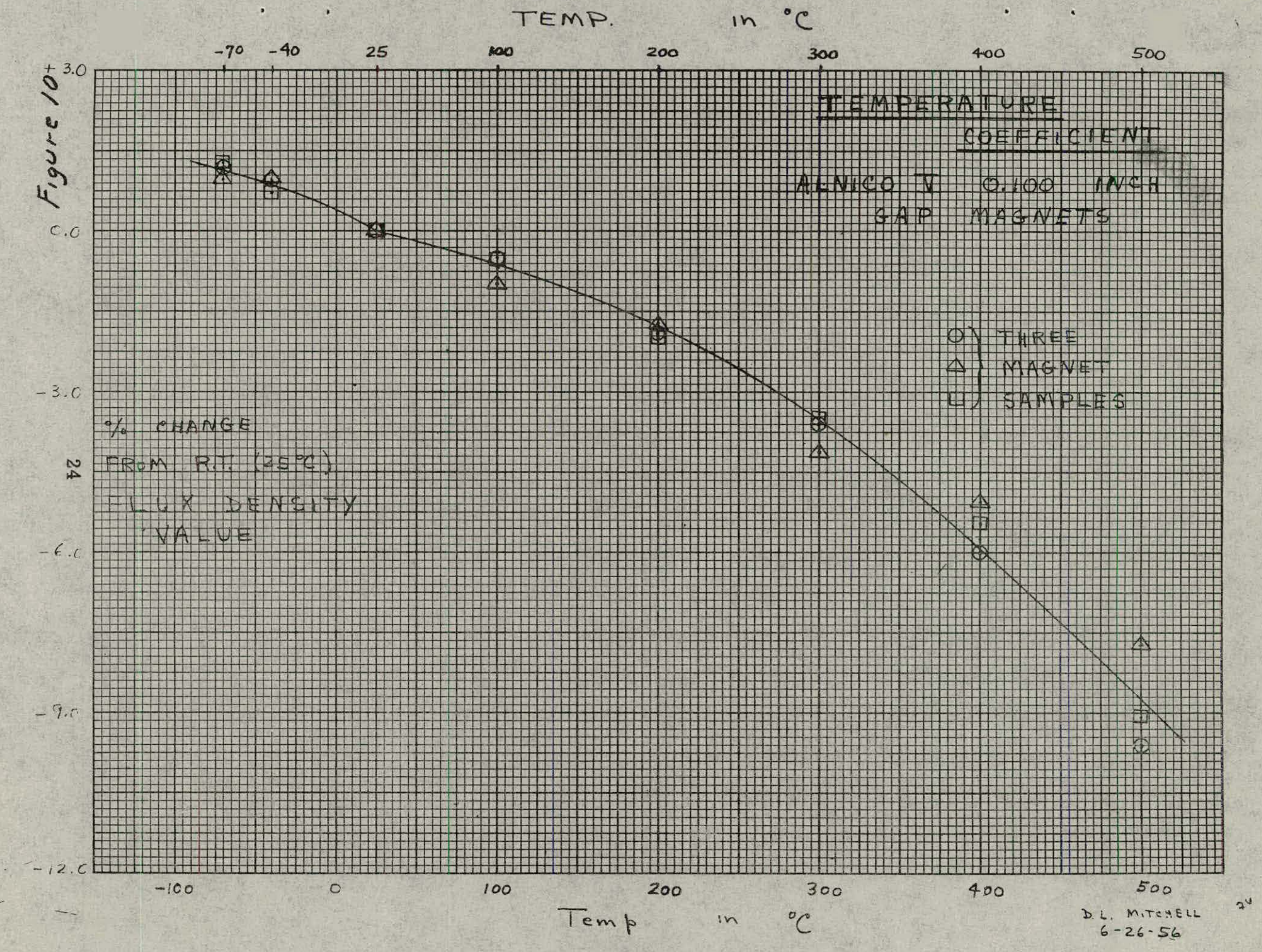




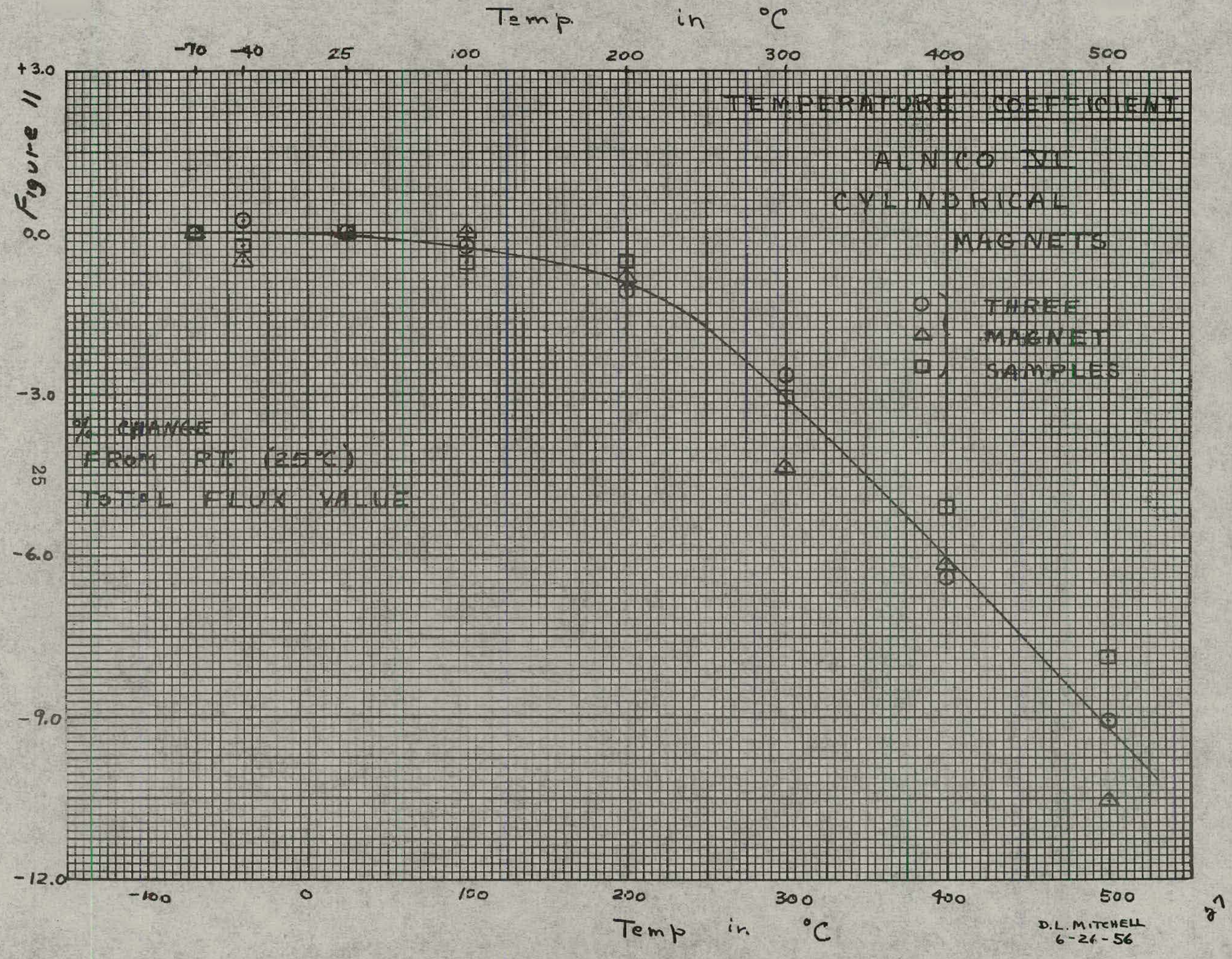


TEMP. in ${ }^{\circ} \mathrm{C}$

$-7 c \quad-40$

25

100

200

300

400

500

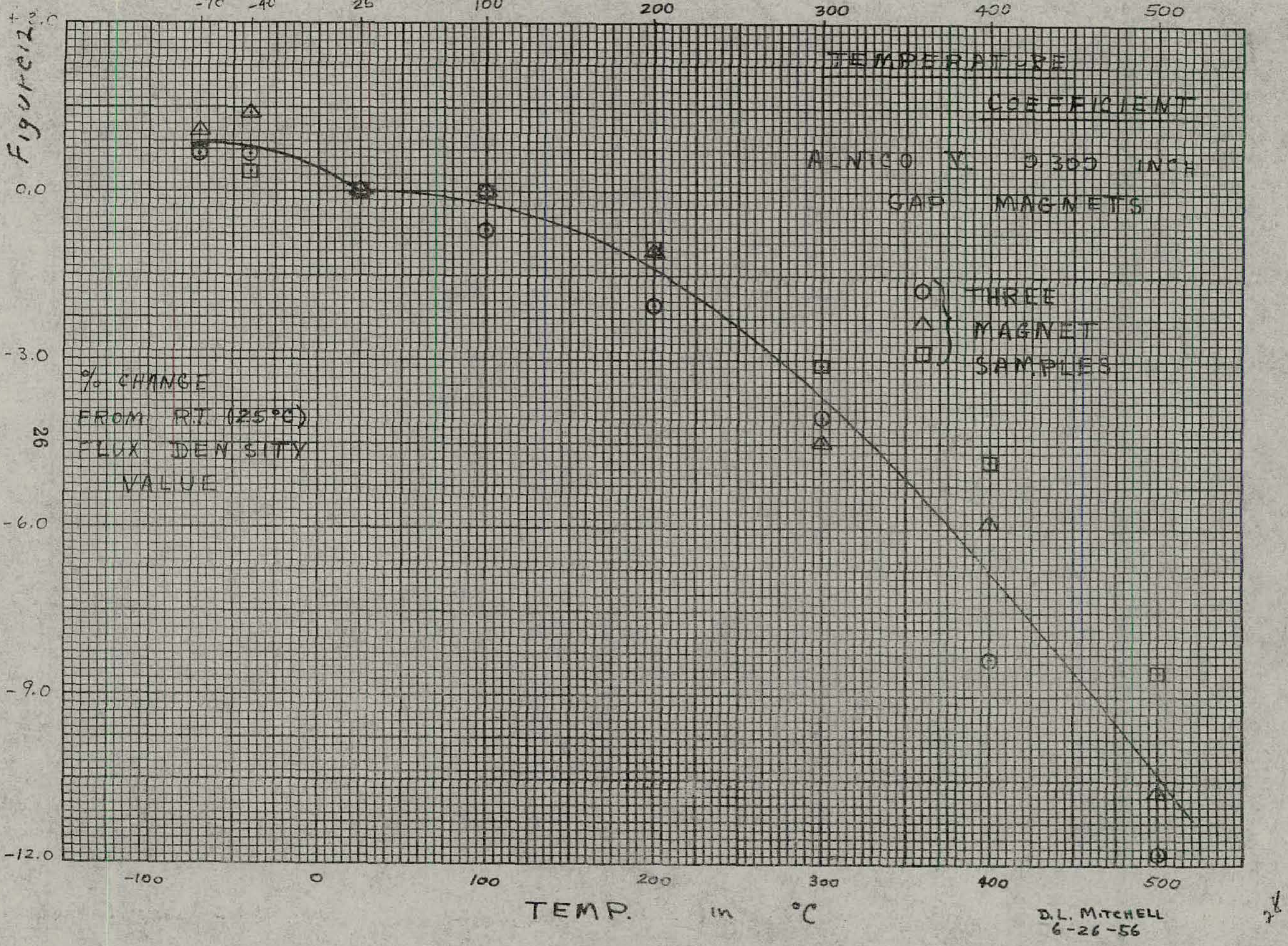




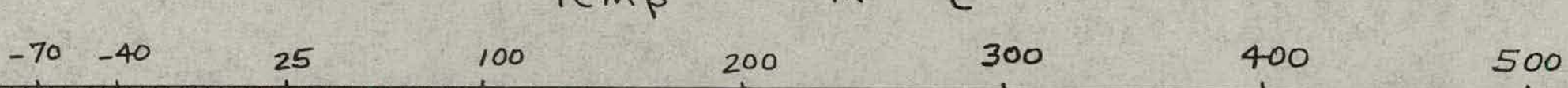

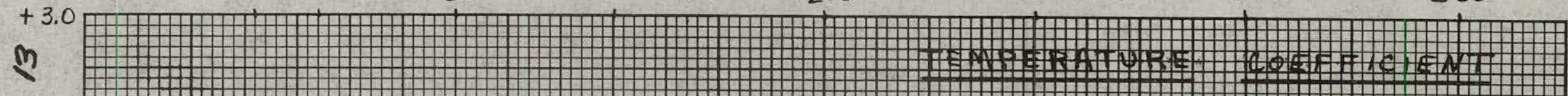

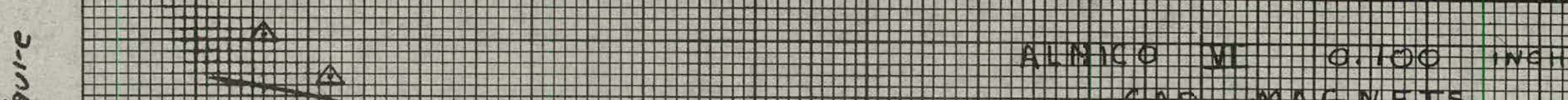

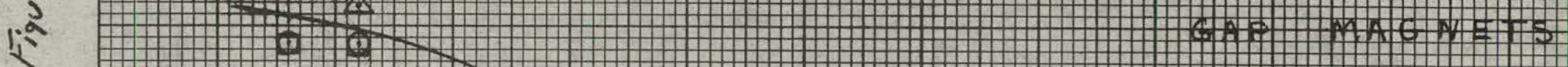

$0.0 \%$

廿

廿

H.

I

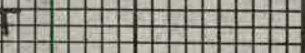

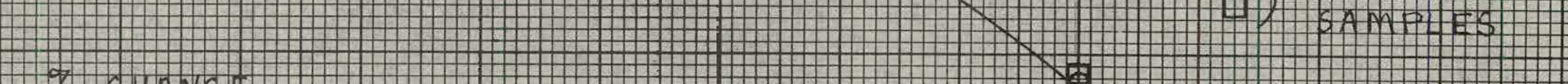

$-3.0$

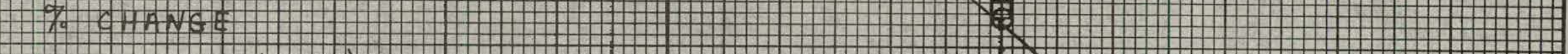

기

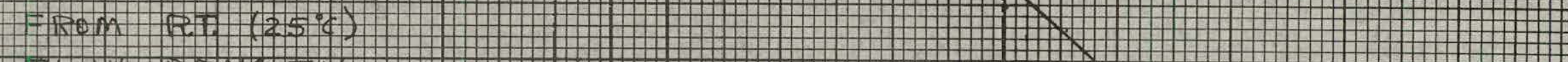

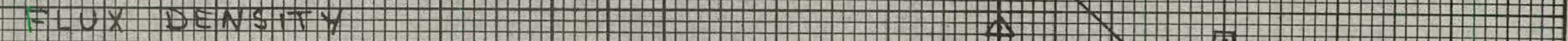

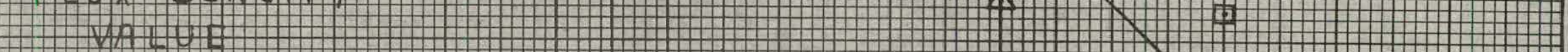

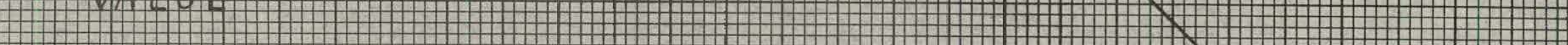

$-6.0$

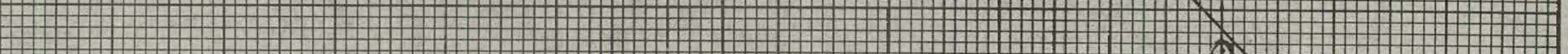

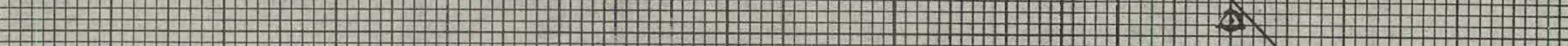
\begin{tabular}{lll}
\hline \\
1
\end{tabular} 廿 \begin{tabular}{ll|l}
\hline \\
\hline
\end{tabular} H
H W \begin{tabular}{l} 
H \\
\hline
\end{tabular} \begin{tabular}{l}
\hline Y \\
\hline
\end{tabular}

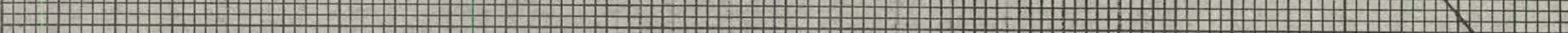

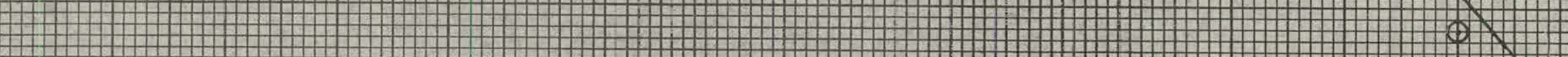
W

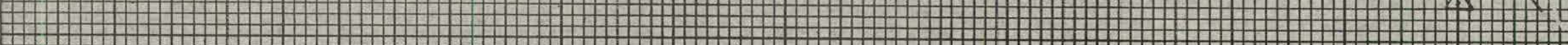

$-12.0 \%$

$-100$

0

100

300
$\circ$

400

500

Temp

in

C

D. L. MITCHELL 
THIS PAGE

\section{WAS INTENTIONALLY LEFT BLANK}




\section{HEAT ACING $500^{\circ} \mathrm{G}$}

Since proposed specifications call for the operation of permanent magnets at $500^{\circ} \mathrm{C}$ for as long as 1000 hourg, it was necessary. to determine what effect this would have on the us eful flux of magnets. At this temper ature, the useful flux of the magnet could be affected by changes in the metallurgical atructure of the material and changes in the magnetization of the magnet. Changes in the useful flux of a magnet due to changes in magnetization are temporary and can be recovered by reducing the temperature and/or remagnetizing. Changes in useful flux caused by changes in the metallurgical structure of the material are relatively permanent and can only be recovered by. reheat treating the magnet.

The purpose of this geries of test was to determine the effect of chantes. in the metallurgical structure of the material due to aging at high temperatures on useful flux. It was decided that the best measure of this. effect could be obtained by holding the magnets at high temperature for a period of time and then meaguring, the useful flux at room temperature. The effects of changes in magnetization and combined effects are dealt with in othing sections of this, report.

Alnico. $V$ and Alnico, VI mapnets of each design were aged for 1000 hour at $500^{\circ} \mathrm{C}$. In order to determine the margin of gafety at $500^{\circ} \mathrm{C}$, a few magretta of each material and exch design wero aged 200 hours at $600^{\circ} \mathrm{C}$. In addition, standard, test bars of Alntco V, Alntico VI, and Alalco VII were aged at $500^{\circ} \mathrm{C}$ far 1000 hours and at $600^{\circ} \mathrm{C}$ for 500 hours to determine the effect on the fundamental magnetic properties.

The effect of aging Alnica V and Alnico VI magnets for 1000 hours at $500^{\circ} \mathrm{C}$ is shown in Figures. $14-21$.

\section{CONCLUSIONS}

From these results it can be concluded that:

1) the useful flux of the magnefo at room temperature increased in every. case except one.

2) most af the changes, occurred during the firgt 200 hours of aging.

3) from 200 1purs to 1000 howr the net change in useful flux at tom temperature.was Ies than $1 \%$ in nearly orexy ense. 


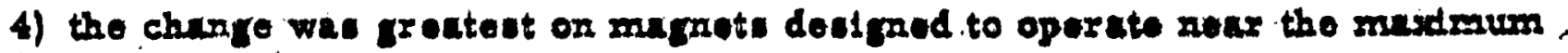
eneroy point $(0.300$ gap).

5) partially demagnatielas the mugnots prlor to aging did not reduce the change in useful gux due to agling.

6) rate of cooling from directlonuling hed little or no offect on the chango in us oful flux due to agling except in cylindrical Alndeo. V mugnete.

7) the change in useful flux of Alndco.V magnets $x$ oxchod a maximum botween 200 hour and 1000 hours and then oither leveled off or begant to decline very slowly.

8) In all cases the useful flux of the Alnico VI magnets continued to increase up to 1000 hours.

\section{TEST BARS}

The effect on the important magnetic properties of agtag. Alnico $V$, Alnico.VI, and Alnico VII test bars at $500^{\circ} \mathrm{C}$ for 1000 hour to shown in Figures 22 - 24 .

\section{CONCLUSIONS}

From the results of these tests it can be concluded that:

1) In all cases the saturation Induction (Bs), residual induction (Br), and maximum energy. (BH max) showed a definite increase up to about 200 hours and then leveled off.

2) in all cases the coercive force (Hc) Increased to a maxdmum and then began to decline between 800 and 1000 hours.

3) the decrease in coercive force was greatest for Aindco VII and least for Alnteo VI.

4) the effect of aging on the fundamental magnetic properties of the test bars confirms the observed effect on the useful flux of the.test magrets.

Both the increage in useful flux of the magnets and the increase in magnetic properties of the test bars due to aging at $500{ }^{\circ} \mathrm{C}$ indicate that the standard precipitation heat treatment givcn theso materials ta not optimum for magnetic properties. The standard treatment which congists of four 
hours at $600^{\circ} \mathrm{C}$ is used by the Instrument Department and most other manufacturers of Alnico. V and Alnico V. This treatment is probably the best compramise between the magnetic properties and the cost of high production magnets. However, the cost of low production magnets for special applications would not be such an important consideration.

The results of this investigation indicate that the best magnetic properties are developed by aging four hours at $600^{\circ} \mathrm{C}$ followed by an additional 200 hours at $500^{\circ} \mathrm{C}$. It is quite possible that the same results could be obtained by. a second treatment consisting of a shorter time at some temperature between $500^{\circ} \mathrm{C}$ and $600^{\circ} \mathrm{C}$. Such treatment would reduce both the cost and the elapsed time in preparing the magnets. This possibility should be investigated more thor oughly. 
$500^{\circ} \mathrm{C}$ AGING OF SATURATED ALNICO I MAGNETS -

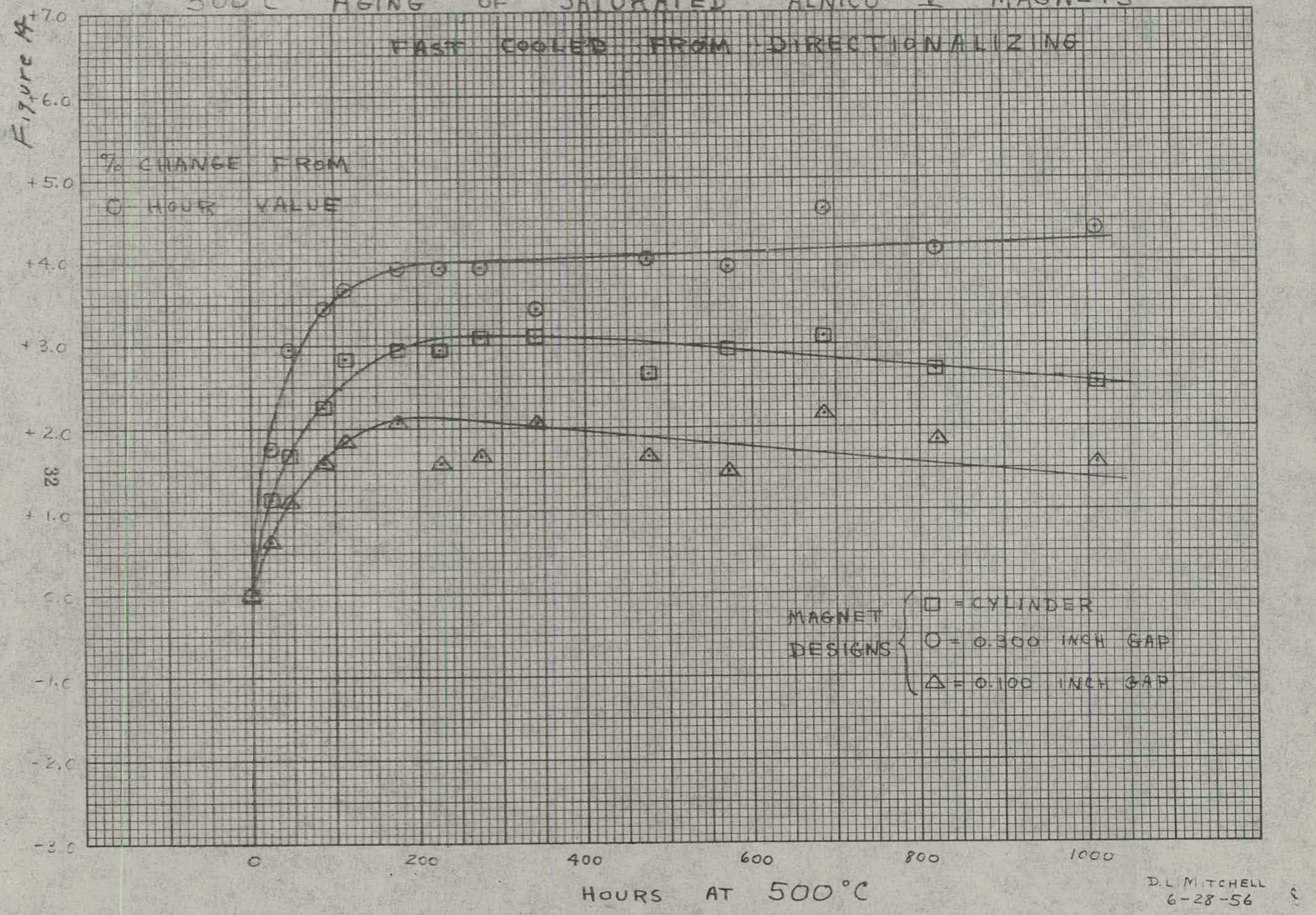




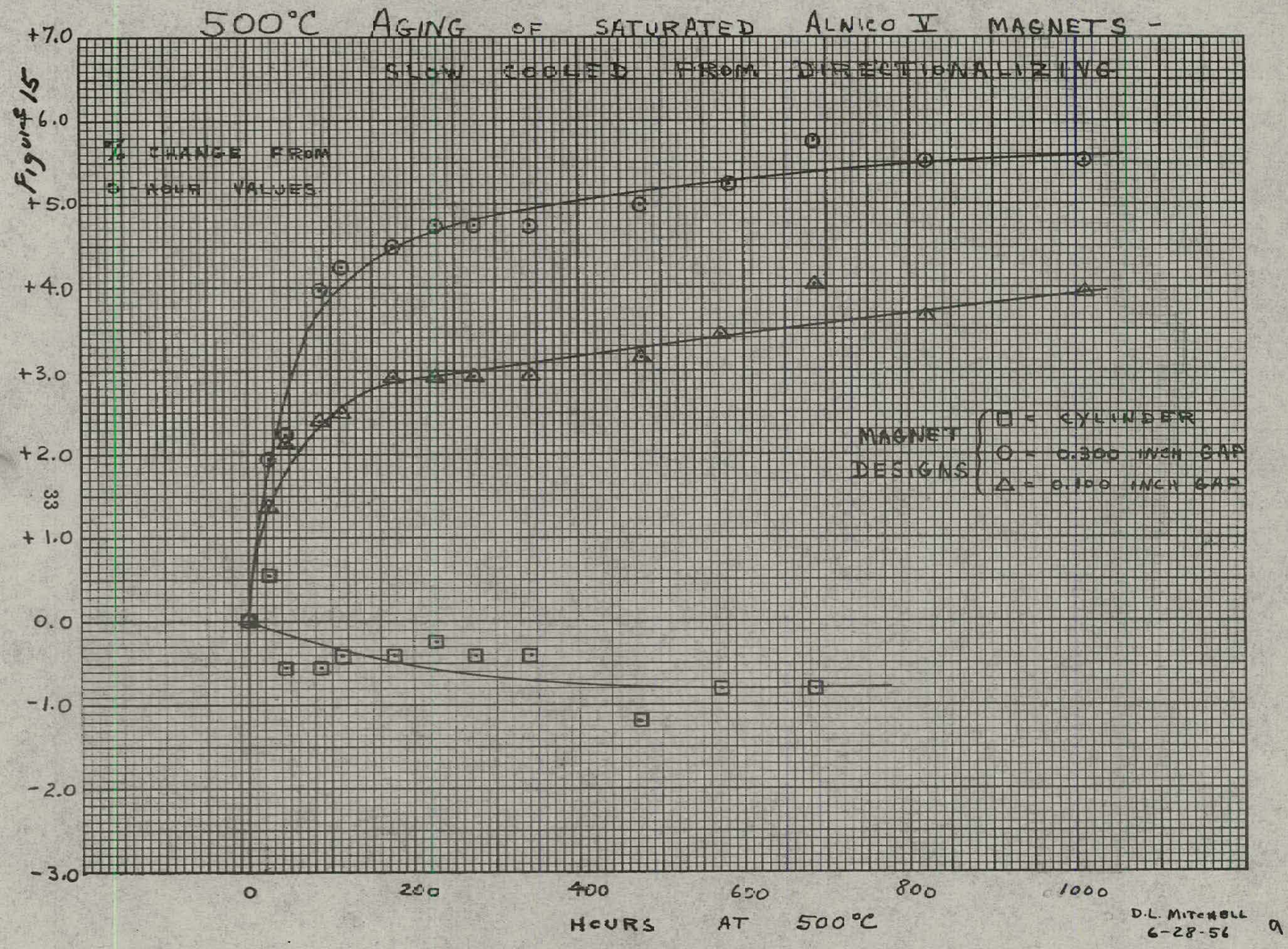




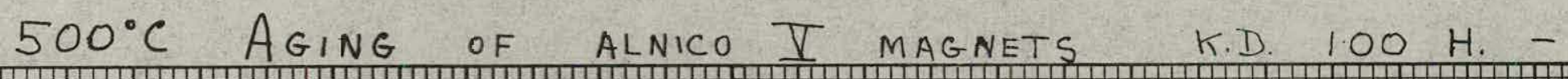

$r^{7.0}$

6.0 \

T.

$5=0$.

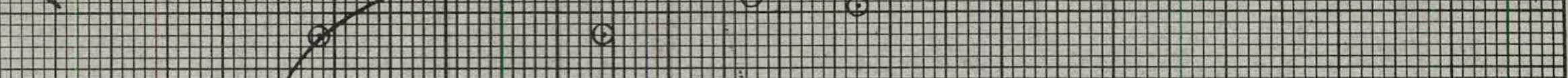

$5 \cdot \mathrm{c} \cdot \mathrm{c}$

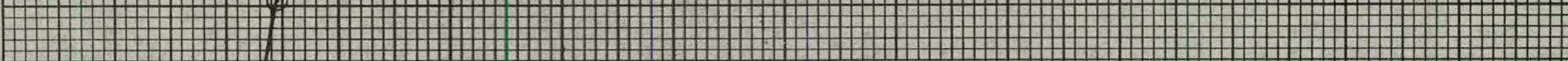
¡

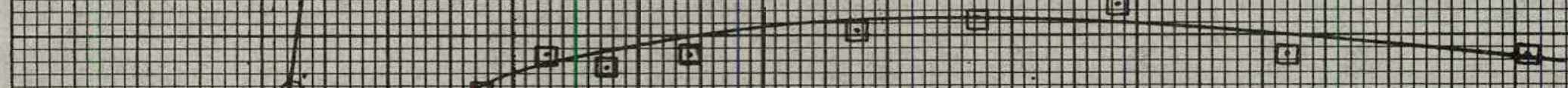

$+3.5$

(

t2.0

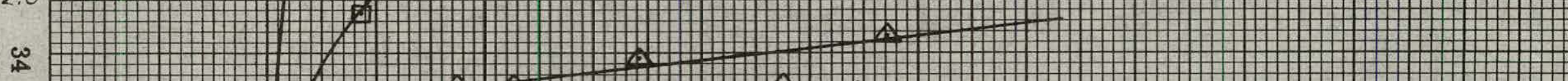

$+1.0$

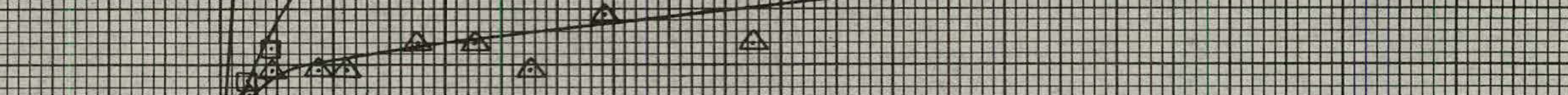
¿ † \.

0.0 $+(+\infty$ 는

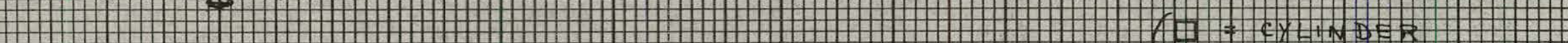
(W

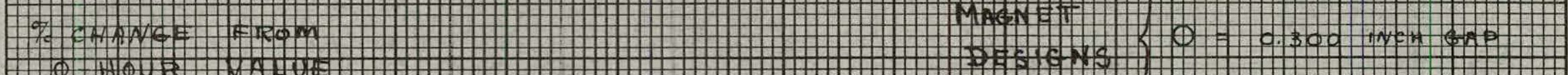

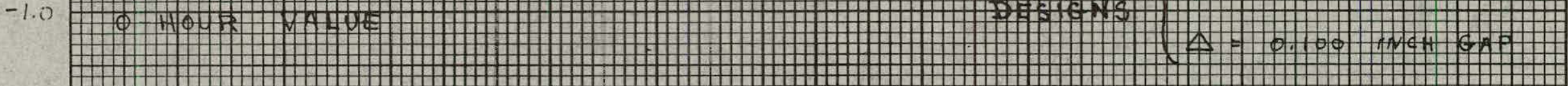
§

-2.0 ํ⼌ -3.0 ๓⿴囗十 0

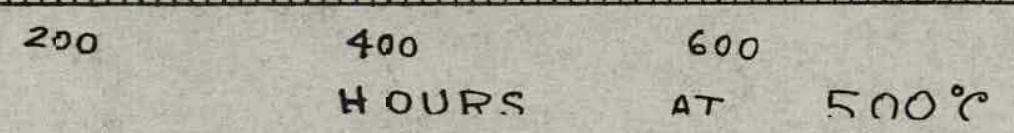

D.L.M.TCHELL
$6-28-56$ 


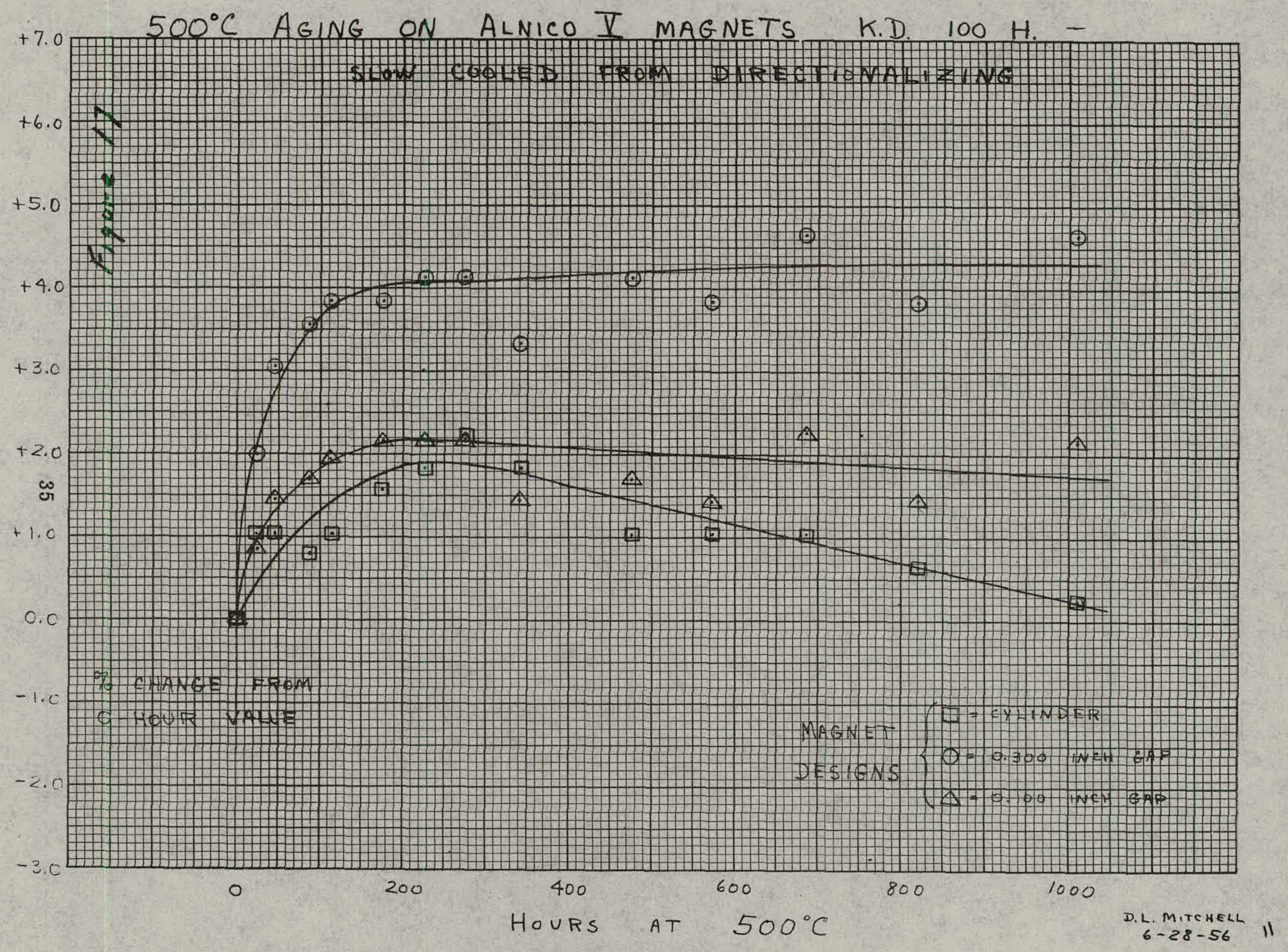




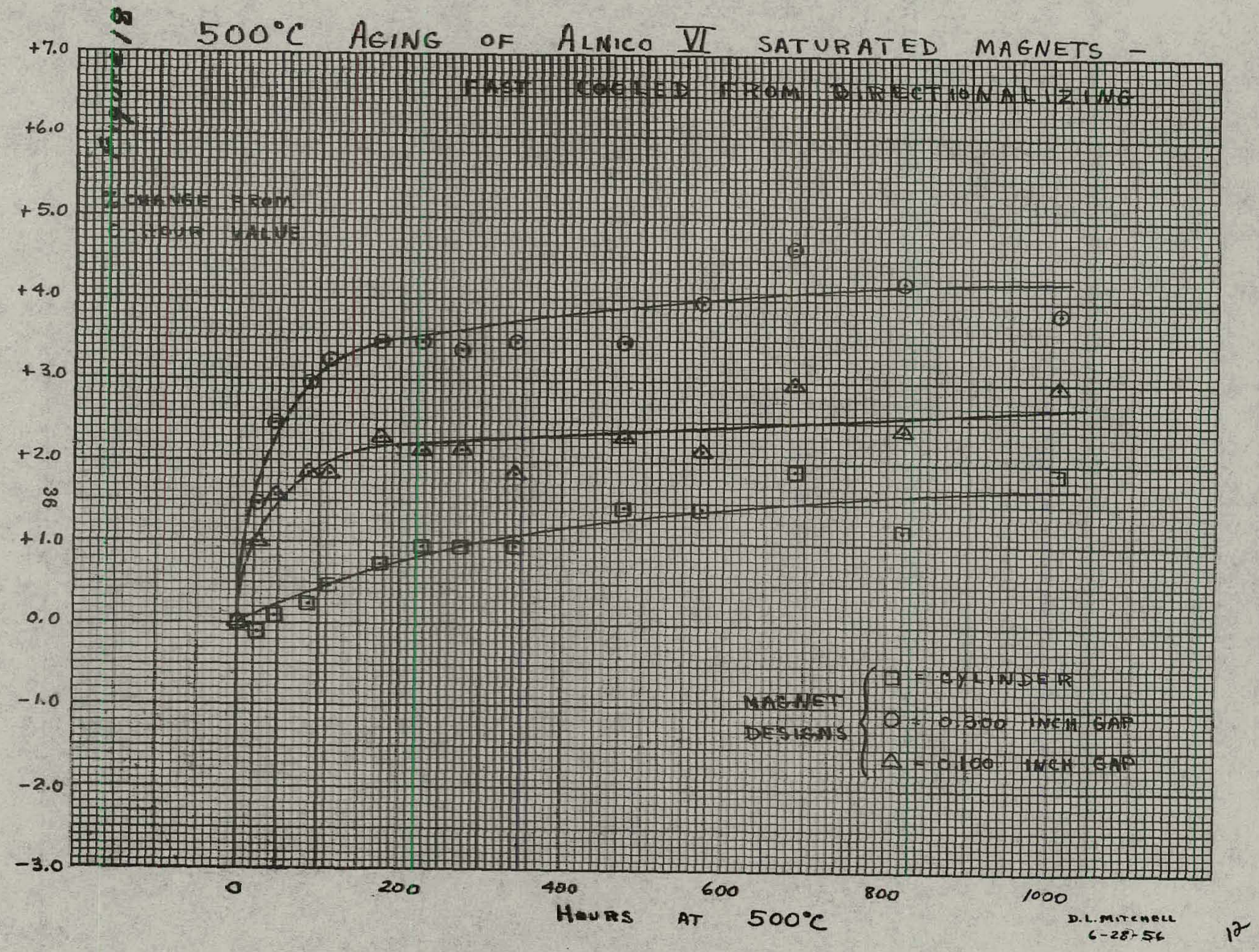




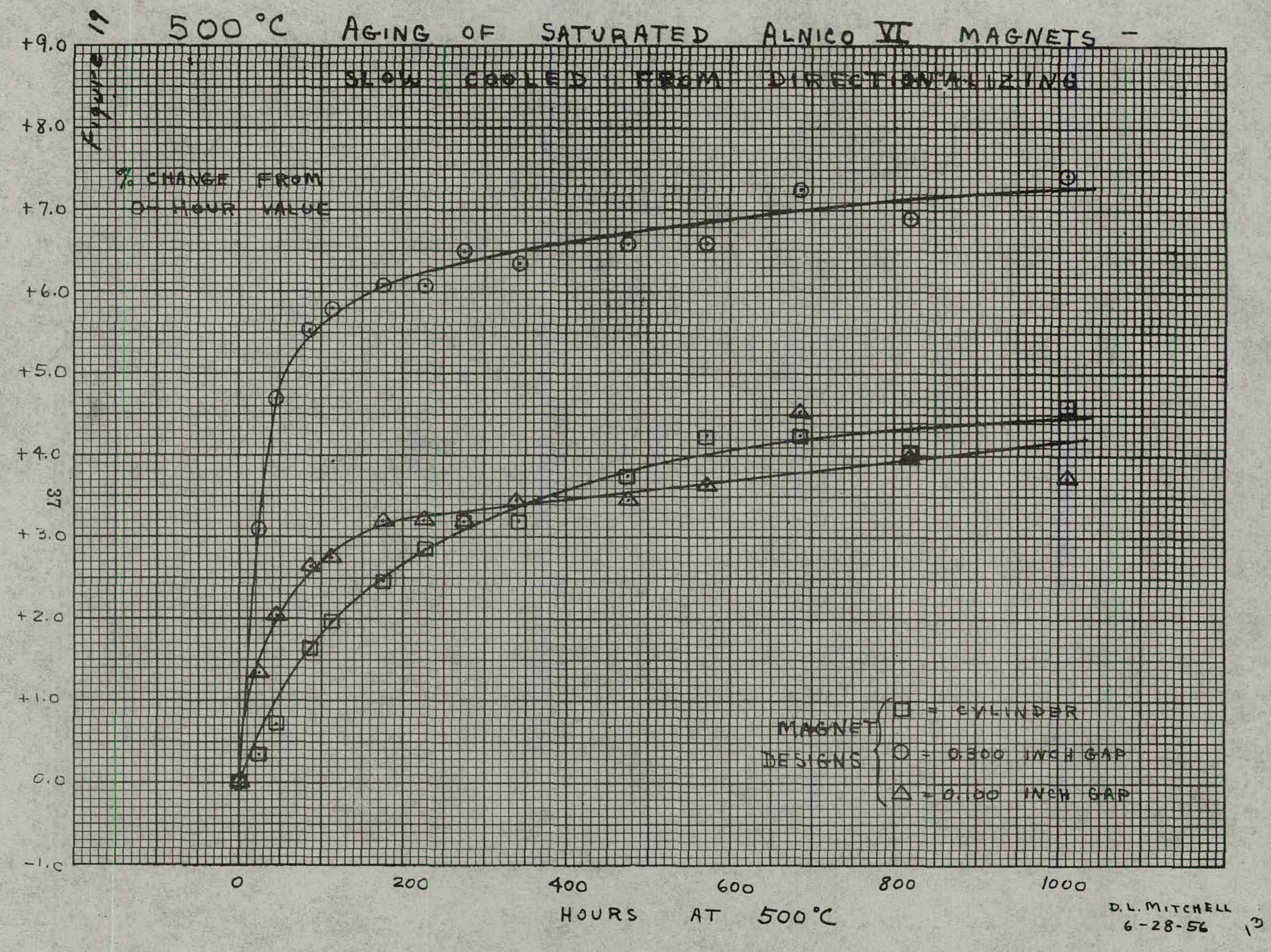


$0_{i}$

$500^{\circ} \mathrm{C} \quad \mathrm{A}_{\mathrm{IN}} \mathrm{I}$

ON A, YT MAsNETS

K.D $100 \mathrm{H}$

$-$

מִ מ

$+6.0$

\#冊曲

$+5.0$

\#\#+

(n)

?

(I)

(") W

$+4.0$

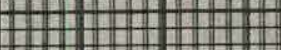

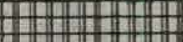

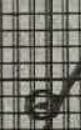

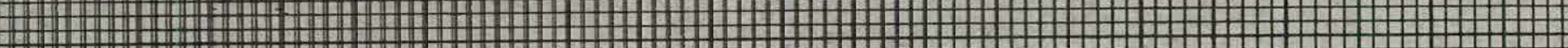

そ

$+3.0$

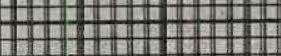

$+2.0$

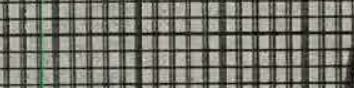

\# \#

曲曲曲地

(")

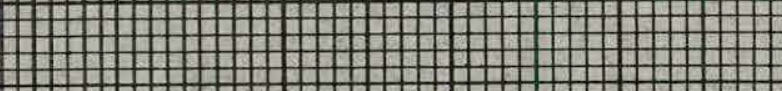

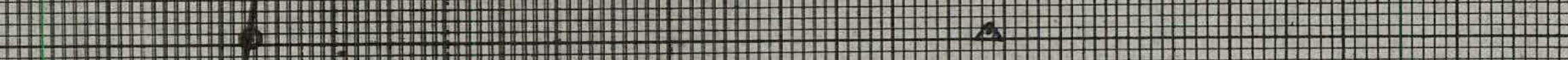

$\stackrel{\infty}{\infty}$

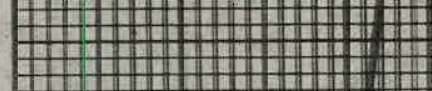

$+1.0$

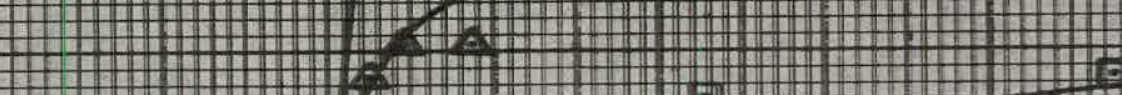

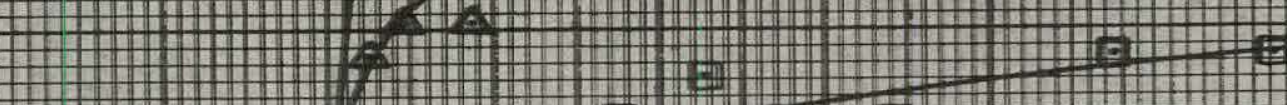

0.0

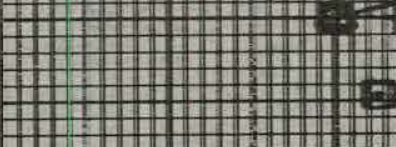

$-1.0$

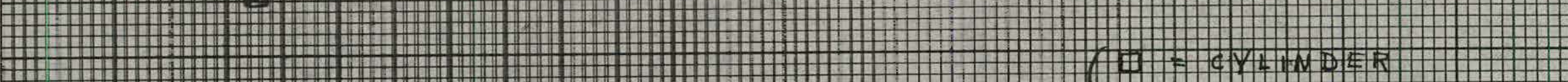

(1)

\#, \#, \# +

(1) †

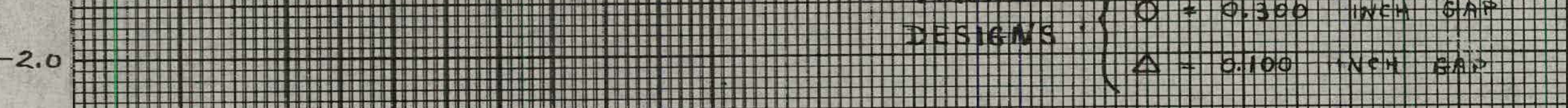

-3.0 ํㅐ

a
200
400

Hours
600 800

D.L. M.TCHELL

6-28-56 i4 


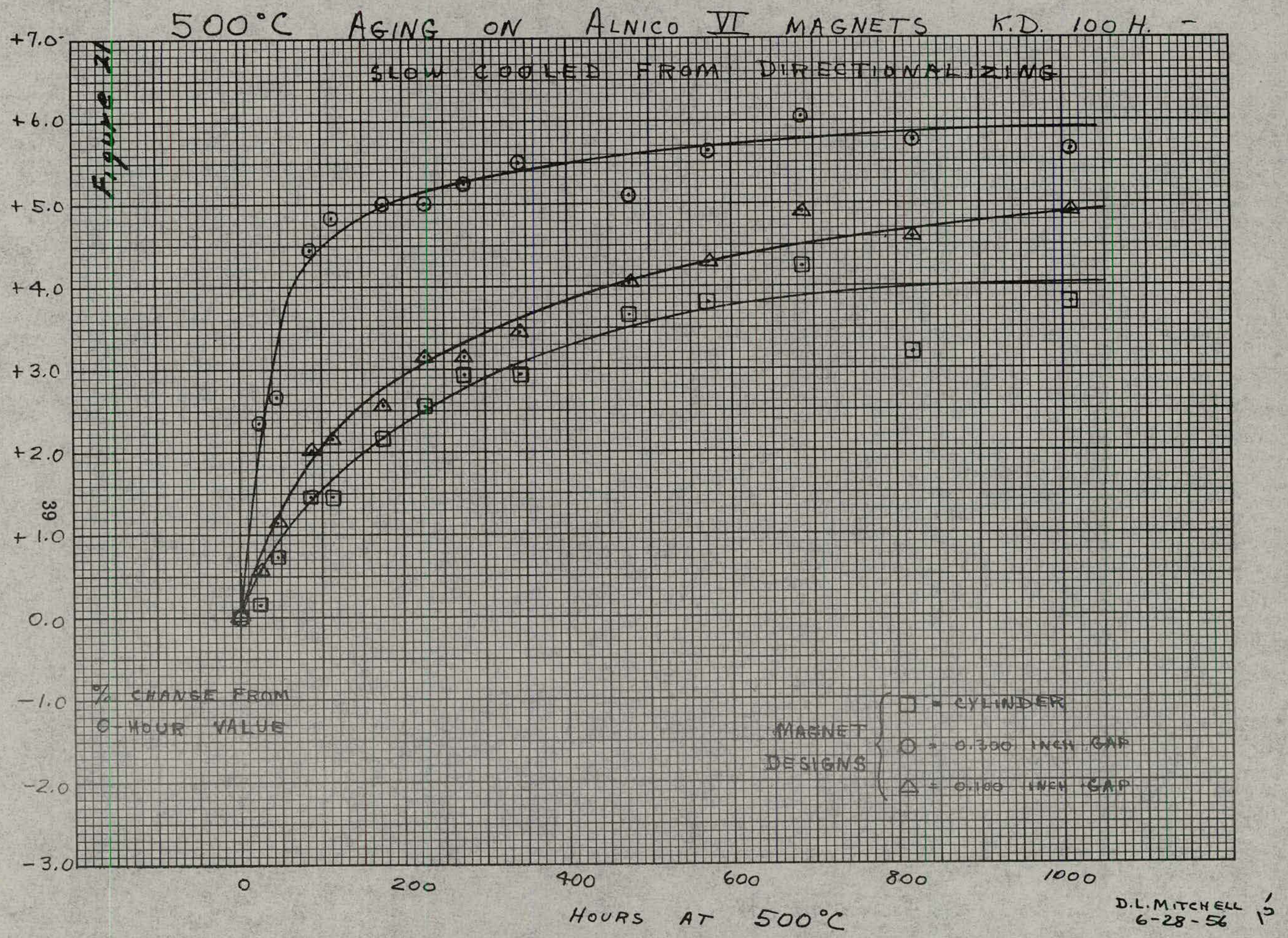




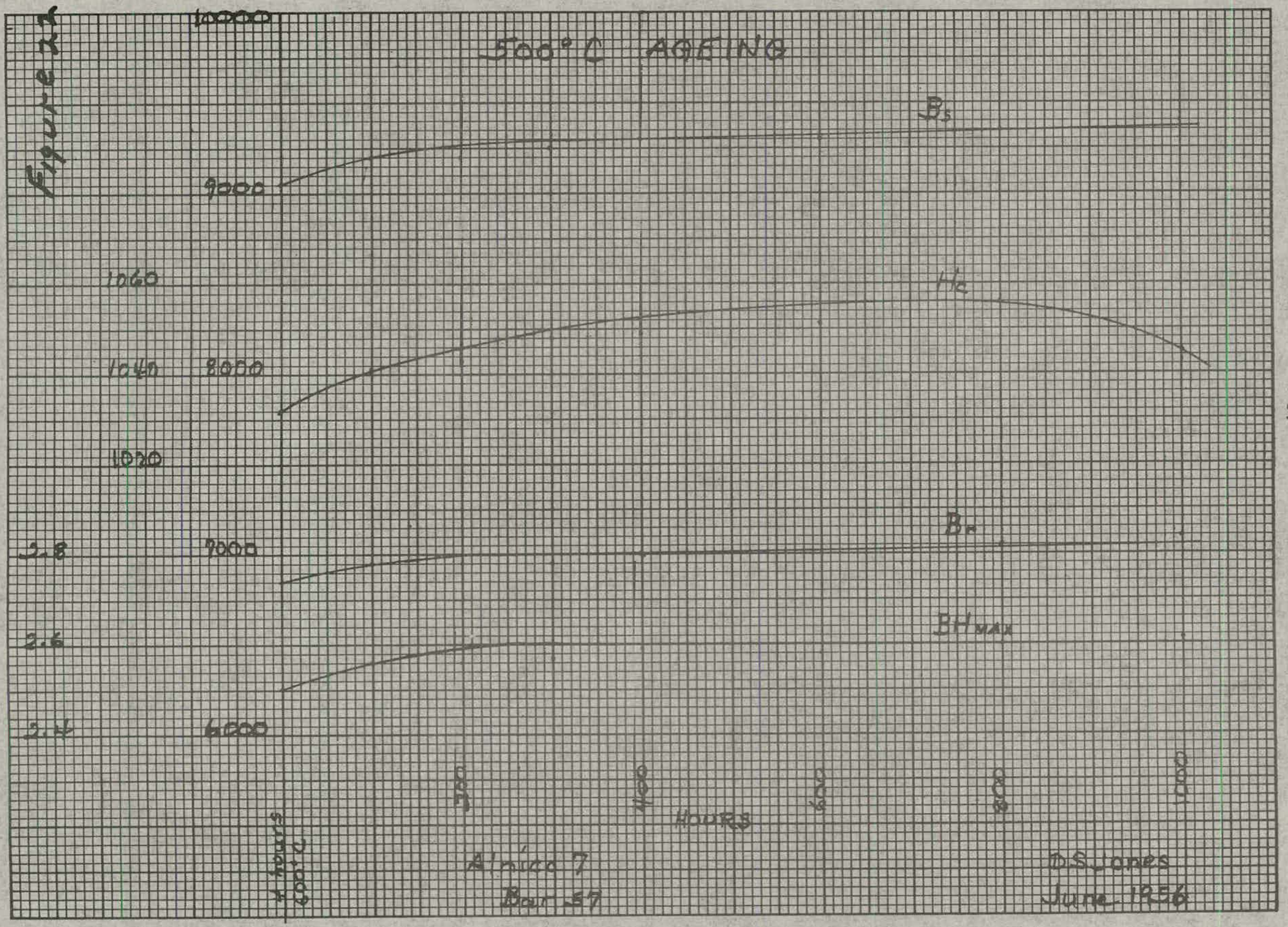




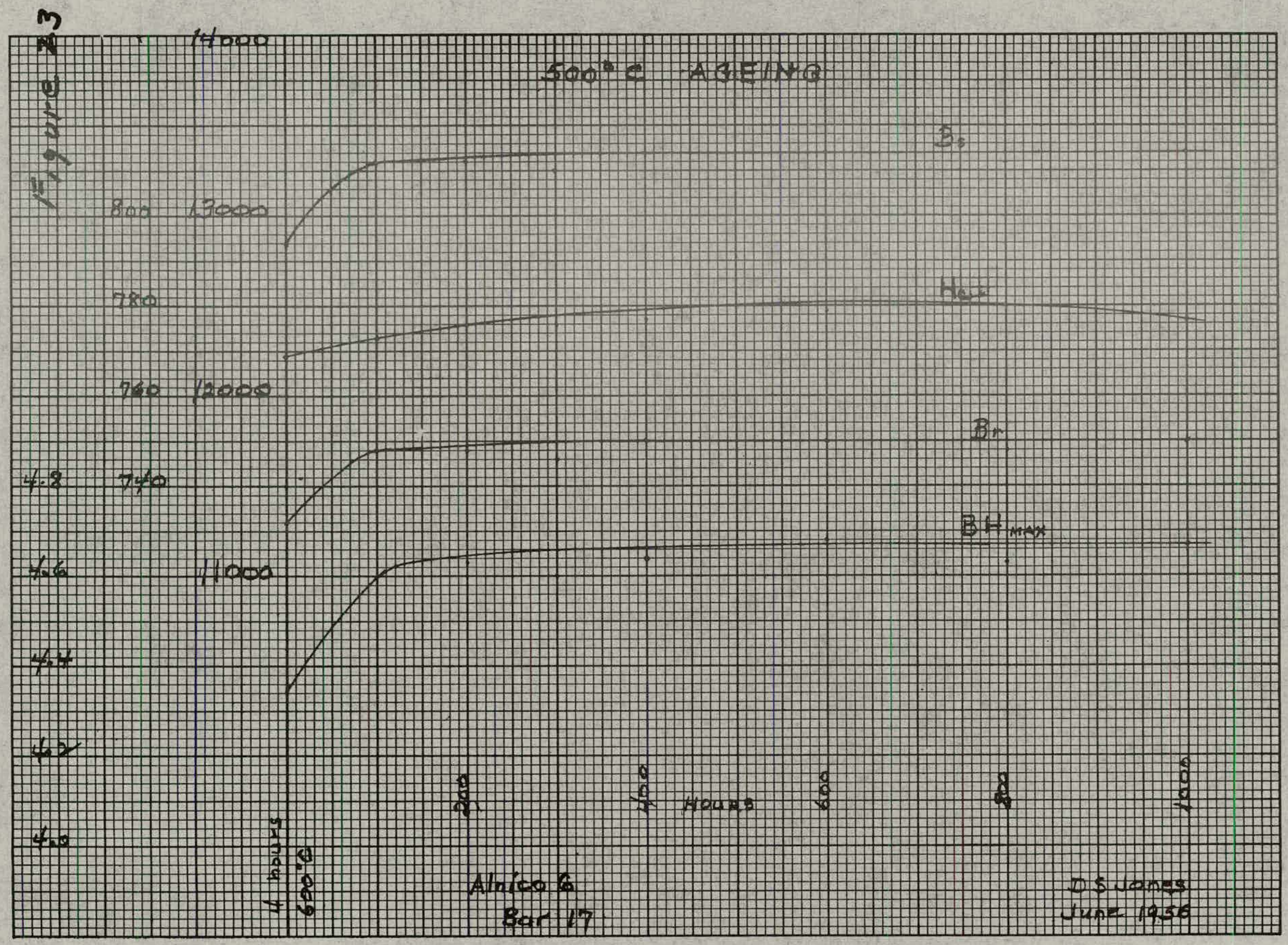




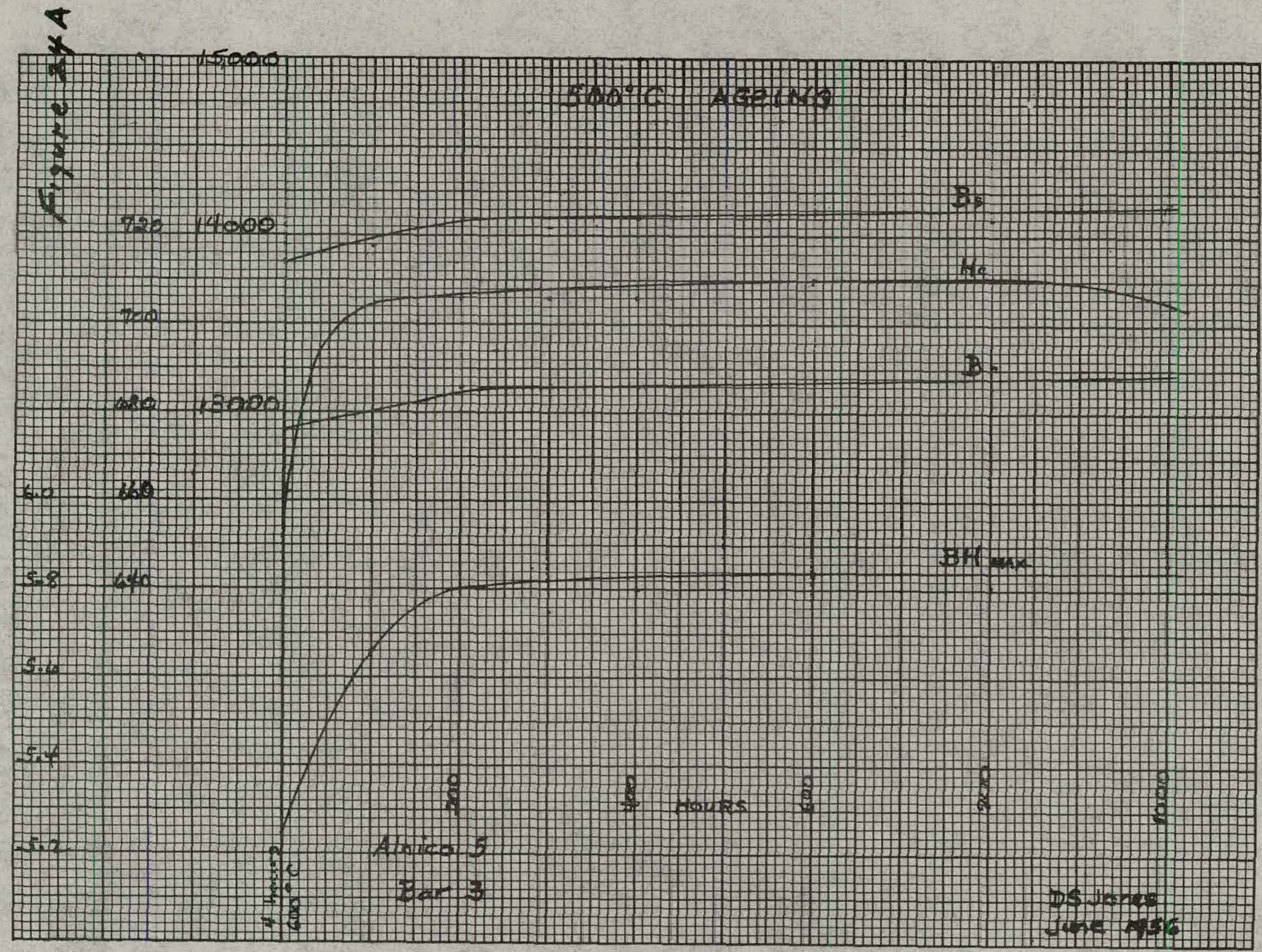




\section{HEAT AGING $600^{\circ} \mathrm{C}$}

It was originally plamned to $r$ un the $600^{\circ} \mathrm{C}$ heat aging experiment for 500 hours. However, this series of test was discontinued at the end of 200 hours because it was obvious that all of the magrets had become unstable.

Unforkunately all of the magnets in this experiment were not aged at exactly the same temperature because of a temperature gradient in the furnace, The actual temperature at which each magnet was aged in indicated on the performance curves. This reduces the precision of the experiment slightly, but it also makes available useful data which otherwise would not kave been obtained. The two $\mathrm{c}$-shaped designs were divided equally between a zone above $600^{\circ} \mathrm{C}$ and a zone below $600^{\circ} \mathrm{C}$. All of the cylindrical magnets were located in a zone that was exactly $600^{\circ} \mathrm{C}$.

The effect on the useful flux at room ternperature of aging the test magnets at about $600^{\circ} \mathrm{C}$ is shown in Figures $24-31$.

\section{CONCLUSIONS}

The useful flux of all of the magrets aged at about $600^{\circ} \mathrm{C}$ changed drastically in the first 200 hours of aging. For the purposes of this experiment, stability is defired as a change in wseful flux of less than $5 \%$ in 500 hours. The useful flux of some of the magnets aged at about $600^{\circ} \mathrm{C}$ decreased as much as $45 \%$ in the first 200 hours of aging. In addition, there seemed to be no tendency to level off as indicated in the $500^{\circ} \mathrm{C}$ aging test.

\section{TEST BARS}

The effect on the important magnetic propexties of Alxico V, Alnico VI, and Alnico VII test bars aged 500 hours at $600^{\circ} \mathrm{C}$ is shown in Figures $32-34$.

\section{CONCLUSIONS}

Although the effect or test bars is not as pronounced as the effect on magnets, the changes in the magnetic properties of the test bars clearly indicate that Alnico V and Alnico VI are not stable at $600^{\circ} \mathrm{C}$. The effect of aging at $600^{\circ} \mathrm{C}$ is somewhat less pxonounced on the magnetic properties of Alnico VII test bars. The lack of stability and eratic behavior of magretic properties of the Alnico V and Alnico VI test bars aged at $600^{\circ} \mathrm{C}$ undoubtedly explain the marked instability of the magnets. 


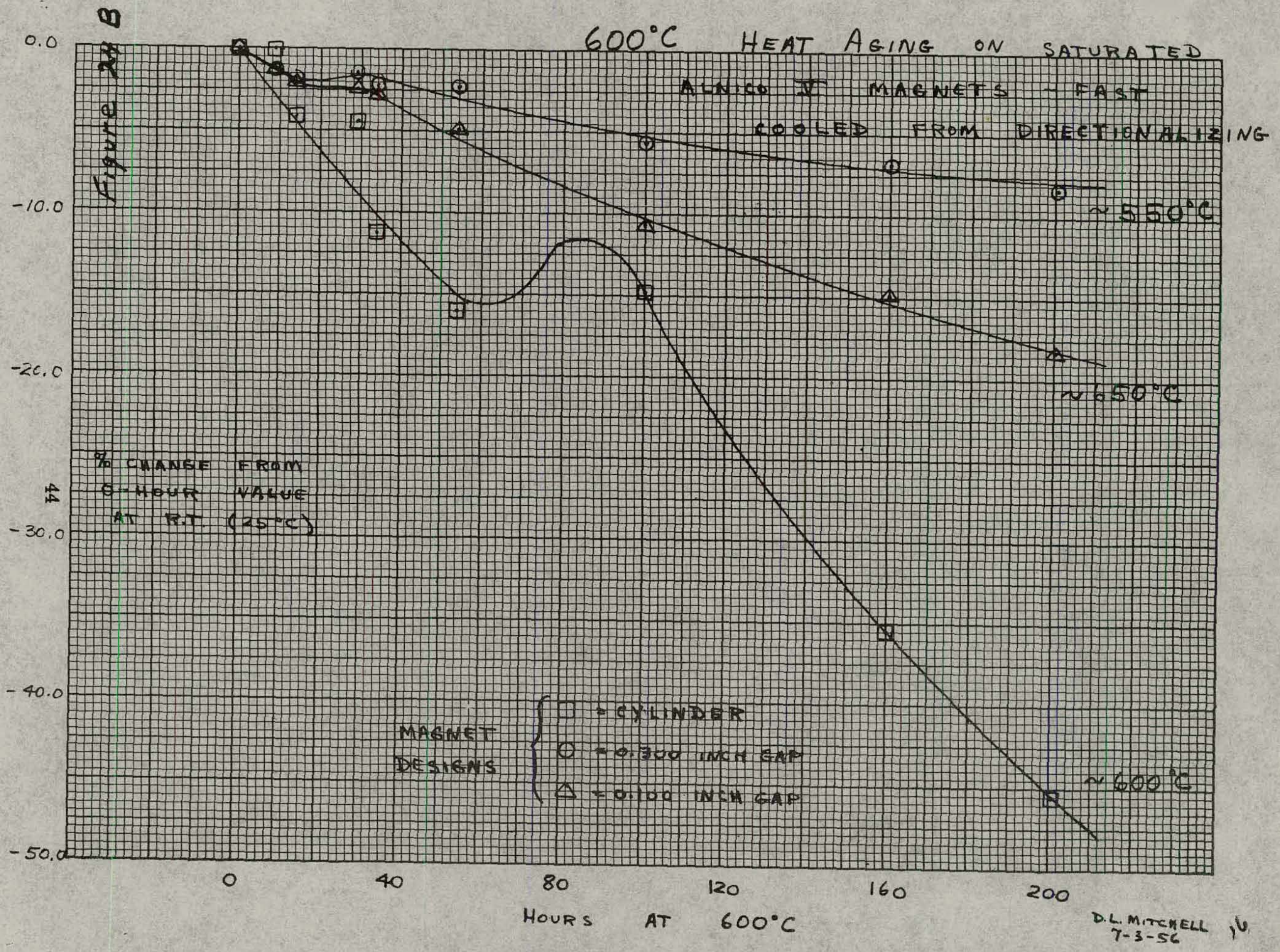




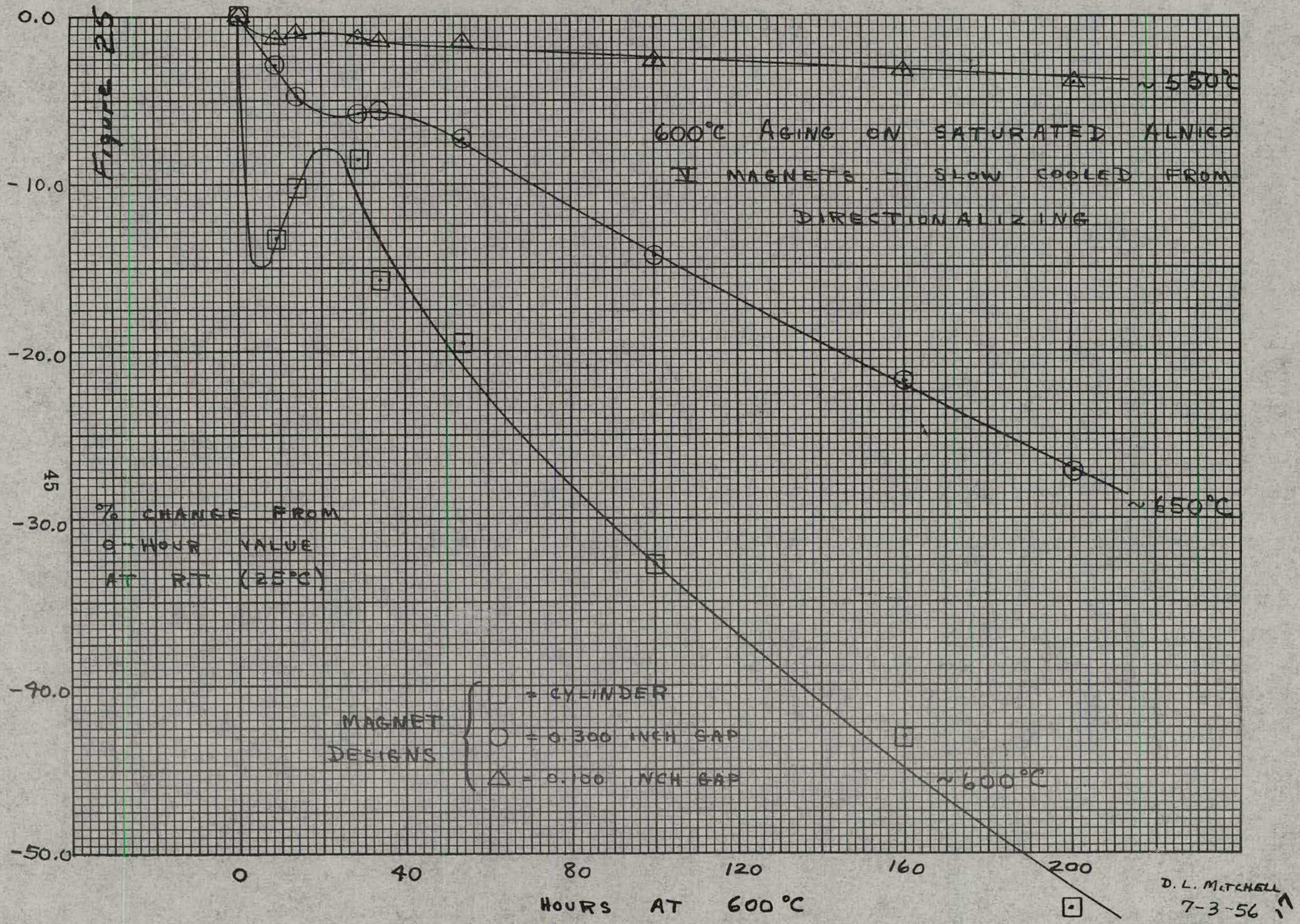




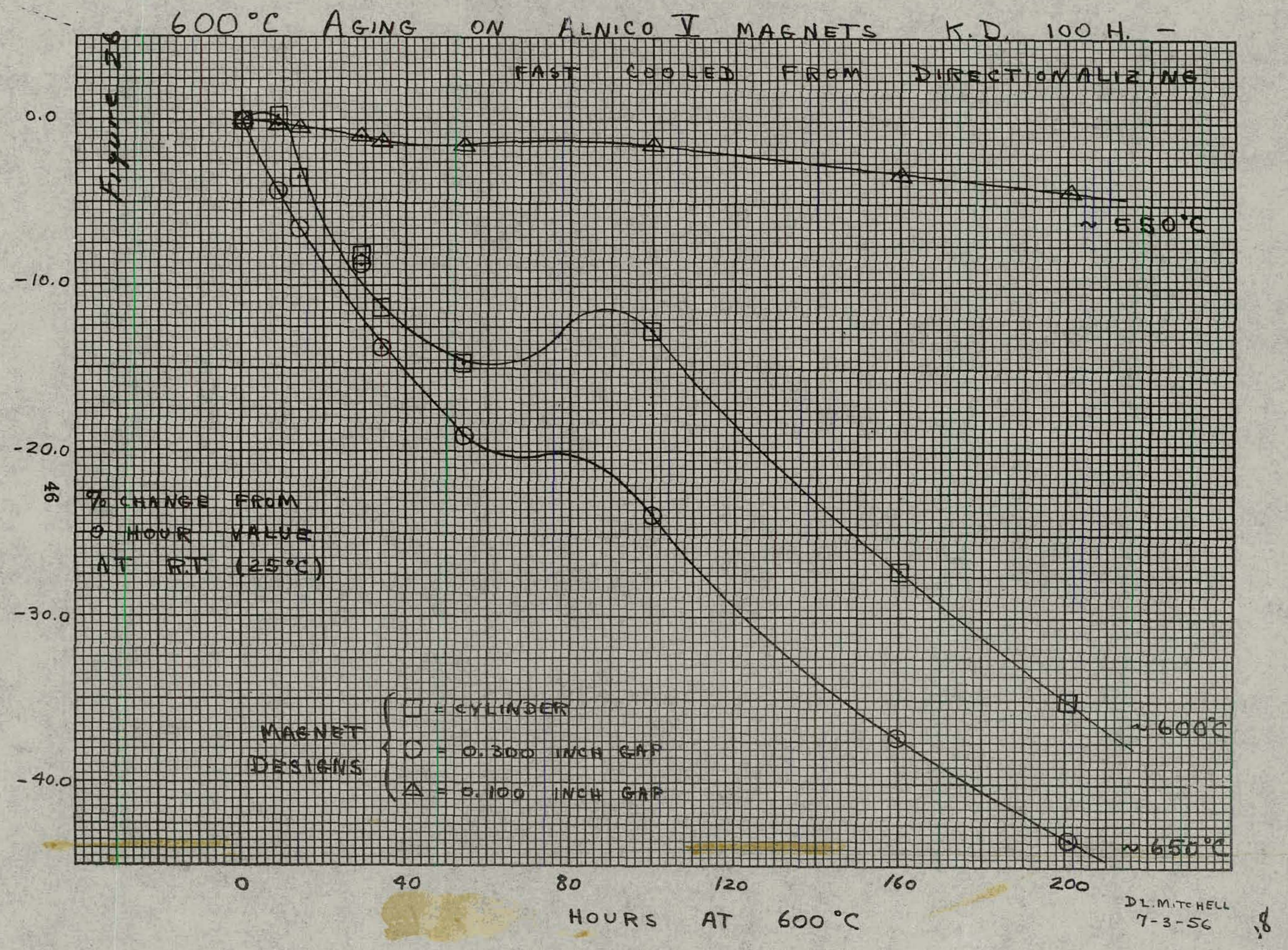




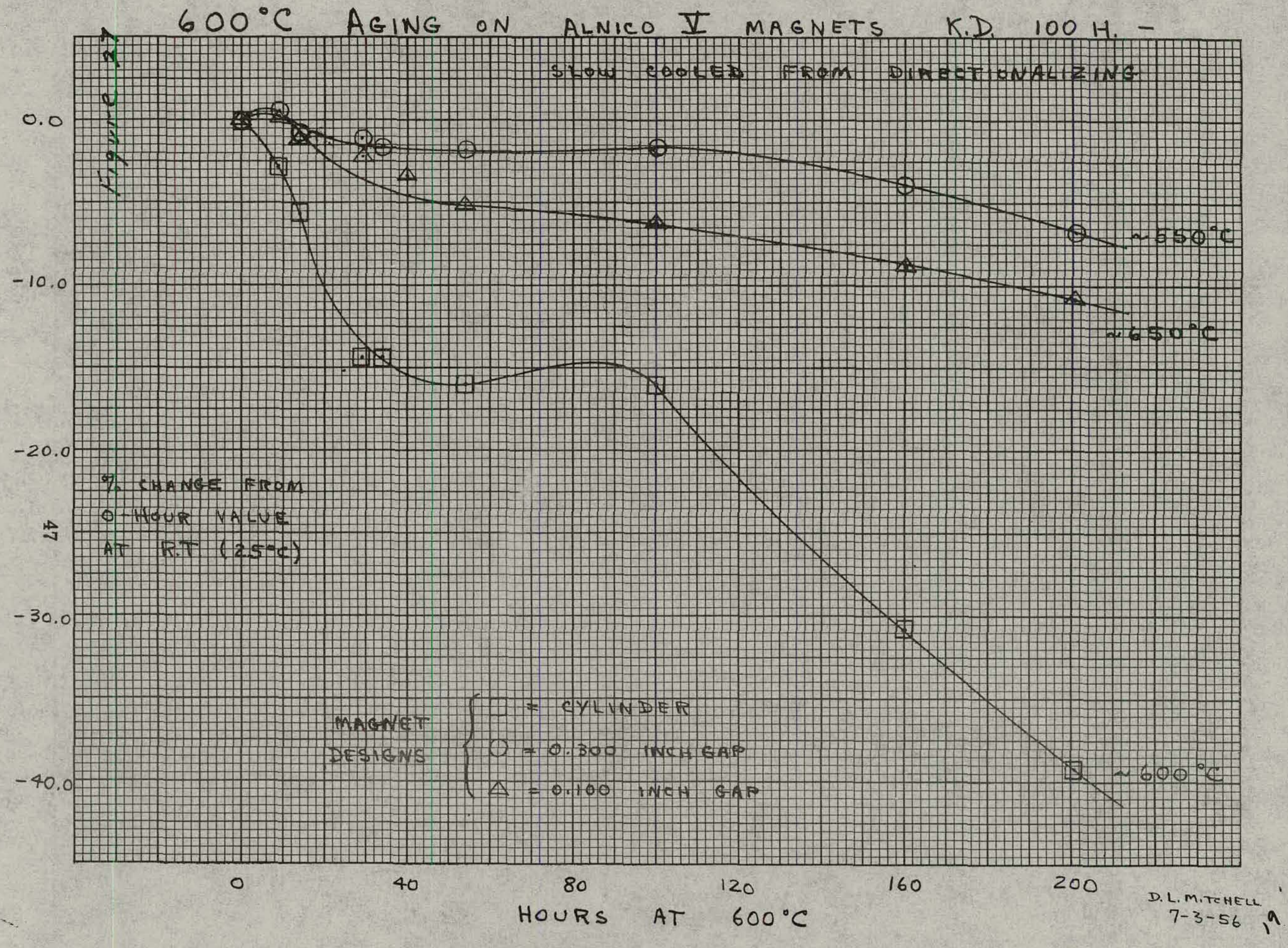




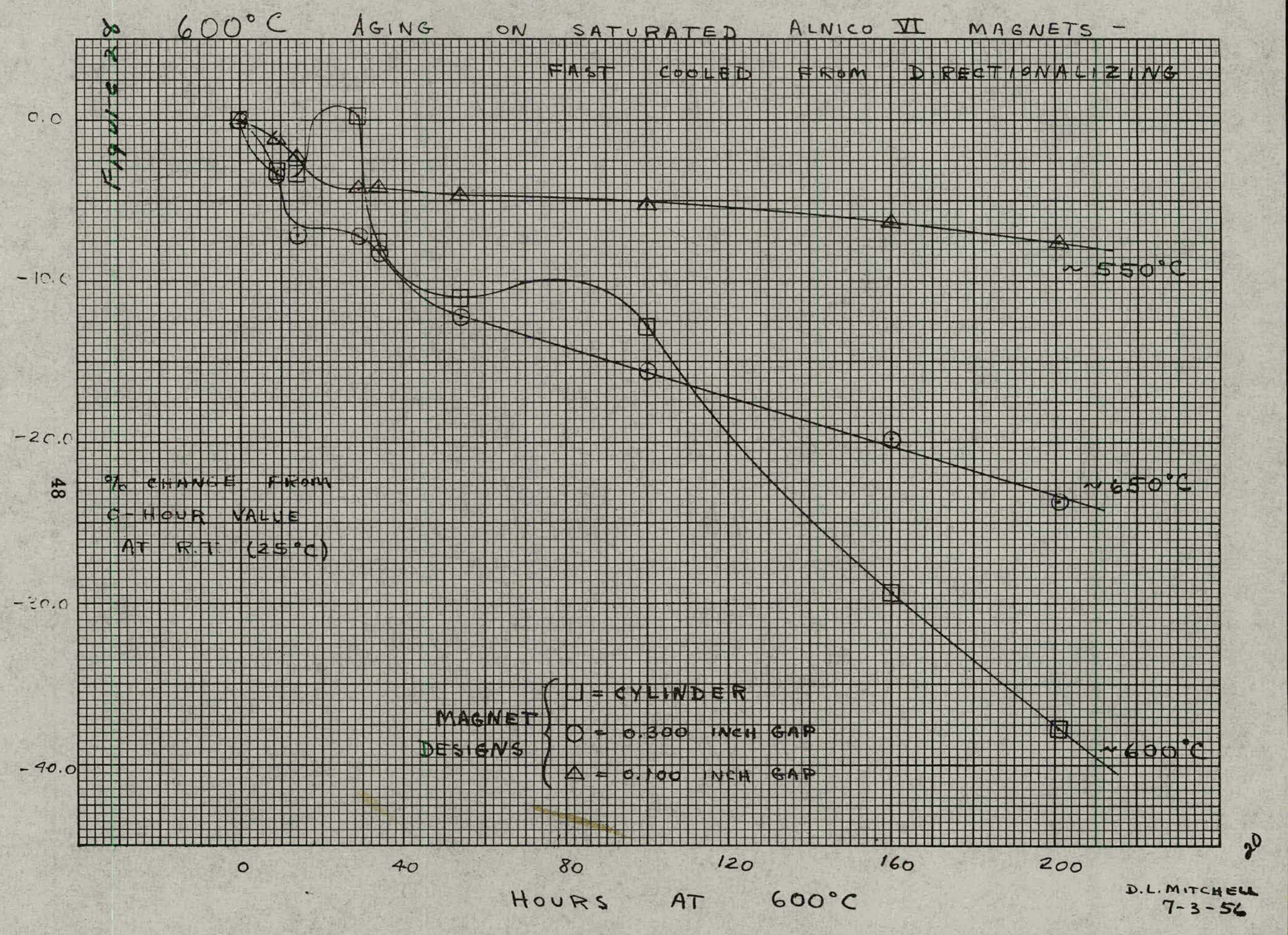




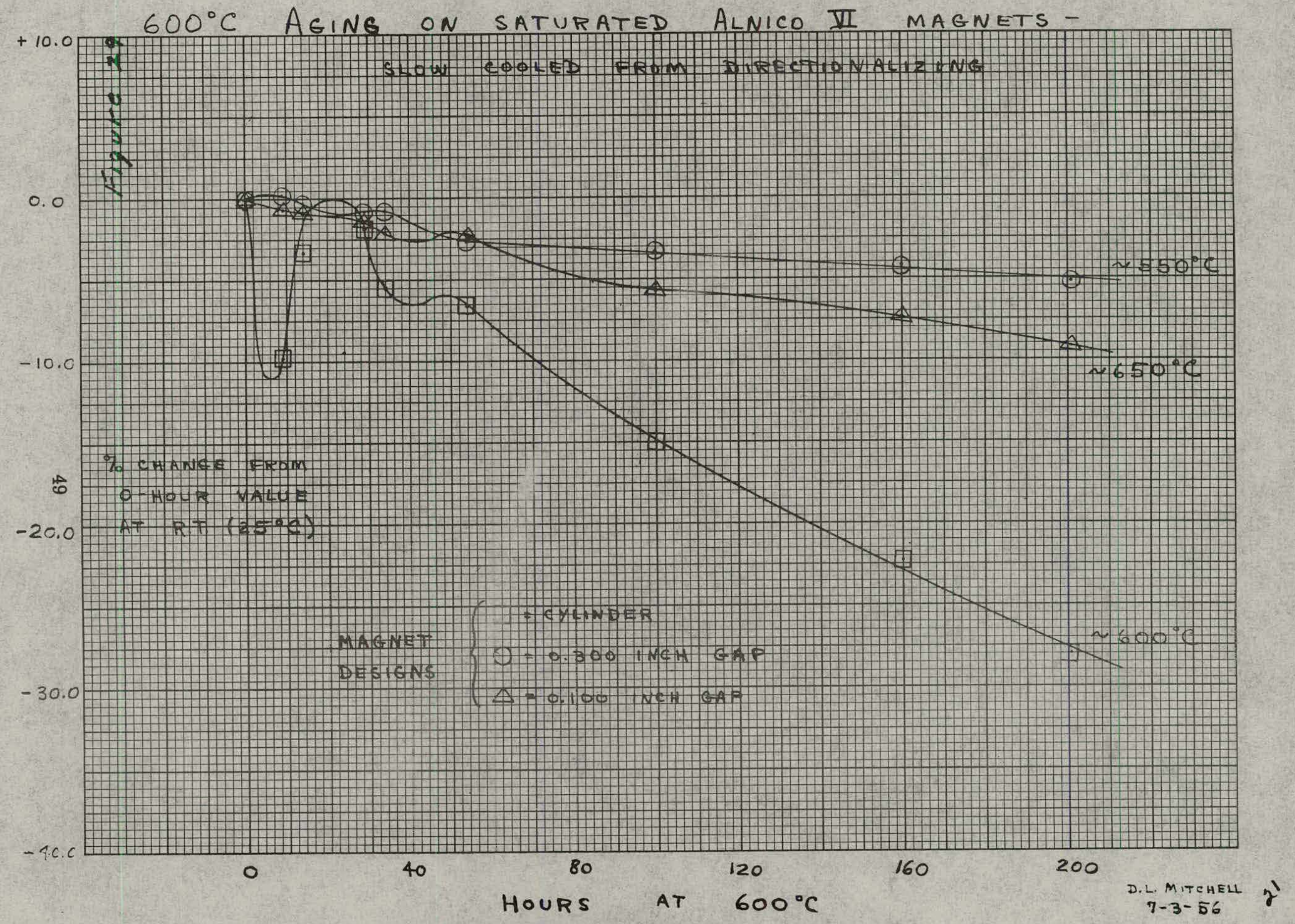




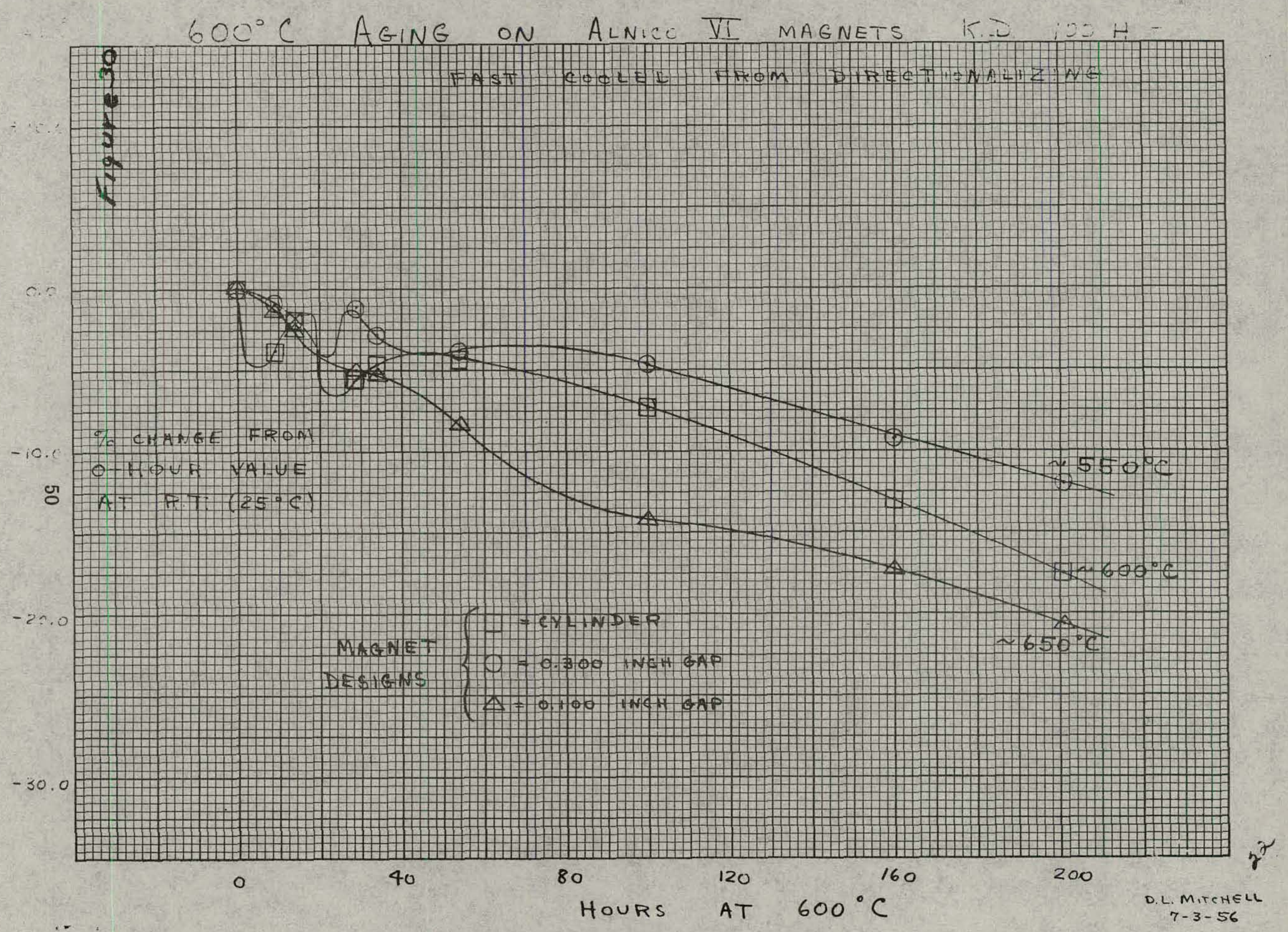


$600^{\circ} \mathrm{C}$ AGING ON ALNICO II MAGNETS K.D, $100 \mathrm{H}$ -

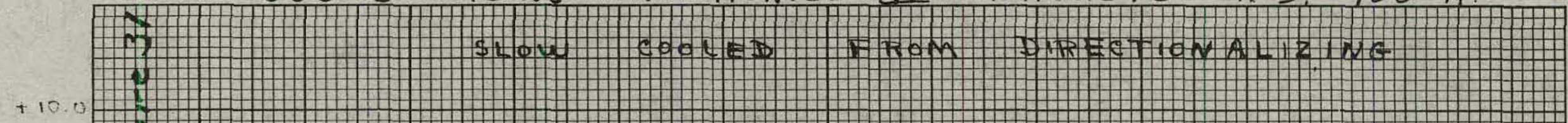
( $\sqrt[3]{ }$

$0 . c$

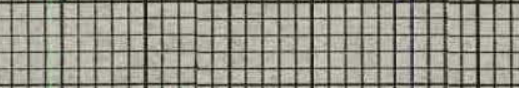
$+$ \# (.).".

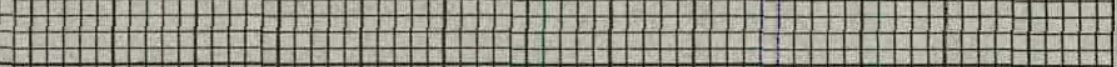
I

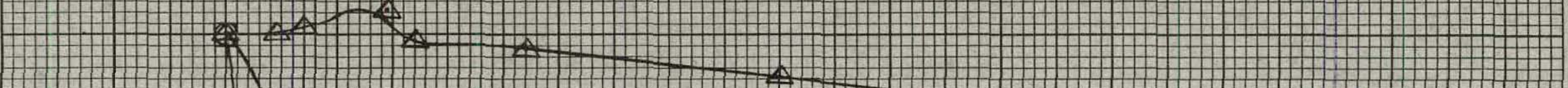

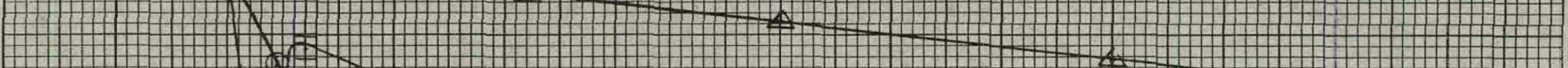

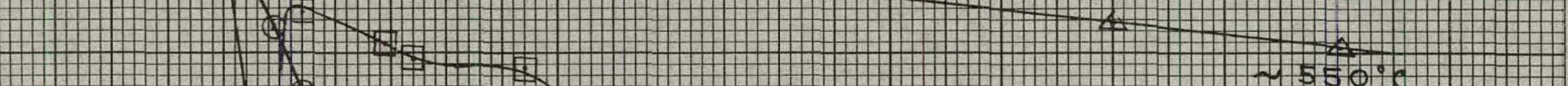

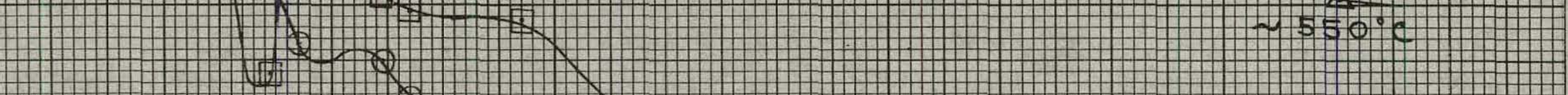

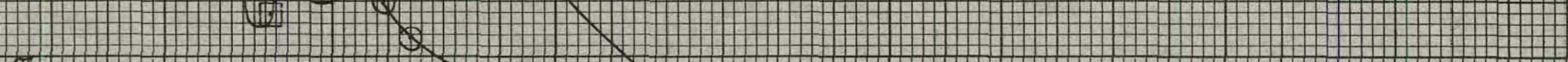

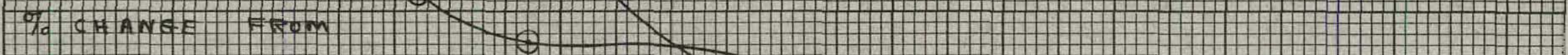

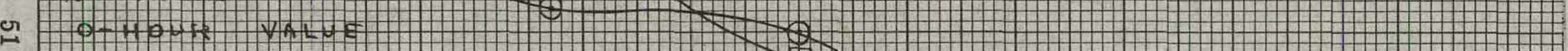
|at Mit

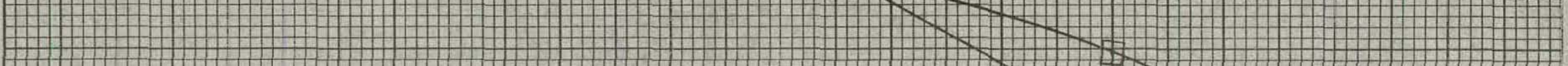
|

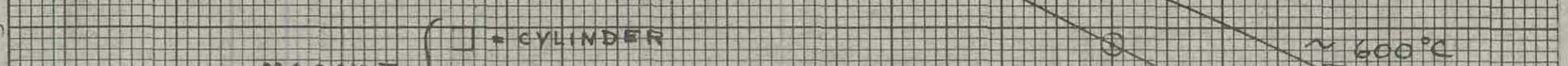
| magnet DESIGNS $0=0.300$ inENGA

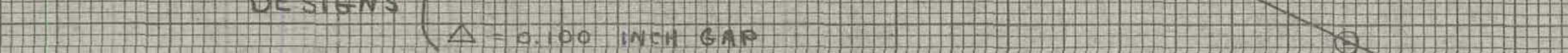

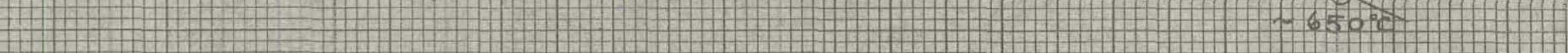

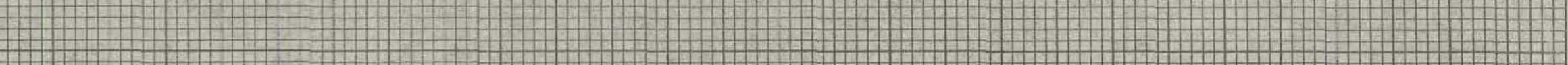

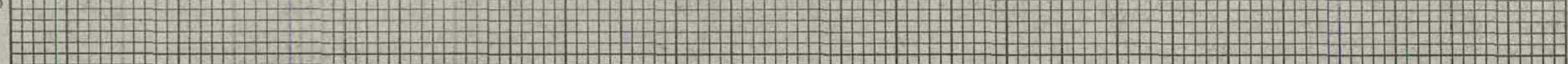
"E.

$\circ$

40

80

HOURS
120

AT $\quad 600^{\circ} \mathrm{C}$
160

160
200 D.L. M.TCHELL 


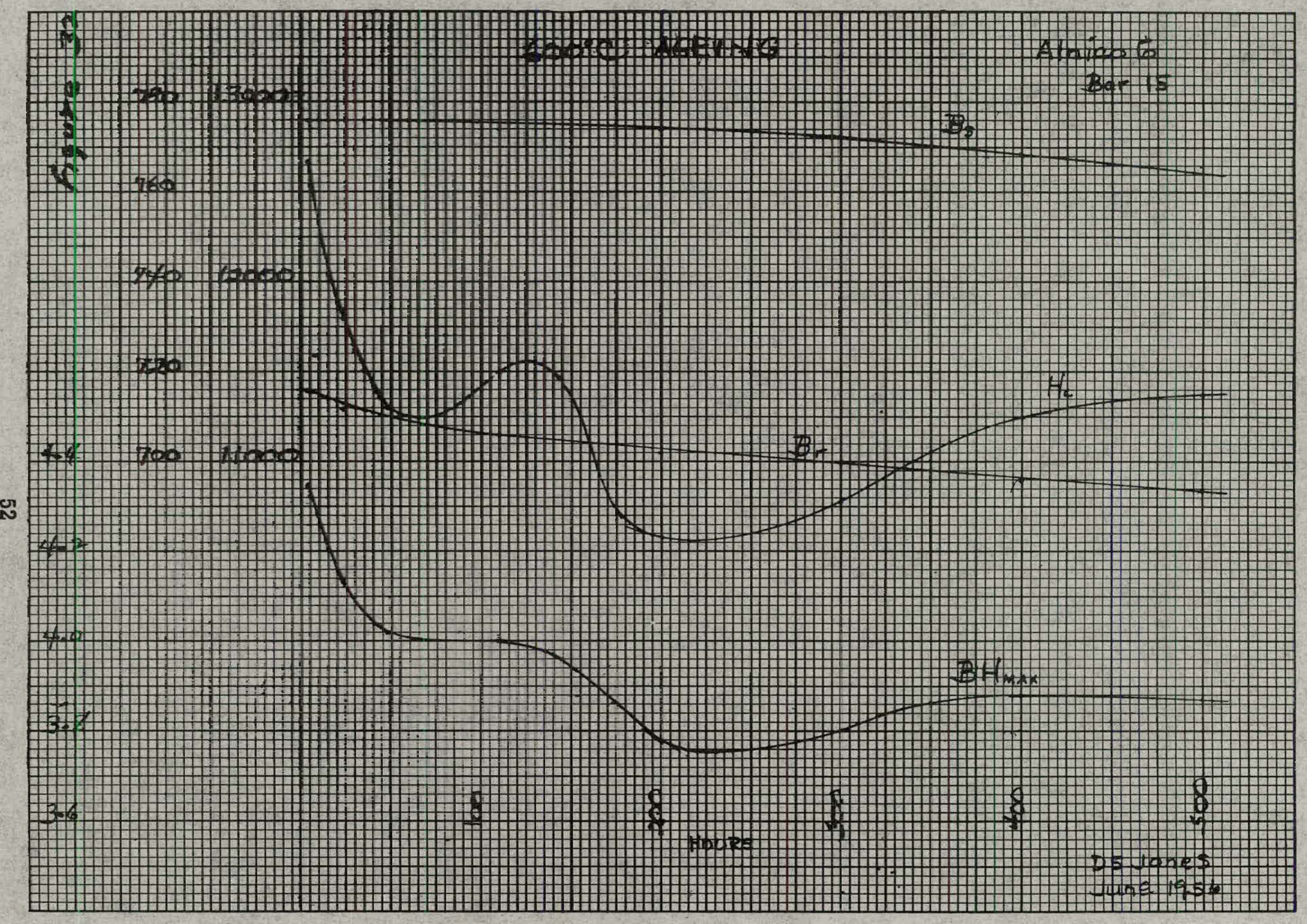




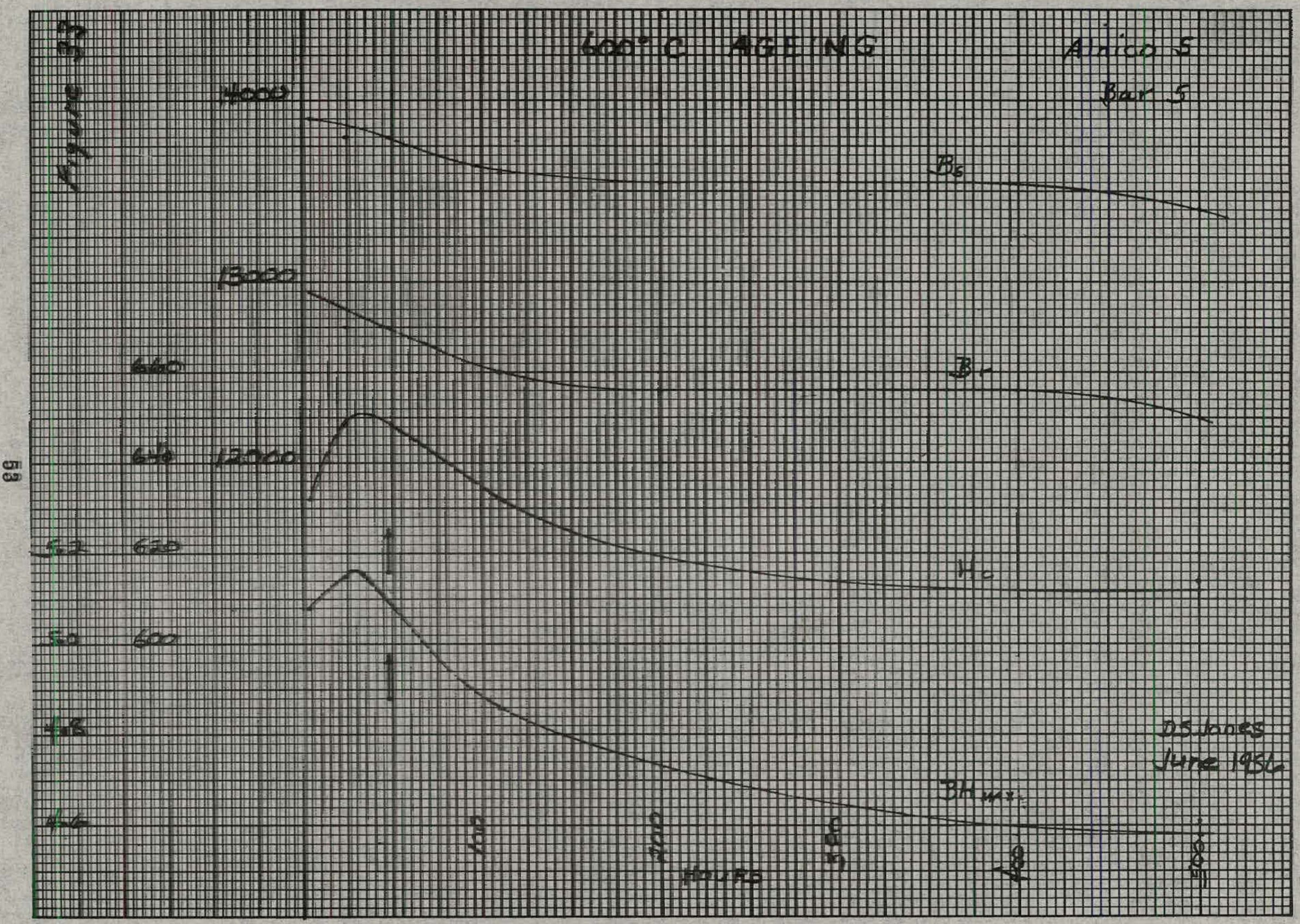




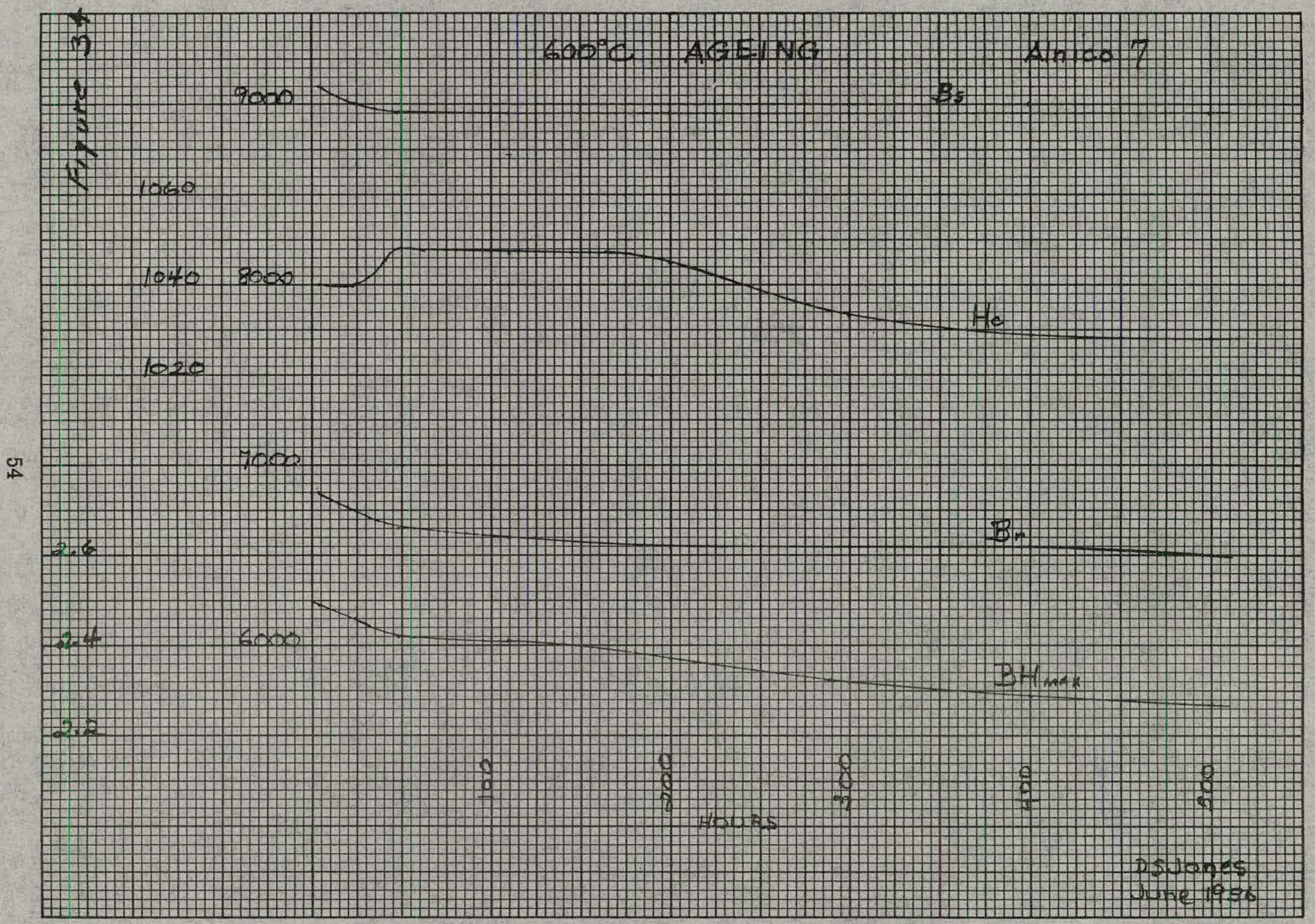




\section{HEAT EXPOSURE $500^{\circ} \mathrm{C}$}

Heat exposure is distipguished from heat aging in that the test magnets were held at $500^{\circ} \mathrm{C}$ continuously and the useful magnetic flux was measured at $500^{\circ} \mathrm{C}$. The heat aging test discussed in a previoue section deals with changes in useful flux due to relatively permanent metallurgical changes in the structure of the alloy. In addition to this effect it was anticipated that continuous exposure to high temperature might produce an effect due to changes in the magnetization of the test magrets.

The purpose of the heat exposure test was to measure the combined effects of metallurgical changes in the structure and changes in magnetization on the useful flux of the test magrets at high temperatures. Since it was desirable to use permanent magnets in mfieasurement applications for as long as 1000 hours at $500^{\circ} \mathrm{C}$ it was dectded that the inftial test would be run under these conditions. If the test magnets proved ungtable at $500^{\circ} \mathrm{C}$. the temperature would be lowered utill the highest stable opexating cemperature was established. The time would then be extended to 1000 hours at that temperature. For purposes of this test magnetic stablitby is defined as a change in useful flux of not more than $5 \%$ in 500 hours.

Although test procedures ard equipment will not be discussed in this section of the report, some of the experience accumulated in building the equipment for the heat exposure teat was be of value to designex s of high temperature Instruments. The teat thiture used to measure the useful flux of the magnets at $500^{\circ} \mathrm{C}$ was in essence falxly sengitive electric instrument which operated continuousiy at $500^{\circ} \mathrm{C}$. for 1000 hour s. Those whe axe interested in this phase of the expertment should refer fo that part of the section on Fixperimental Procedure and test equipment which deals with the heat expesure test.

The effect of $500^{\circ} \mathrm{C}$ heat exposure on the useful flux of the tert magnets 15. hhown in F4gures 35 , 44. The reaults of the heat exposure test indicate the followingi

1) the useful Alux of the cylindrical magnets which operated near the coerctve force of the material decreased in all cases.

2) the useful flux of the c-shaped magnets which operated near the maximum energy point or residual Induction of the material increased in all cases.

3) most of the change in usefü fiux occurred during the flrst 200 hourg of heat exposure. 
4) between 200 and 1000 hour's stability within $-2 \%$ can be realized for all designs at $500^{\circ} \mathrm{C}$.

5) prior ac demagnetization had little or no effect an magnetic stability at $500^{\circ} \mathrm{C}$.

The principle difference between the results of the $500^{\circ} \mathrm{C}$ heat aging test and the $500^{\circ} \mathrm{C}$ heat exposure test was the effect or the cylindrical magnets. The useful flux of the cylindrical magnets subjected to heat aging at $500^{\circ} \mathrm{C}$ increased in all cases except one where as the useful flux of the cylindrical magnets subjected to $500^{\circ} \mathrm{C}$ heat expogyre decreased in all cases. This would suggest that there is some loss of coercive force at $500^{\circ} \mathrm{C}$ since the cylindrical magnets operate very near the coercive force of the material.

The effect of $500^{\circ} \mathrm{C}$ heat aging and $500^{\circ} \mathrm{C}$ heat exposure was approximately the same for the c-shaped magnets. The useful flux of the c-shaped magnets subjected to both tesis increased about $4 \%$, above the useful flux at the beginning of the test. It should be pointed out; bowever, that the $4 \%$ increase in useful flux of the c-shaped magnets subjested to the beas exposure test does not represent a net gain over the useful lux of his magnet at room temperature. The temperature coefficient would reduce the wseful flux of these magnets about $10 \%$ when the temperature of the magnets was increased to $500^{\circ} \mathrm{C}$. This means that the magnets would lose $10 \%$ dre to the fracrease in temperature and regain about $4 \%$ due to aging for got lose of about $6 \%$ of the useful flux. 


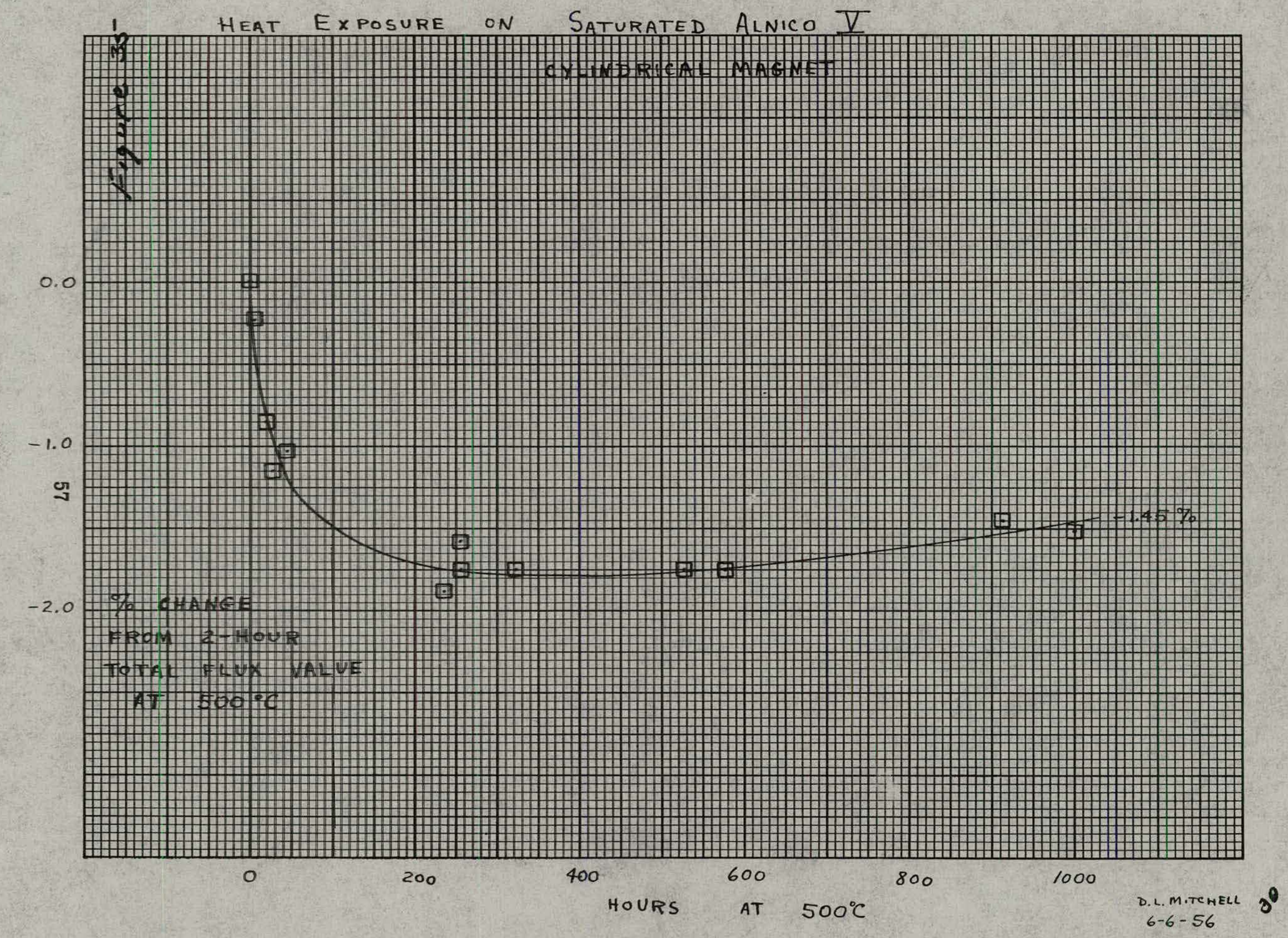


+5.0 HEAT EXPOSURE ON SATURATED ALnico I

$+5.00 \%$

ח ( ๒ \\.

$+4.0$

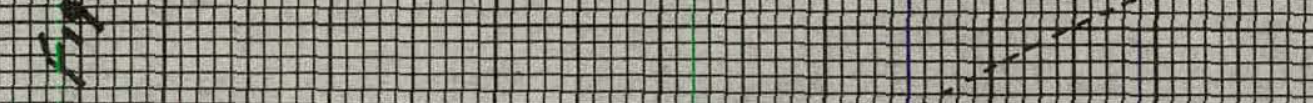

\#

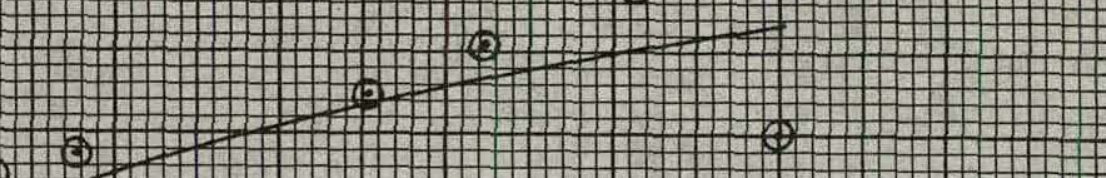
$\ldots$

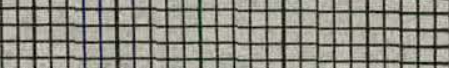

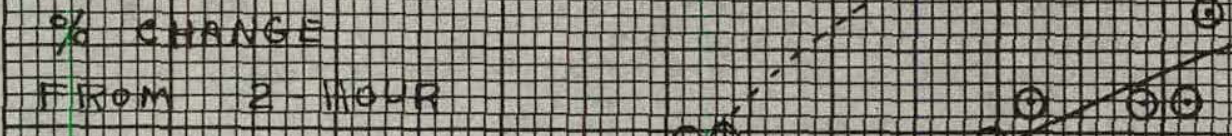

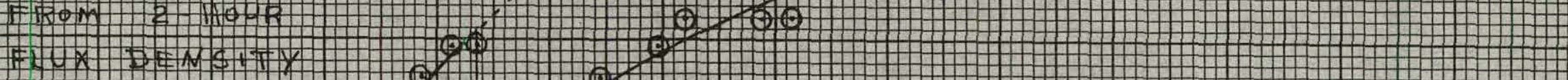

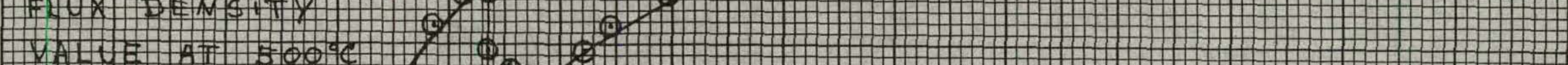
\#\# +

$+3.0$

œ ๓ \#

$+2.0$ ( 늘 \#\#巫) ( ๓ \ ๓ \. \}

$+1.0$ ( \ Y Ґ) \๐ 乡

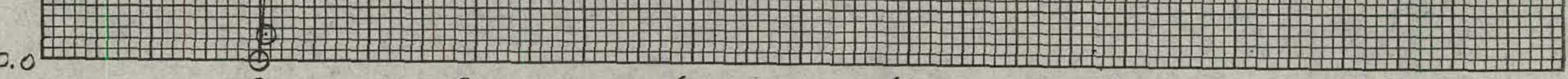
○ 200 $400 \quad 600 \quad 800$ HOURS AT $500^{\circ} \mathrm{C}$ 1000 
HEAT EXPOSURE ON SATURATED ALNICO V $+\ldots .08 \%$

${ }^{5} 5.0 \mathrm{FW}$ ח $+$

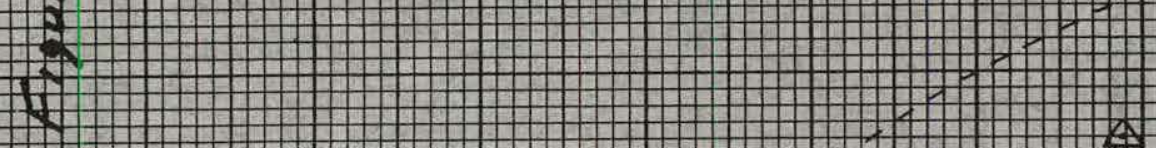

$+4.0$ \#\# \# 1 ¿ a) CWANG Ham 2- 2) HL

$+3.0$ MAL UE A| 500 C.

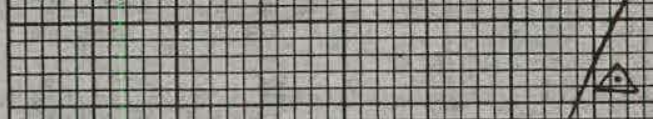
H.

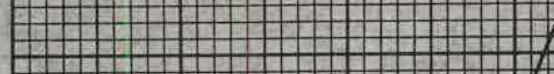

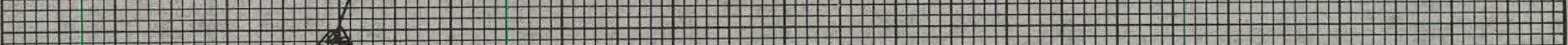

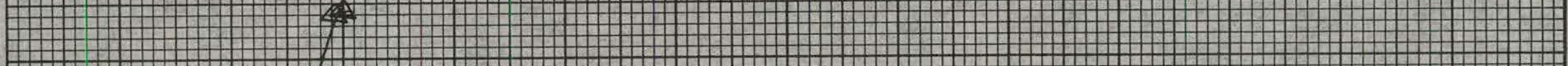

$+2.0$

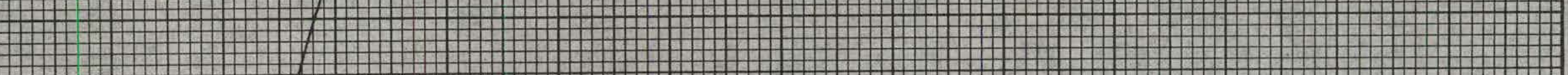

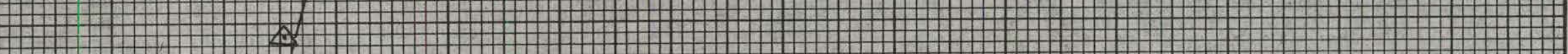

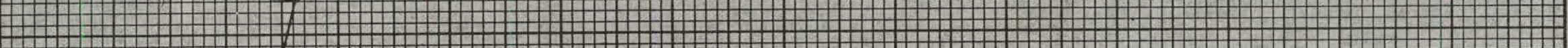

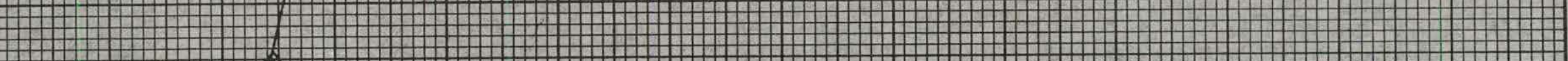

$+1.0$

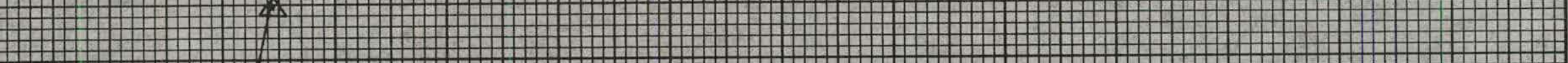
\}

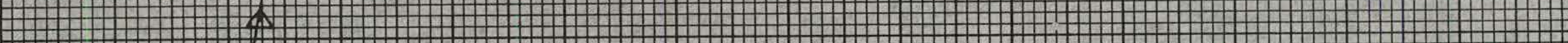
\一) 0.0

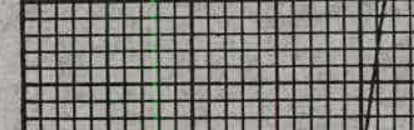
0 200 400 600 HOURS
AT

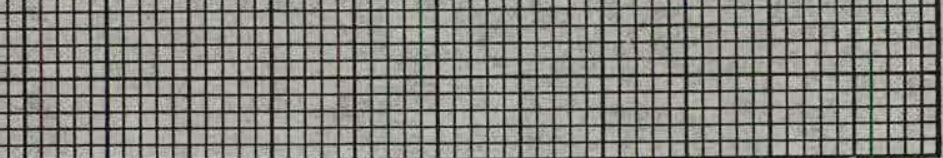




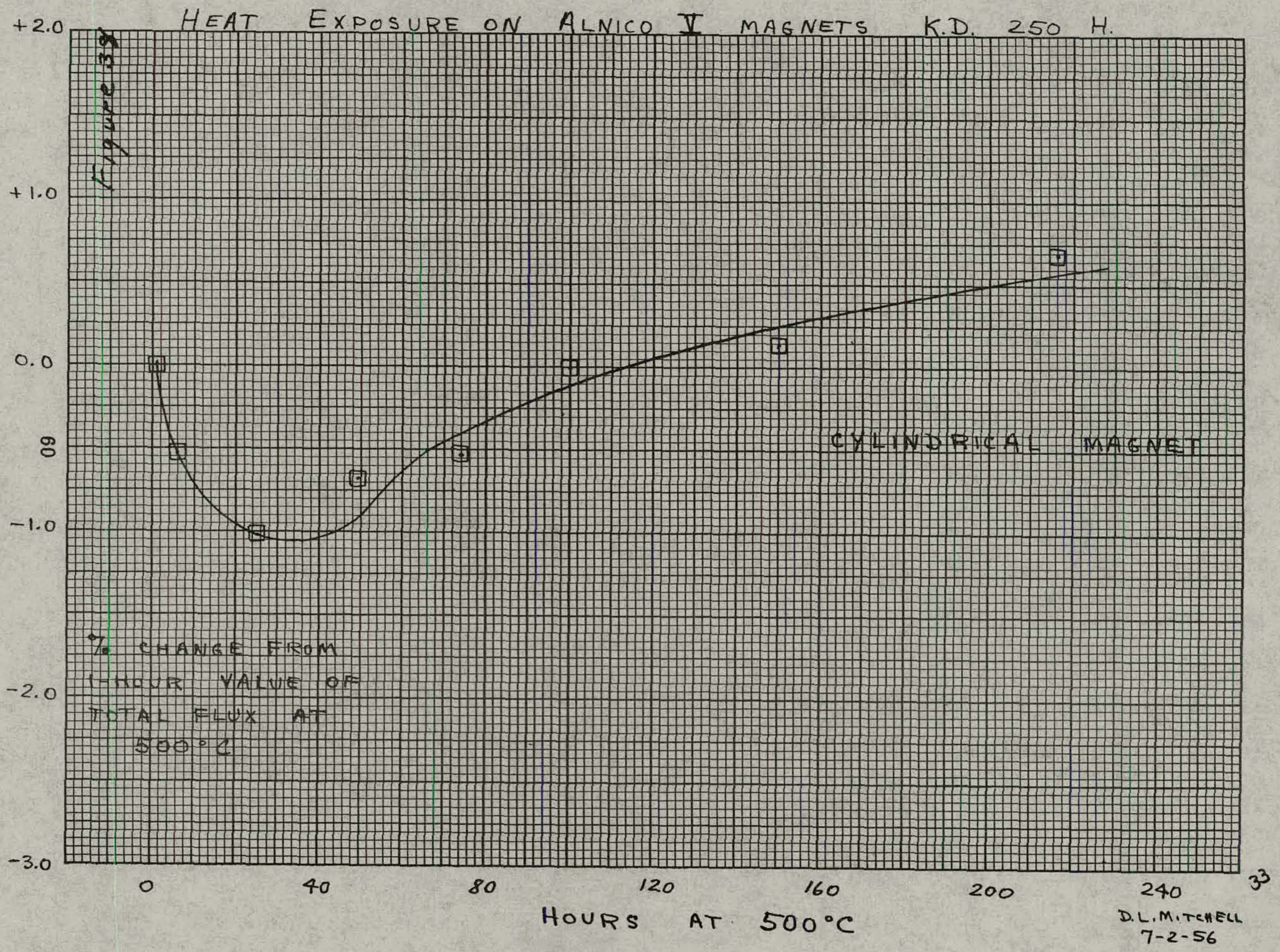




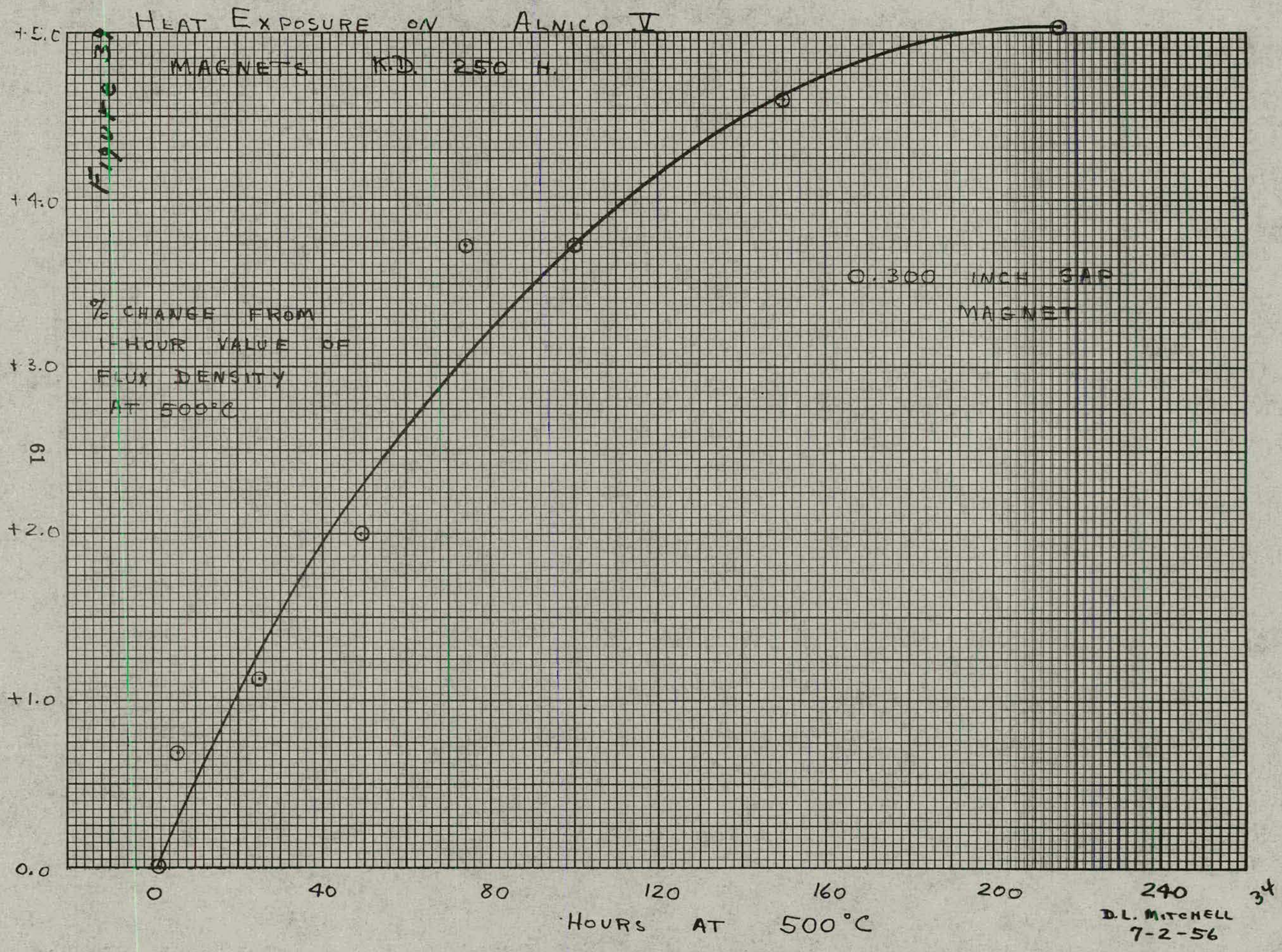




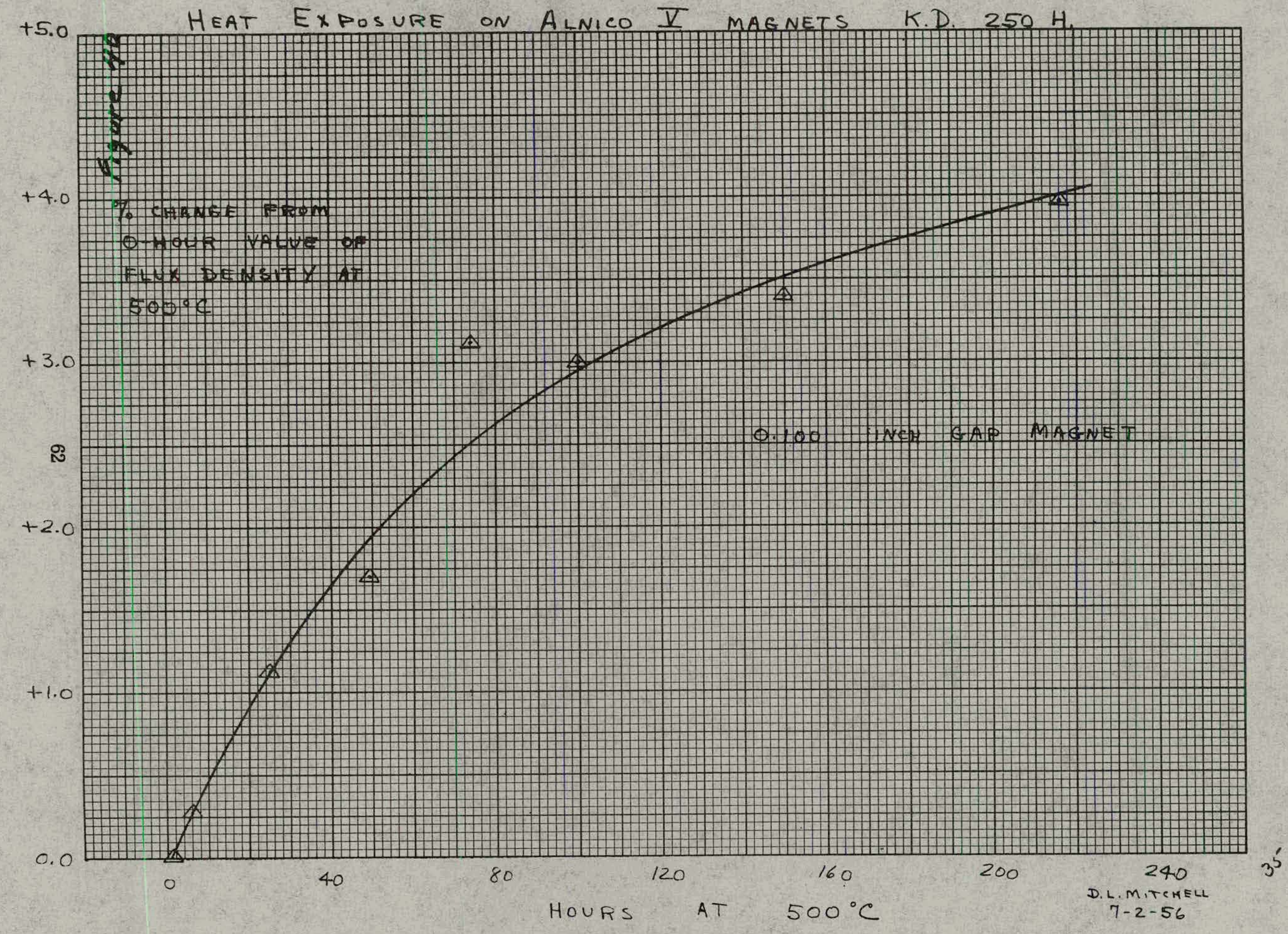




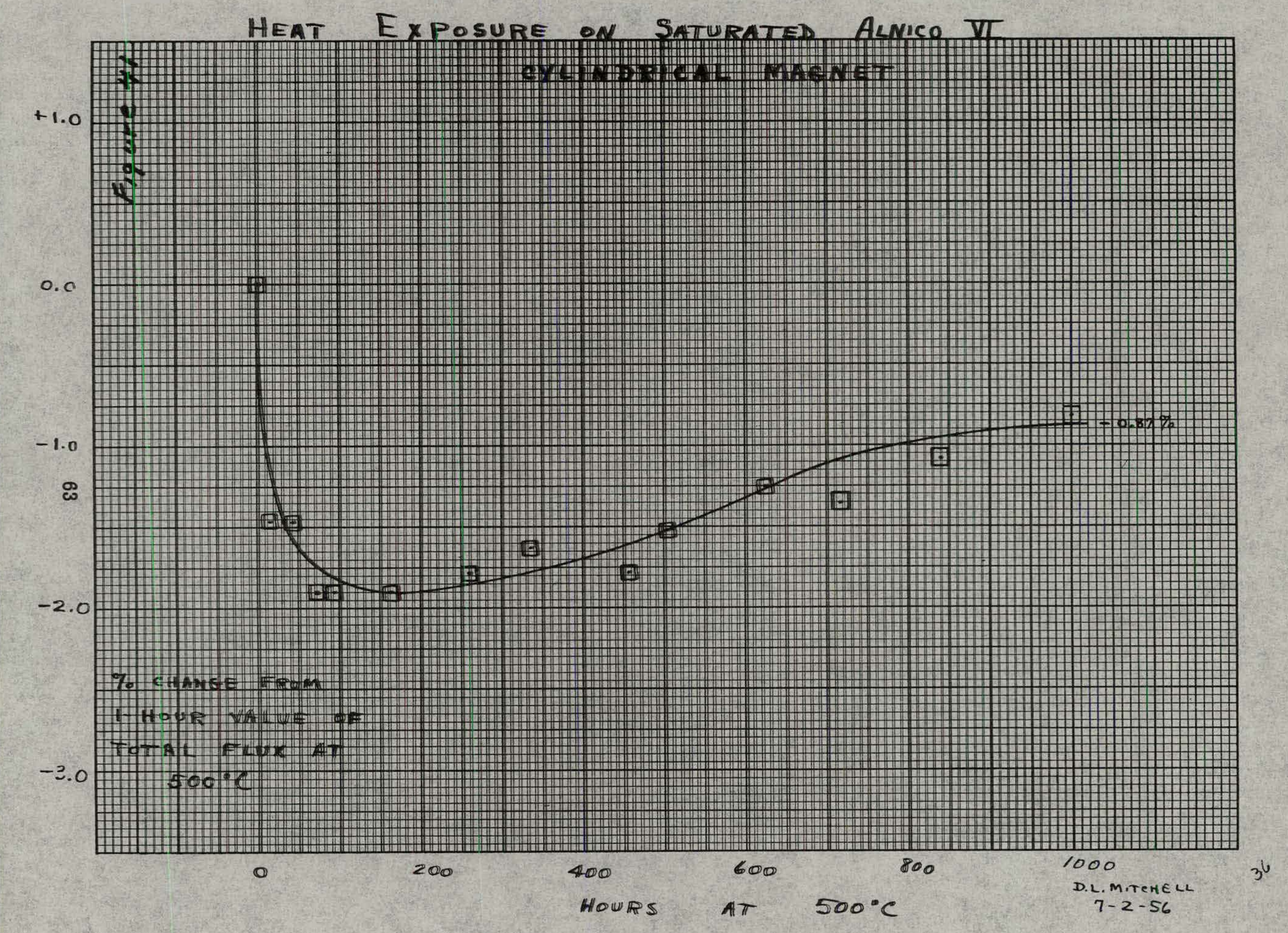




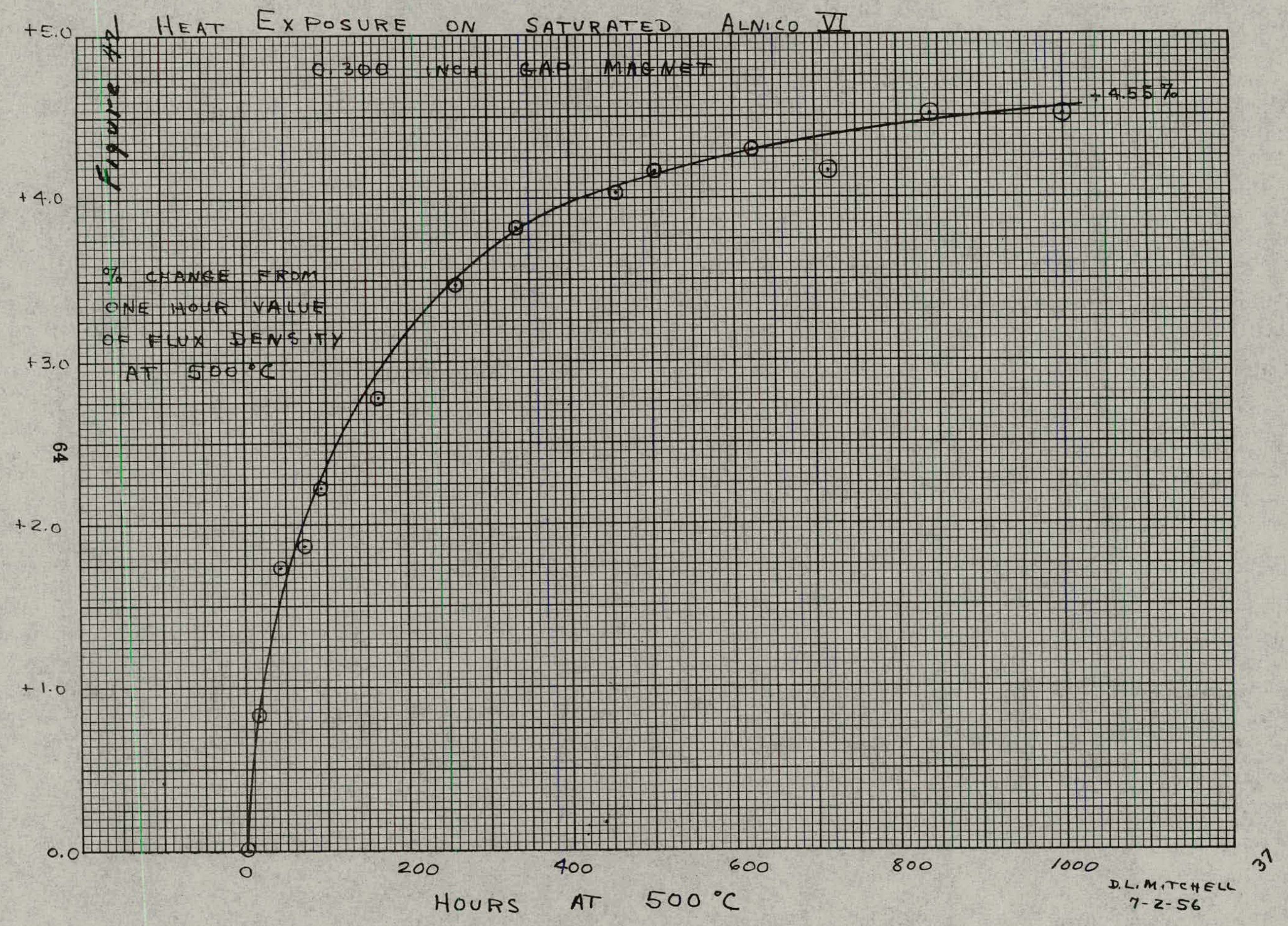


+7.0 HEAT EXFOSURE ON SATURATED ALNICO VI D

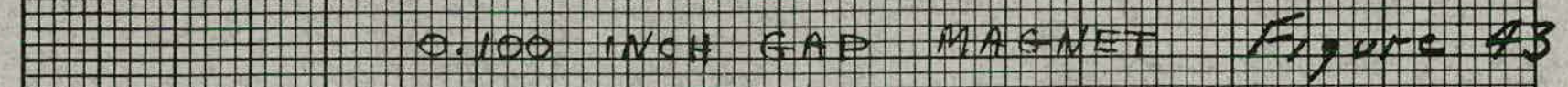

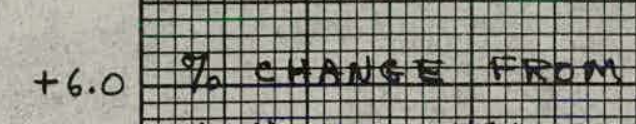

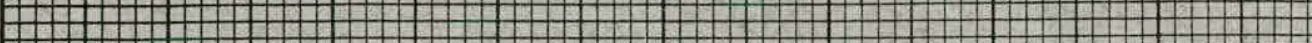
\# \# H hut valve

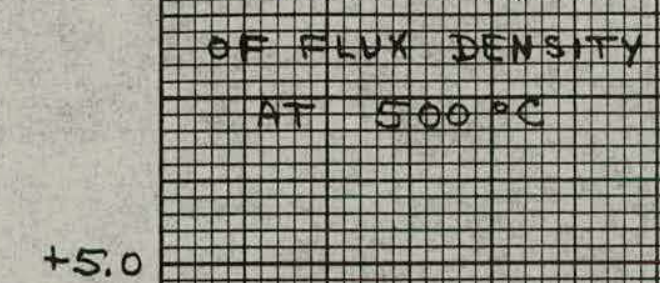

$+5.0$

$+4.0$

$+3.0$

$+2.0$
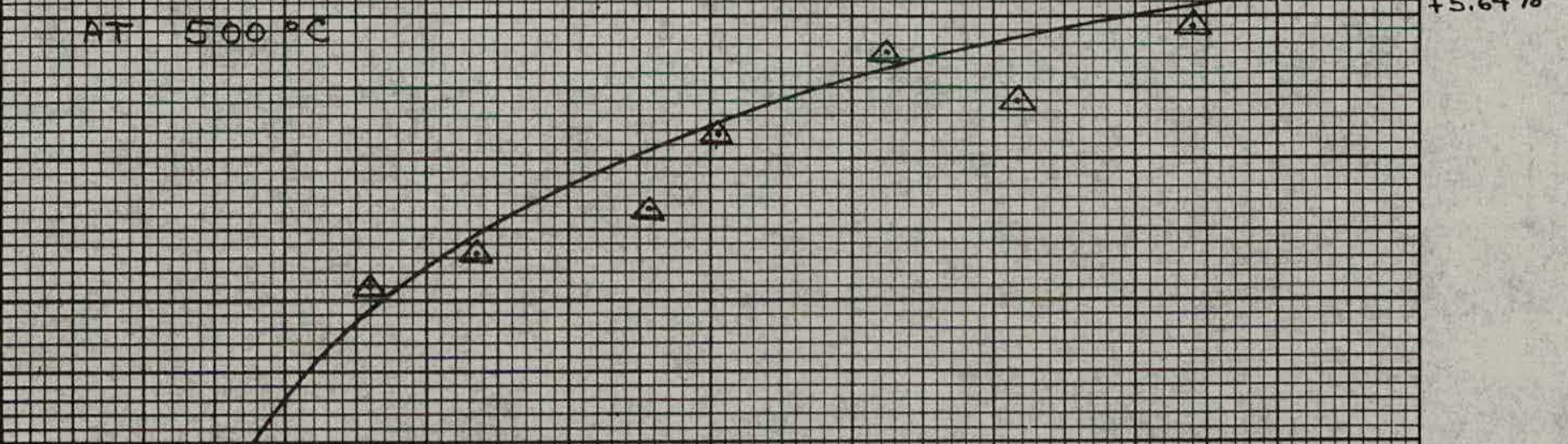
HEAT EXPOSURE ON ALNICO Y MACNET $250 \mathrm{H}$

ter ( vi 는

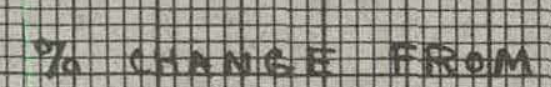

$+3.0$ 2. How (I) \. † $2.91 \%$

$+2.0$ 는 \} Y (

\&

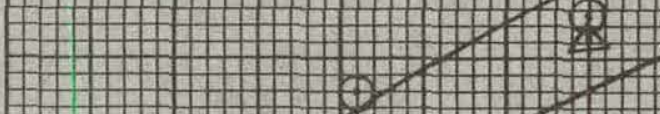

\} (⿻上丨 (ㄴ. t1.0 ¿ Y Y Y |

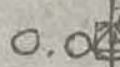

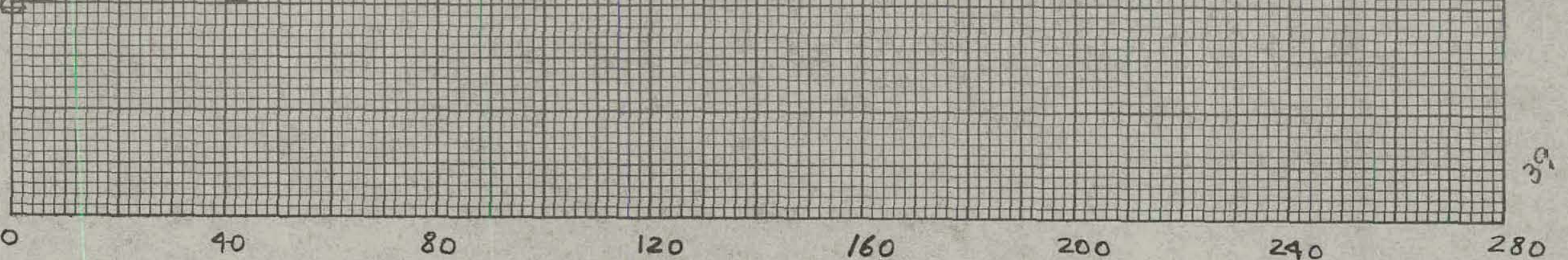

HOURS AT $500^{\circ} \mathrm{C}$

D. L. MITCHELL 


\section{COMBINED HEAT \& VIBRATION}

Vibration and shock are known to have a detrimental effect on the magnetization of the very low coercive permanent magnet materials 8 uch as chrome steel. : Several investigators have reported that the ge conditions have little or no effect on the magnetization of the higher coercive materials such as the Alnico's at or near room temperature. However, there was no information available on the effect of vibration at temperatures appreciably above or below room temperature.

The mechanism of magnetic hardening or development of coercive force is not the same for chrome steel and the Alnico's. Because of this there is no reason to expect them to act the same under conditions of vibration. However, the coercive force of Alnico V decreases slightly as the temperature is reduced and very rapidly at some high temperature near the curie point. The addition of vibrational energy to the effect of thermal energy might have been 8 ufficient to change the magnetization of the magnet there by reducing the useful flux. For this reason it was necessary to determine the effect of combined high or low temperatures and vibration on the useful flux; of Alnico $V$ and Alnico VI magnets.

Combined heat and vibration tests were made at $-70^{\circ} \mathrm{C}, 25^{\circ} \mathrm{C}$, and $250^{\circ} \mathrm{C}$. The frequency was varied from $5 \mathrm{cps}$ to $2000 \mathrm{cps}$, but most of the exposure was to the five or six.most resonant or damaging frequencies. The amplitude of the vibration depended on the frequency, but was sufficient to produce an acceleration of at least $20 \mathrm{Gs}$ in all cases and as high as $30 \mathrm{Gs}$ in some cases. The vibration time at each temperature is shown below.

The results of the combined heat and vibration test are given in the following table.

\begin{tabular}{|c|c|c|c|c|}
\hline & $\begin{array}{l}\text { Temperature } \\
\text { Time }\end{array}$ & $\begin{array}{c}-70^{\circ} \mathrm{C} \\
33 \mathrm{hr} .\end{array}$ & $\begin{array}{l}25^{a} \mathrm{C} \\
37 \mathrm{hr} .\end{array}$ & $\begin{array}{c}250^{\circ} \mathrm{C} \\
38 \mathrm{hr} .\end{array}$ \\
\hline Alnico V & $\begin{array}{l}\text { Cylinder } \\
0.300 \text { gap } \\
0.100 \text { gap }\end{array}$ & $\begin{array}{l}-0.25 \% \\
-0.25 \% \\
+0.50 \%\end{array}$ & $\begin{array}{r}-0.25 \% \\
0.00 \% \\
-0.50 \%\end{array}$ & $\begin{array}{c}-0.75 \% \\
--- \\
-0.50 \%\end{array}$ \\
\hline Alnico VI & $\begin{array}{l}\text { Cylinder } \\
0.300 \text { gap } \\
0.100 \text { gap }\end{array}$ & $\begin{array}{l}+0.50 \% \\
+0.75 \% \\
+0.75 \%\end{array}$ & $\begin{array}{l}-0.75 \% \\
-0.25 \% \\
-0.25 \%\end{array}$ & $\begin{array}{r}0.00 \% \\
-0.25 \% \\
-0.75 \%\end{array}$ \\
\hline
\end{tabular}


$-5$

THIS PAGE

WAS INTENTIONALLY

LEFT BLANK 


\section{CONCLUSIONS}

Since none of the above changes are large enough to be significant because of experimental exror, the effect of combined heat and vibration appears to be insignificant over the temperature range explored. 
THIS PAGE

\section{WAS INTENTIONALLY LEFT BLANK}




\section{GENERAL CONCLUSIONS}

The results of this investigation show that it is definitely practical to use Alnico V and Alnico VI magnets at temperatures up to $500^{\circ} \mathrm{C}$ for long periods of time. Earlier Instrument Department investigations have shown that these alloys can be used at temperatures as low as $-196^{\circ} \mathrm{C}$. Vibration at temperatures either above or below room temperature does not effect the useful flux of magnets made from these alloys.

The performance of Alnico $\mathrm{V}$ and Alnico VI magnets at temperatures up to $500^{\circ} \mathrm{C}$ is so nearly the same that one alloy cannot be preferred over the other for that reason. The selection of the alloy. should be based on magnet design and other operating conditions.

The use of standard Alnico V or Alnico VI at temperatures above $500^{\circ} \mathrm{C}$ for more than a few hours does not appear practical. The deterioration of the magnetic properties of these alloys above $550^{\circ} \mathrm{C}$ is caused by over aging or excessive growth of the precipitate. If it is necessary to operate magnets between $500^{\circ} \mathrm{C}$ and $600^{\circ} \mathrm{C}$ the effective life might be extended some by using the silicon-zirconium or columbium modifications of Alnico $\mathrm{V}$. The addition elements in these alloys tend to reduce the rate of precipitation or aging. This could be confirmed by a simple aging experiment.

The effect of magnet design on performance at temperatures up to $500^{\circ} \mathrm{C}$ is secondary for magnets operating at or above the maximum energy point. Both temperature cycling and temperature exposure have a detrimental effect on the'useful flux of very short magnets with long air gaps. However. this type of design does not efficiently utilize the magnetic properties of Alnico V and Alnico VI and therefore is seldom used.

Partial demagnetization in an ac field reduces the number of temperature cycles required to achieve stability and the useful flux lost in stabilization. Unless it is necessary to partially demagnetize for calibration or to protect against extraneous fields, there is little point in doing so. The loss of useful flux due to demagnetization will probably be greater than the loss due to temperature cycling.

The precipitation or aging heat treatment has a significant effect on the magnetic properties. Aging magnets 200 hours at $500^{\circ} \mathrm{C}$ after the standard treatment. increases the useful flux at least four percent. In addition, this treatment probably. reduces the temperature coefficient to less than half the normal value. Within the limits of this investigation, rate of cooling from 
the directionalizing temperature did not have a significant effect on the pexformance of magnets at high temperatures. The use of Alnico $V$ magnets in appications uch as tachometex generator 8 , torque motors and permanent magnet motors should present no particular problem. In this type of application, the accuracy of the device is not a direct function of the flux output of the magnet. However, it is generally necessary to maintain some minimum level of flux. This can be accomplished by over designing the magnet for room temperature operation.

The amount of over design required is determined by the temperature and the 10ss of useful flux due to temperature cycling and temperature coefficient associated with that temperature. For instance, in a tachometer generator with an Alnico VI rotor to be operated at $500^{\circ} \mathrm{C}$, the $1088^{\circ}$ in useful flux will be $2 \%$ due to temperature cycling and $9 \%$ due to temperature coefficient. Therefore, the generator should be designed so that the voltage output at room temperature is at least $11 \%$ greater than the minimum voltage required when the generator is operating at $500^{\circ} \mathrm{C}$.

From the experience gained in this investigation, it would appear that at least two other major components will present much greater problems in the devices described above. The most important of these is an insulation system which will withstand both the temperature and the vibration associated with such devices. Another important problem will be bearings which will operate over a wide temperature range without galling or seizing.

In certain applications the accuracy of the device is a direct function of the flux output of the magnet. The design and preparation of permanent magnets for use in this type of device will prosent a greater problem than it does in devices where magnet output does not effect accuracy. Examples. of this type of device are D.C. ammeters and volt.meters, the magnetic standard, and the second harmonic selsyn.. ,

If it is necessary to use permanent magnets that have a direct effect on the accuracy of a device in the temperature range $200^{\circ} \mathrm{C}$, to $500^{\circ} \mathrm{C}$, the magnets should be made from Alnico V, Alnico VI, or Alnico VII. In addition, the magnet should be designed to operate as high on the demagnetization curve as is practical. This can be accomplished by. using long magnets with very. small air gaps, less than :. 100 inches for most small magnets.

The following procedure should be used to prepare magnets for applications up to $500^{\circ} \mathrm{C}$ in this type of device: 
1) Cast, heat treat, grind and/or otherwise fabricate the magnet to the finished shape.

2) Preage the magnets for 200 hours at $500^{\circ} \mathrm{C}$ even if the maximum operating temperature is below $500^{\circ} \mathrm{C}$.

3). Saturate the magnets.

4). Expose the magnets to an ac field 50 to 100 oergteds higher than the maximum extraneous ac or dc field they are likely to be exposed to in the device.

5a) C.altbrate the magnets to the strength required for the device by exposing them to an ac or reverse dc field.

5b) If the magnet design and operating temperature are auch that some loss of strength should be expected due to temperature cycling, the magnets should be calibrated one or two percent stronger than required by the device.

6) Temperature cycle the magnets through the maximum and minimum temperature expected in service for at least five cycles.

7) Determine the exact temperature coefficient for the ragnet and other components which work in ronjunction with the magnet.

8) Compensate for the temperature coefficlent of the system by the use of temperature sensitive resistors or same other electrical method.

If the above procedure is carefully followed, it should be possible to limit the magnet error in this type of device to about $1 \%$ for operation at $500^{\circ} \mathrm{C}$ for 1000 hours. The error contributed by the magnet will be reduced if the operating temperature is lowered or the time of operation shortened. However, the results of this investigation indicate that an error much less than $1 \%$ cannot be realized at $500^{\circ} \mathrm{C}$ for a pefiod of 1000 hours if the accuracy of the device is a direct function of the flux output of the magnet.

It does not seem feasible to use permanent magnets in devices where the magnet error is seen as a squared error in the device at temperatures more than a few degrees above $100^{\circ} \mathrm{C}$. An example of such a device is a tachometer indicator. Fortunately, such devices are usually panel mounted and therefore would not be required to operate at very high temperatures. 
The general conclusions which can be drawn from the reaults of this investigation are quite favorable. The use of Alnico V and Alnico VI permanent magnets in most aircraft applications under conditions of vibration and temperatures up to $500^{\circ} \mathrm{C}$ appears to be quite feasible. Because of the temperature coefficient and variation in the temperature coefficient. it will probably be necessary to use a design not involving per manent magnets for a very few devices if the ambient temperature exceeds $100^{\circ} \mathrm{C}$ by more than a few degrees. 
In this section of the report, the test equipment and experimental procedure used for the varlous tests will be discusaed. The various tests will be described individually except where there is a duplication of equipment or procedure used in a previous test. Each experiment will be described in sufficient detail to permit duplication of the experiment.

\section{MATERIALS}

The materials tested were selected because of a combination of high magnetic energy and high curie temperature. The curie temperature was an important consideration because that is the temperature at which a magnetic material is transformed to a non magnetic materlal by thermal energy. The emphasis was placed on Alnico V and Alnico VI because they have a desirable combination of the important properties described above, and they are readily avallable. Alnico VII was also studied under certain conditions. The table below showr the nominal composition of these alloys.

\begin{tabular}{|c|c|c|c|}
\hline & Alnico V & Alnico VI & Alnico VIr \\
\hline Aluminum & $8.25 \%$ & $8.25 \%$ & $8.50 \%$ \\
\hline Nickel & 14.00 & 15.00 & 18.00 \\
\hline Cobalt & 24.00 & 24.00 & 24.00 \\
\hline Copper & 3.20 & 3.00 & 3.25 \\
\hline Titanium & - & 1.25 & 5.00 \\
\hline Iron & Bal. & Bal. & Bal. \\
\hline
\end{tabular}

The curie temperatures of these alloys are approximately the same; about $875^{\circ} \mathrm{C}$. The significant Magnetic properties are listed in the following table:

\begin{tabular}{|c|c|c|c|}
\hline & Alnico V & Alnico VI & Alnico VII \\
\hline $\begin{array}{l}\text { Residual Induction (BR) } \\
\text { gauss }\end{array}$ & 12 000 & 11000 & 6500 \\
\hline $\begin{array}{l}\text { Coercive Force }(\mathrm{Hc}) \\
\text { oersteds }\end{array}$ & 650 & 750 & \\
\hline $\begin{array}{l}\text { Energy Product (B Hmax) } \\
\text { gauss-oersteds } \times 10^{\circ}\end{array}$ & 4.5 & 3.5 & 2.5 \\
\hline
\end{tabular}




\section{MAGNET DESIGN}

Because magnet design was known to effect both, resistance to demagnetization and magnetic temperatur e coefficient, three differ ent magnet designs of each material were tested. (See Figure 1). The principal difference between these designs is the ratio of the length of the magnetic. flux path inside the magnetic material to the length of the flux path in the air gap. Roughly speaking, the self-demagnetization of a magnet increases as the air gap increases and decreases as the magnet length increases. This is generally expressed as the slope of an operating or load line. '(See Figure 2f: By design these magnets were. selected to operate near the following points on the demagnetization curve:

1) Neat the residual induction, $\mathrm{Br},(0.100 \mathrm{in}$. gap).

2) Near the maximum energy point $\mathrm{BH}$ max, (0.300 in. gap).

3) Near the coercive force, Hc, (cylindricai).

\section{HEAT TREATMENT}

The magnets were cast in baked sand molds and broken out hot approximately 60 seconds after casting. After casting the magnets were heated to about $950^{\circ} \mathrm{C}$; a temperature slightly above the curie temperature, and cooled in a magnetic field of at least 1000 ,oersteds. This treatment produces a preferred direction of magnetization and results in a considerable increase in the magnetic properties parallel to that direction. Because the rate of cooling. during the directionalizing treatment was known to effect the results of subsequent heat treatments, cooling rates both faster and slower than the standard rate for magnets of this gize were also investigated. The following table shows the approximate time to cool from $950^{\circ} \mathrm{C}$ to $600^{\circ} \mathrm{C}$.

\section{Cooling Rate}

Fast

Standard

Slow

\section{Time in Min.}

2.5

8.0

15.0 .

After directionalizing, all of the magnets were given the standard precipitation or aging heat treatment (four hours at $600^{\circ} \mathrm{C}$ ), to fully develop the magnetic properties. 


\section{PREPARATION OF THE SAMPLES}

The air gaps and the two Iarge flat surfaces af the two C-shaped magnets were ground. The cylindrical magnets were ground an all external owrfaces and were ground concentric about the center locating hole. After grinding all magnets were permanently marked with identification numbers uging an electrie engraving pencil.

In order to be sure that all magnetle tests would be comparable, a set of standard magnets was prepared for tibrating teat coils. These standards consisted on one Alnico $V$ magnet of each degign which had been saturated and then calibrated by demagnetizing slightly. in an a c field of 100 oersteds. To further stablize these standards they were temperature cycled five times between $-20^{\circ} \mathrm{C}$ and $75^{\circ} \mathrm{C}$. After stablizing the standards, magnets were placed in a box made of wood and brass to isolate them from extraneous demagnetizing forces. 
THIS PAGE

\section{WAS INTENTIONALLY LEFT BLANK}




\section{TEMPERATURE CYCLNA}

The purpose of this serieg of testa was to determine the mumer of cyeles between minimum temperature and a maximum temperaturo required to stabilize a magnet over that temperature. range. This fixture was constructed of $12 \mathrm{in}$. dla. by $1 / 4 \mathrm{in}$. thick transite. thelves separated by stainless steel posts. The total height of the fixture was about 15 in. The various test magnets were rigldly attached to the fixture by means of brass posts.

Temperatures above room temperature were obtained by dropping the fixture into a 8 mall Lindherg forced alr furnace. Temperature regulation was accompliahed by means of a thermocouple and a recorder contraller. Temperatures below room temperature were abtained by submerging the fixture in a container of dry ice and alcohol.

Six magnets of each design and each material (2 saturated, 2. KD-100 and $2 . \mathrm{KD}-250 \mathrm{H}$ )* placed on the fixture in such a way that the demagnetixing effect of one magnet on the magnets adjacent to it was minimized.

After preparation, the magnetic strength of each magnet was determined at room temperature. Temperature cycling consiated of coaling the fixture and magnets to $-70^{\circ} \mathrm{C}$, heating to the highest temperature for that cycle and then cooling to room temperature. All magnetic measurements in this series of test were made at room temperature. Temperature cycling was continued between each set of temperature extremes until there was an insignificant change in the useful flux of the magnets at room temperature between two consecutive cycles. This condition was defined as stability.

The temperature extremes investigated in this series of test are shown in the following table:

$$
\begin{aligned}
& \text { 1. }-70^{\circ} \mathrm{C} \text { to } 25^{\circ} \mathrm{C} \\
& \text { 2. }-70^{\circ} \mathrm{C} \text { to } 100^{\circ} \mathrm{C} \\
& \text { 3. }-70^{\circ} \mathrm{C} \text { to } 200^{\circ} \mathrm{C} \\
& \text { 4. }-70^{\circ} \mathrm{C} \text { to } 300^{\circ} \mathrm{C} \\
& \text { 5. }-70^{\circ} \mathrm{C} \text { to } 400^{\circ} \mathrm{C} \\
& \text { 6. }-70^{\circ} \mathrm{C} \text { to } 500^{\circ} \mathrm{C} \\
& \text { 7. }+25^{\circ} \mathrm{C} \text { to } 600^{\circ} \mathrm{C}
\end{aligned}
$$

*IED-100H means the magnets were saturated and then exposed to an a $c$ field of 100 oersteds. 
The came set of magnets were used throughout the test, but the magnets were resaturated or resaturated and demagnetined by the appropriate a c.field before utarting the next range of temperature cycles. The time $x$ equired for the magnets and fixture to come to temperature was a function of the particular temperature cycle, however, all magnets were held at tumperature for at least 15 minutes before teating.

The useful flux of the G-ahaped magnets was determined by accurately locating a search coil of known $n a$, In the air gap of the magnets, removing the search coil, and reading the reaultant deflection on a. G. E. fluxmeter. The useful flux of the cylindrical magnets was determined by locating a search coil in the neutral or magnetically central section of the magnets, removing it, and feading the fesultant deflection in the manner described above.

Only deflection or percent change in deflection were recorded in this invegtigation because change from the original valve or stability were the prime consideration. However, flux denstiy can be calculated from the formula, deflection in mm $X K=B$. In this formula $K$ is a constant for a

the particular flumeter which wag lised and $n$ is the number of amper turns per unit area expressed in square contimeters. 


\section{TEMPERATURE COEFFICIENT}

The purpose of this series of test was to determine the percentage of the useful flux which was either lost or gained due to changes in the temperature of a stabilized magnet. The test equipment used for these tests was the same equipment used for the heat exposure test. This will be described in detail in a later section of the report. The same furnace used for the heat exposure test was used to obtain temperatures above room temperature and $d r y$ ice and alcohol were used to obtain temperatures below room temperature.

Three magnets of each design of Alnico V and Alnico VI were used to obtaln the data in this experiment. These magnets wexe saturated and then preaged 100 hours at $500^{\circ} \mathrm{C}$.to minimize the effect of any aging that might occur during the temperature coefficient test. The magnets were then given five temperature cycles from $-70^{\circ} \mathrm{C}$ to $500^{\circ} \mathrm{C}$ and mounied in the test equipment.

The temperature coefficient curves were obtained by starting at the lowest temperature and increasing the temperature in steps of about $100^{\circ} \mathrm{C}$. After coming to temperature, the magnets were held at temperature for an additional 15 minutes before measuring the useful flux.

Measurements were made at $-70^{\circ} \mathrm{C},-40^{\circ} \mathrm{C}, 25^{\circ} \mathrm{C}, 100^{\circ} \mathrm{C}, 200^{\circ} \mathrm{C}$, $300^{\circ} \mathrm{C}, 400^{\circ} \mathrm{C}$, and $500^{\circ} \mathrm{C}$. After completing the test, the room temperature $\left(25^{\circ} \mathrm{C}\right)$ measurement was repeated to be sure there had been no permanent change in the useful flux of the magnets as a result of the test: 
THIS PAGE

\section{WAS INTENTIONALLY LEFT BLANK}




\section{HEAT AGING}

The purpose of this series of tests was to determine the permanent change in the useful flux of the test magnets and magnetic properties of the materials caused by aging or metallurgical changes in the structure of the materials. The fixture used for the $500^{\circ} \mathrm{C}$ aging test was the same as the fixturo ued for the temperature coefficient test. The fixture used for the $600^{\circ} \mathrm{C}$ aging was of similar design but adapted to fit anather furnace. The magnets aged at $500^{\circ} \mathrm{C}$ and all of the teat bars were aged in a Linberg forced air furnace. The magnets aged at $600^{\circ} \mathrm{C}$.were aged in a muffel-type electric furnace,

Four magnets of each deaign and each material were used for the heat aging test. Two of these magnets were cooled rapidly from directionalizing temperature and two were cooled slowly from the directionalizing temperature. This was done because the rate of cooling from directional izing was known to effect the results of the precipitation heat ir eatment and ther efore might effect the results of additional aging at $500^{\circ} \mathrm{C}$ or $600^{\circ} \mathrm{C}$.

One magnet of each design and each heat treatment was partially demagnetized by exposing it to an a field of 100 oersteds. This was done because there was some indication that this might reduce the effect of aging at high temperature.

In addition to the magnets, two test bars of Alnico V, Alnico VI, and Alnico VII were aged at $500^{\circ} \mathrm{C}$ and $600^{\circ} \mathrm{C}$. This test was performed to determine the effect of aging at $500^{\circ} \mathrm{C}$ and $600^{\circ} \mathrm{C}$, on the fundamental magnetic properties of the materials. The test bars were prepared by casting int magnetic fleld to obtain a more uniform heat treatmeat and make them more comparable to standard test bars. After cooling to room femperature, they were given the standard aging or precipitation heat treatnuent, 4 hours at $600^{\circ} \mathrm{C}$.

Since the time at temperature was. so long in this series of tests, heating and cooling rates are insignificantly small. The magnets aged at $500^{\circ} \mathrm{C}$ were held at temperature for 1000 hours. Alihough it was originally planned to age magxets for 500 hours as $600^{\circ} \mathrm{C}$, the test was discontinued after 200 hours because nearly all of the magnets had failed by that time. Test bars were aged 1000 houra at $500^{\circ} \mathrm{C}$ and 500 hours at. $600^{\circ} \mathrm{C}$.

The temperature in the furnace used to a.ge the magnots $2 t 600^{\circ} \mathrm{C}$, and the test bars at both $500^{\circ} \mathrm{C}$ and $609^{\circ} \mathrm{C}$ was quite uniform throughout the furnace. Shortly, after the magnets t; be aged at $600^{\circ} \mathrm{C}$ were placed an test, 
a temperature gradient of about $100^{\circ} \mathrm{C}$ was observed from the top to the bottom of the furnace. The control thermocouple was located near the center of the furnace so that this area was maintained at $600^{\circ} \mathrm{C}$. The area near the top of the furnace was about $650^{\circ} \mathrm{C}$ and the area near the bottom of the furnace was about $550^{\circ} \mathrm{C}$. All of the cylindrical magnets were located in the center of the furnace so they were aged at $600^{\circ} \mathrm{C}$. The two c-shaped magnets were distributed between the top and bottom of the furnace so that some were aged at $550^{\circ} \mathrm{C}$ and some at $650^{\circ} \mathrm{C}$. The actual aging temperature for oach of the c-shaped magnets is indicated on the performance data.

All of the measurements in this series of tests were made at room templyture. The fixture and magnets or test bars being removed from the furnace and allowed to cool to room temperature before any measurements were made. The useful flux in the magnets and the magnetic properties of the test bars were measured at shorter intervals of time at the beginning of the test and longer intervals as the test progressed.

The useful magnetic flux of the magnets was measured in the same manner described in the temperature cycling test. The magnetic properties of the test bars were measured with a saturation permeater. Only the important points on the demagnetization curve were reported. These included saturation induction $\left(B_{g}\right)$, residual induction $\left(B_{r}\right)$, maximum energy (B $\mathrm{H}$ max. ), and coercive force $\left(\mathrm{H}_{\mathrm{c}}\right)$. 


\section{HEAT EXPOSURE}

The purpose of this series of tests was to determine the effect of changes in magnetization and metallurgical changes caused by continunus exposure to temperatures as high as $500^{\circ} \mathrm{C}$. It is distinguished from the heat aging test in that the magnets subjected to this test were held at temperature throughout the test and the useful flux of the magnets was measured at temperature.

Prior to starting this investigation it was decided that the initial experiment would be made at $500^{\circ} \mathrm{C}$ and that the time of exposure would be 1000 hours. If the magnets proved to be unstable at $500^{\circ} \mathrm{C}$, the tempexature would be lowered in steps of $50^{\circ} \mathrm{C}$ until the maximum stable operating temperature was established. Foxp purposes of this experiment magnetic stability is defined as a change in useful flux of les 6 than $5 \%$ in 500 hours.

Building the test equipment for this experiment presented a particularly difficult task since the test equipment was in essence a fairly sensitive electric instrument to be operated at temperatures up to $500^{\circ} \mathrm{C}$. This test equipment was al so used for the semperature coefficient experiment and was intended for use in the confined temperature and vibration experiment.

This equipment consisted on a non-magnetic stainless steel box with the two $\mathrm{c}$-shaped magnets attached to the bottom by means of stainless steel plates and the cylindrical magnet bolted to one end. The search colls used to measure the useful flux of the two $\mathrm{c}$-shaped magnets. were attached to a stainless steel tube. Magnetic measurements were made by rotating the search coils from an accurately located position in the gaps of the magnets to a position remote from the gaps and reading the resultant deflection on a fluxmeter. The search coil used to measure the useful flux of the cylindrical magnet was located in the center of a cup which fitted over the magnet. This cup was attached to a second stainless ateel tube. Magnetic measurements were made by pulling the search coil from the neutral or magnetically central section of the magnet to a point remote from the magnet and reading the resultant deflection on a fluxmeter.

The search coils used to measure the useful flux of the c-shaped magnets were wound on stainless steel coil forms. The leads to the search coils were taken through the base of the colls forms into a sinterpd reramic insulator. This insulator ran through the stainless steel tube to a point remote from the hot zone of the test equipment. At this point the leads were 
attached to a terminal block which was rigidly atiached to the tube. After pulling the leads from the search coils through the insulator, the coil form was bolted and then welded to the tube to insure dimentional stability.

The search coil used to measure the useful flux of the cylindrical magnet was wound on the outside of the cup. Leads from this search coil were brought back along the outside of the cup and into a ceramic insulator located inside the tube, to a terminal board rigidly attached to the other end of the tube. The other two holes in the ceramic insulator were used to bring back leads from a Chromel-Alumel thermocouple used to control the temperature in the hoi zone of the test equipment. The cup was welded to the end of the stainless sieel tube to insure dimentional stability.

Insulation of the wire used for the search coils and lead wires proved to be one of the most difficult problems in consiructing the test equipment for the heat exposure test. Although the voltages involved were low. millivolts, turn to ground and turn to turn insulation was essential. In the first case, shorts made measurement impossible and in the second case shorts caused inaccuracies in the measurement.

Coils made from 0.009 in. dia. anodized aluminum wire were easy to construct and performed very well in service. In order to obtain better physical and electrical separation of the anodized aluminum wire a suspension of aluminum in amyle acetate was applied while the coils were being wound. The lower resistance of this wire made it possible to make the connection to the fluxmeter leads external to the hot zone of the test equipment. After winding, a mixture of high temperature metal oxides and solium silicate was used with much success to support and protect both the coil windings and the exteinul tarminals.

The stainless steel tube, which was pulled back and forth through a set of bearings gave much more bearing trouble than the tube which was rotated in a set of bearings. Bearing failures were generally due to galling and seizing in the bearing nearest to the hot zone of the test equipment. This problem was eventually solved by using graphite bushings for the bearing surface and increasing the clearance between the stainless steel tube and the graphite bushing to about $0.015 \mathrm{in}$. on the diameter.

Two special electric furnaces with rectangular muffels designed to fit over the test equipment were constructed for the heat exposure test. These furnaces maintained an essentially constant temperature of $500^{\circ} \mathrm{C}$ over the $61 / 2$ in. length in which the magnets and test coils were located. These furnaces were reverse wound so that the magnetic fields resulting from the current flowing in the winding was canceled out. This was done to minimize a c demagnetizing due to the heating current. 
One magnet of each design of Alnico $V$ was saturated, placed in the test equipment, and the useful flux was measured at room temperature. The test equipment was then placed in the furnace, brought to $500^{\circ} \mathrm{C}$, held at temperature for one hour, and the useful flux was measured at $500^{\circ} \mathrm{C}$. The initial useful flux at $500^{\circ} \mathrm{C}$ was used as a reference and future changes were calculated as a percentage of that quantity. Measurements were made at increasingly larger intervals of time up to 1000 hours. The above procedure was repeated using one magnet of each design of Alnico VI.

An additional set of magnets of each design of Alnico $\mathrm{V}$ and Alnico VI were saturated and partially demagnetized by an a c field of 250 oerstedg. These magnets were exposed to $500^{\circ} \mathrm{C}$ for 250 hours kecause the major effect of heat exposure on the saturated magnets had occurred during that period. 
THIS PAGE

\section{WAS INTENTIONALLY LEFT BLANK}




\section{COMBINED HEAT AND VIBRATION}

The purpose of the combined heat and vibration was to determine whether exposure to vibration at temperatures elther appreciably abox: or below room temperature would have a significant effect on the useful flux of the test magnets. Originally, it was planned to make the high temperature vibration test at $500^{\circ} \mathrm{C}$ using the test equipment designed for the heat exposure test. However, this proved to be impossible because of electrical fallures in the search colls and lead wire.

The search coils and lead wire in the heat exposure test equipment were replaced several times, but none could withstand more than one or two hours of vibration at $500^{\circ} \mathrm{C}$. The only fine wire avallable with a satiafactory insulation at $500^{\circ} \mathrm{C}$ was anodized aluminum. When the strength of the anodized aluminum wire at $500^{\circ} \mathrm{C}$ proved to be too low to withstand vibration, this approach was abandoned. However, no change in useful flux whlch could be attributed to vibration was observed in the relatively short period these tests were run at $500^{\circ} \mathrm{C}$.

When it became apparent that the heat exposure test equipment could not be used for the high temperature vibration test, another test fixture was built. This fixture was constructed so that the search coils and leads could be removed during vibration and then inserted in the gaps of the magnets only during the measurement of useful flux when the vibration was shut off.

The vibration fixture consigted of a non magnetic insulated container with heating coils wound on the outside of the container. Six magnets, one of each design of Alnico V and Alnico VI were bolted to the bottom of the fixture. The fixture was attached rigidly to the table of the Caladyne unit.

A mixture of dry ice and alcohol was used to obtain a temperature af $-70^{\circ} \mathrm{C}$. A, Lavite salt bath to obtain a temperature of $250^{\circ} \mathrm{C}$. Operating the test equipment at temperatures above $2.50^{\circ} \mathrm{C}$ proved to be impractical because the thermal mass of the Caladyne table caused considerable variation in temperature. Measuring the useful flux of the magnets by this method at temperatures above $250^{\circ} \mathrm{C}$ alk o presented a considerable prob. lem because the precision required precluded the use of asbestos gloves. Measurements were made by locating a search coil at the end of a long handle accurately in the gap of the magnet, withdrawing it, and reading the resultant deflection on a flux meter. 
The effect of combined vibration and temperature was determined for one magnet of each design and each material at $-70^{\circ} \mathrm{C}$, room temperature $\left(25^{\circ} \mathrm{C}\right)$ and $250^{\circ} \mathrm{G}$. The magnets were saturated, placed in the fixture, brought to temperature held at temperature for fifteen minutes, and the useful flux was measured. This initial value of useful flux was used as a reference and all changes are reported as a percentage of this quantity.

The initial vibration tests were made according to the following schedule:

Erequency

$$
\begin{array}{r}
5-10 \text { cps. } \\
10-75 \text { cps. } \\
75-2000 \text { cps. }
\end{array}
$$

Dopble Amplitude

$$
\begin{aligned}
& 0.050 \mathrm{in} . \\
& 0.036 \mathrm{in} . \\
& \pm 10 \mathrm{a}
\end{aligned}
$$

These tests were made for the purpose of determining the resonant frequencies of the test fixture and magnets. Later the useful flux of the magnets was measured after about five hours of vibration at each of the six most resonant frequencles at kach temperafure. The total time of vibration at each temperature was abput 35 hour $\$$. The frequency of vibration varied from 5 to 2000 crcles per second and the amptitude was the equivalent of at least $20 \mathrm{C}$ and in spme cases as high as $30 \mathrm{G}$. 